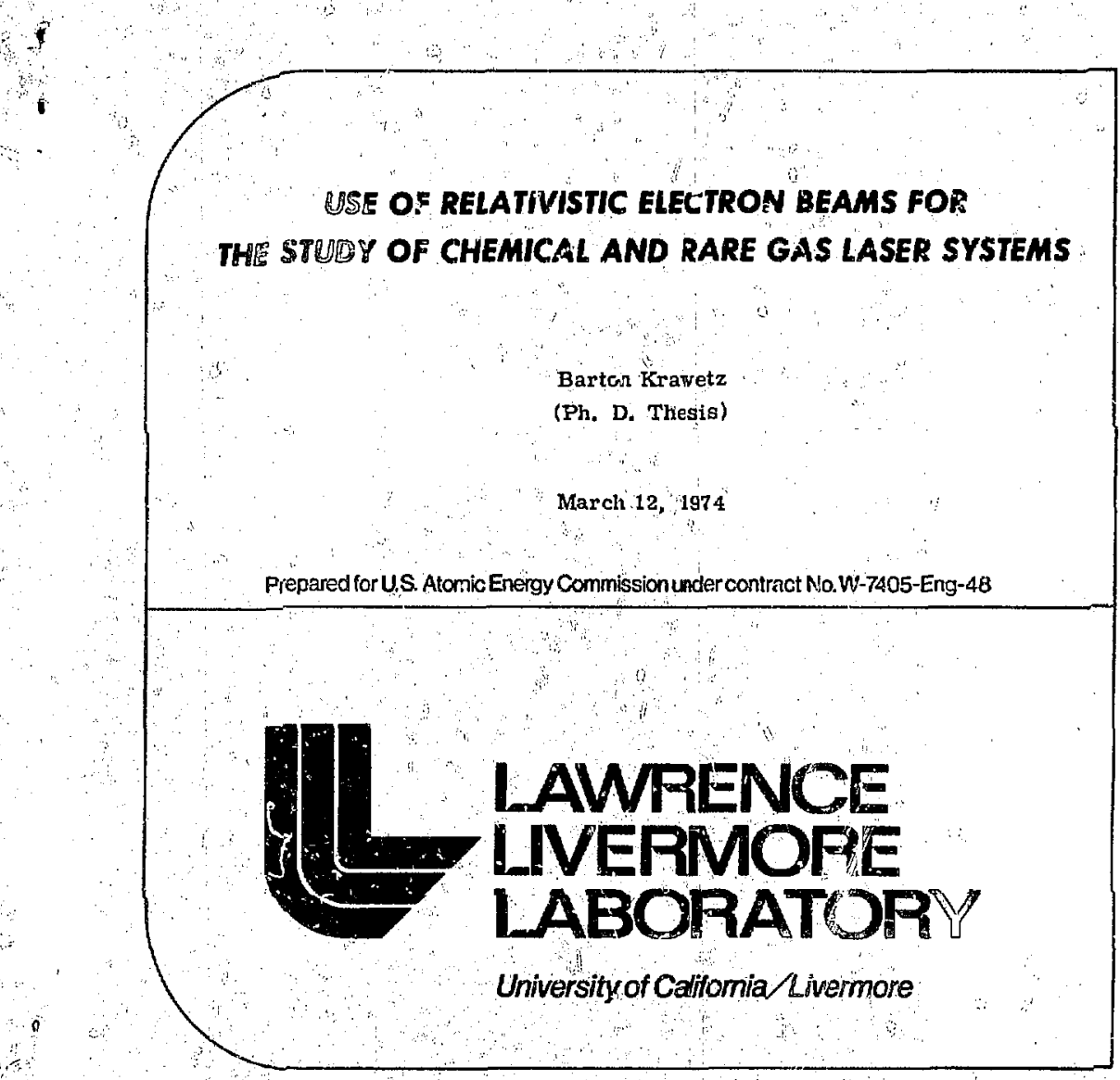




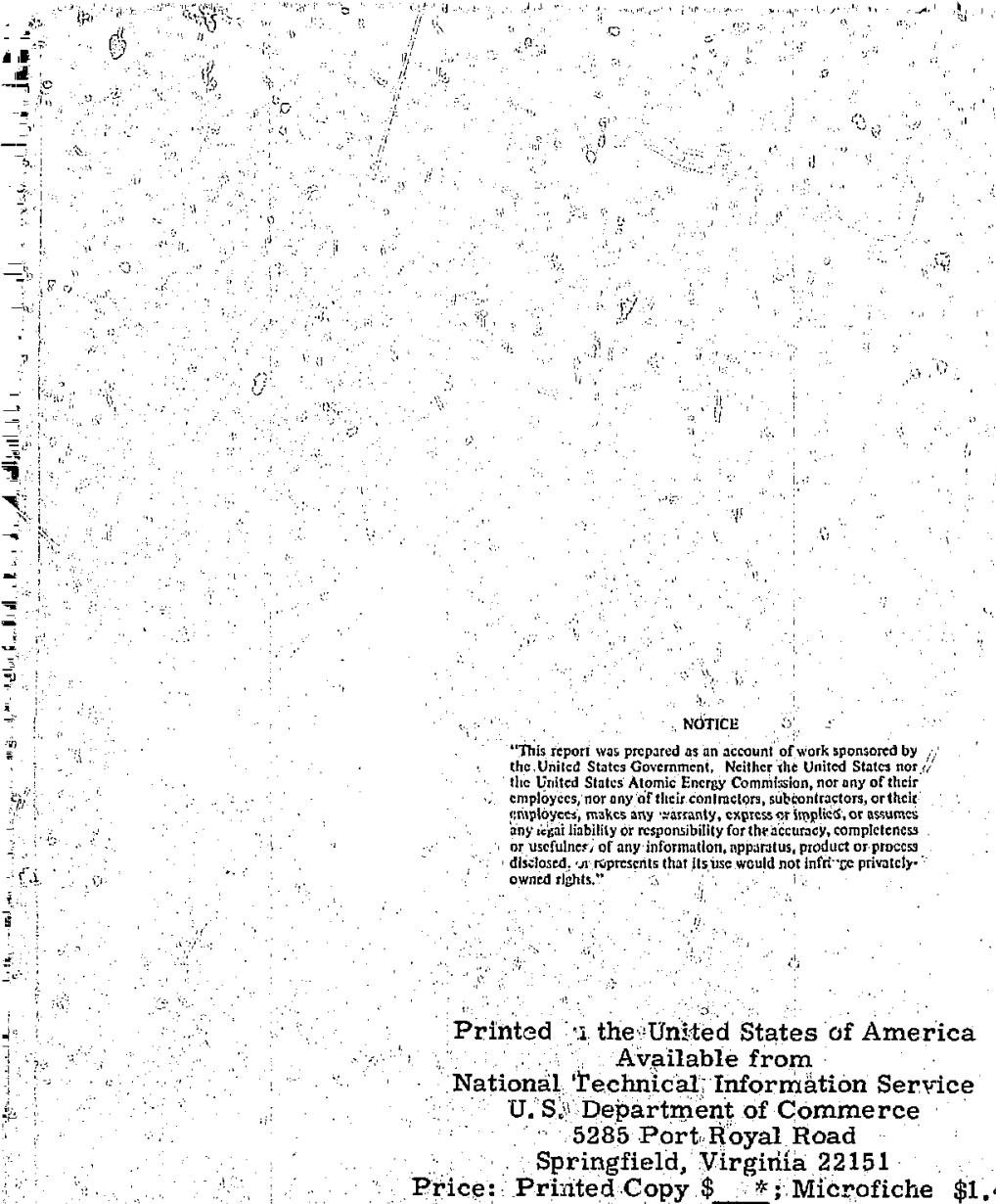

Available from
National Technical Informätion Service
U. S Department of Commerce
5285 Port Royal Road
Springfield, Virginia 22151
rice Prited Copy $\$$, Microfiche $\$ 1.45$

Pages

$1-50$

51-150

151-325

$326-500$

501-1000
NTIS

Selling Price

$\$ 4.00$

$\$ 5.45$

$\$ 7.60$

$\$ 10.60$

$\$ 13.60$ 
TID-4500, UC-34d

Physics - Particles and Fields

\section{노 \\ LAWRENCE LNERMORE LABORATORY \\ Unversity of Callomia Livarmore, Callomiag 94550}

\section{UCRL-51402 \\ USE OF RELATIVISTIC ELECTRON BEAMS FOR THE STUDY OF CHEMICAL AND RARE GAS LASER SYSTEMS}

Barton Krawetz

(Ph. D. Thesis)

MS. date: March 12, 1974 


\section{Preface}

The author wishes to express thanks to the following people:

To. Dr. C. K. Rhodes for his interest and key suggestions throughout the study.

To Dr. R. E. Kidder, sincere appreciation for his indulgence in affording sufficient time, resources and freedom to pursue this study.

To Barry Schleicher, a superb mechanical technician, for indispensable aid in constructing and running the chemical phase of this study.

To Jack Wengert and Derek Ray for their day and night efforts during modification and execution of the rare gas studies.

To Major E. P. Sims, eternal gratitude for remaining the link with Lawrence Livermore Laboratory after reassignment.

This work under the auspices of the United States Atomic Energy Commission at the Lawrence Livermore Laboratory. 


\section{Contents}

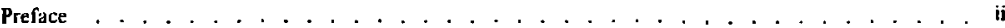

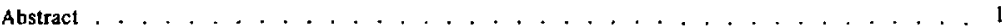

Introduction . . . . . . . . . . . . . . . . . . . . 1

A. General . . . . . . . . . . . . . . . . . . . 1

B. Chemical Systems . . . . . . . . . . . . . . . . . . . . . . . . . . . . . . 2

I. Description of Experimental Apparatus . . . . . . . . . . . . . . . . . . . . . . . 4

A. Electron Beam Generator . . . . . . . . . . . . . . . . . . . . . . . 4

B. Oscillator. . . . . . . . . . . . . . . . . . 6

C. Amplifier . . . . . . . . . . . . . . . . . . . . . . . 9

D. Instrumentation . . . . . . . . . . . . . . . . . . . 14

E. Fast Fill System . . . . . . . . . . . . . . . . . . . . . . . . . . . . 16

F. Electrical and Mechanical Interconnections . . . . . . . . . . . . . . . . 21

G. Vacuum Systems . . . . . . . . . . . . . . . . . . . . . 25

H. Calculations. . . . . . . . . . . . . . . ..... 25

II. Results of Chemical Studies . . . . . . . . . . . . . . . . . . . . . . 33

A. Linear Gain Calculations, and P, R Btanch Gain Ratios . . . . . . . . . . . . . . . 33

B. Nonlinear Amplification . . . . . . . . . . . . . . . . . . . . . . . . 36

C. Electron Beam Dosimetry . . . . . . . . . . . . . . . . . . . . . 43

D. Calorimetry ..................... 45

E. Maximum Energy Extraction . . . . . . . . . . . . . . . . . . 46

III. Discussion of Chemical Studies . . . . . . . . . . . . . . . . . . . 47

A. Reaction Rates . . . . . . . . . . . . . . . . . . . . 47

B. Gain Activation Relation . . . . . . . . . . . . . . . . . . . . . . . . . . . 47

C. Maximum Energy Extraction . . . . . . . . . . . . . . . . . . . . . . 48

D. Kinetic Processes . . . . . . . . . . . . . . . . . . . . . . . . . . . . . . 48

E. Nonlinear Amplification . . . . . . . . . . . . . . . . . . . . . . . . . . 48

IV. Rare Gas Studies . . . . . . . . . . . . . . . . . . . . . . . . . . . . . . . . . 54

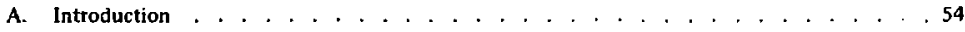

B. Experimental Modifications for Rare Gas Work . . . . . . . . . . . . . . . . . . . 54

v. Results of Rare Gas Experiments . . . . . . . . . . . . . . . . . . . . . . 56

A. $\mathrm{Ar} / \mathrm{Xe}$ Energy Transfer . . . . . . . . . . . . . . . . . . . . . . . . . 56

B. $\mathrm{Xe}, \mathrm{Kr}, \mathrm{Ar}$ Studies ... . . . . . . . . . . . . . . . . . . 58

VI Discussion of Rare Gas Studies . . . . . . . . . . . . . . . . . . . . . . . . . 64

A. Basic Processes . . . . . . . . . . . . . . . . . . . . . . . 64

B. Source of 2200 \& Continua . . . . . . . . . . . . . . . . . . . . . 67

C. Excited Atom Decay Processes . . . . . . . . . . . . . . . . . . . . . . . . 67

D. Laser Gain Estimate for $\mathrm{Xe}_{2}^{*} \ldots \ldots$. . . . . . . . . . . . . . . . . . . . .6B

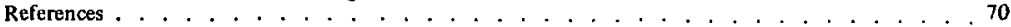




\title{
USE OF RELATIVISTIC ELECTRON BEAMS FOR THE STUDY OF CHEMICAL AND RARE GAS LASER SYSTEMS
}

\author{
Abstract
}

Chemical $\left(\mathrm{NF}_{3}+\mathrm{H}_{2}\right)$ and rare gas molecular $\left(\mathrm{Ke}_{2}\right.$, $\mathrm{Kr}_{2}, \mathrm{Ar}_{2}$ ) laser systems are examined. Intense relativistic electron beams are used as a source of initiation and stimulation respectively. For the high gain chemical system, nonlinear amplification and pulse propagation are examined. The experimental result shows all the qualitative features of the theoretical prediction. In addition certain kinetic excitation end deactivation mechanisms are studied through the short stimulation time available with the electron beam. Results obtaincd from the examination of laser action of the test system compare well with more conventional schemes for kinetic rate data extraction.

For rare gas molecular systems, the electron beam provided an excellent tool for studying the energy flow beginning with formation of the diatomic eximer to final decay by spontaneous radiative decay. Laser action in Krypton $\left(\mathrm{K}_{2}\right)$ is predicted. Symmetry in excitation mechanisms is demonstrated for the rare gases as a class.

\section{Introduction}

\section{A. GENERAL}

This study represents a synthesis of two separate experiments linked together by their common use of pulsed electron: beams.

Taken in chronological order, the firs? portion of this work treats the gain properties of explosive mixtures of nitrogen triflouride $\left(\mathrm{NF}_{3}\right)$ and hydrogen $\left(\mathrm{H}_{2}\right)$ gas. The amplifying medium, initiated by the electron beam, was probed with the soherent light from a sulfur he wa llouride $\left(\mathrm{SF}_{6}\right) / \mathrm{H}_{2}$ "spiral pin discharge" oscillator. The operating characteristics of the ascillator. cxcept as otherwise noted, were chosen so as to generate the longest possible pulus. The oscillator output was then taken as continuous wave (cw) relative to the physies unter study in the amplifier.

Data extracted from the chemical laser study fell into three categories:

- Calculation of chemical pumping rates prevailing during small signal (linear) amplification.

- Calculation of overall population growth tim. constant. This demonstrated the dominance of binary kinetic processes over a wide range of reactant pressures.

- Examination of nonlinear amplification processes occurring in the amplifier at pressures in excess of 15 Torr. The nonlinear processes referred to here are those resulting from the interaction of material polarization and the stimulating ficld.'
The second major area of study was that of the spontaneous emission spectra of several noble gases (Xe, Ar, Kr). Recent work in the Soviet Union on the possibility of noble gas laser action stimulated this phase of the investigation. The experimental apparatus used for the chemical laser work made the changeover to the noble gas very easy. The feature of this experiment that made it unique relative to other efforts ${ }^{2}$ was the excitation rate and intensity made available by the electron beam generator. The pure gases and argon/xenon mixtures were examined at pressures up to $5 \mathrm{~atm}$.

The results of this study arc summarized as follows:

1) Time resolved spectra showing the formation and Jecay of the low lying triplet and singlet states of $R_{2}^{*}$ wer: vi:sined. ( $R_{2}^{*}$ represents an electronically excited rare gas dimer.) One concludes from a study of these spectra that the excited states are formed in a condition of high vihrational excitytion with subsequent rapid decay to the ground vibrational state.

2) Certain energy cascades from high lying molecular states (excited core configuration) werc observed to occur in a systema!ic way for all the rare pases.

3) Line narrow, $n_{z}$. s observed in krypton gas over the range of pressure 3-5 a1m. Thus, it is exjected that laser action in pure krypton may be possible.

4) Energy transfer rates and processes wert: cxamined in the mixed rare gas system composed of argon and xenon. 


\section{B. CHEMICAL SYSTEMS}

Chemically produced population inversion leading to laser action was first demonstrated by Piment: ${ }^{3}$ in the first half of 1967. The current interest in chemical lasers is best understood by a consideration of the dominant gain producing inechanisms that attend the detonation of $\mathrm{H}_{2}+\mathrm{F}_{2}$. These processes are:

$$
\begin{aligned}
& \mathrm{F}+\mathrm{H}_{2} \rightarrow H F^{*}+\mathrm{H} ;-\mathrm{H}=32 \mathrm{kcal} / \mathrm{mole} \\
& \mathrm{H}+\mathrm{F}_{2} \rightarrow H \mathrm{~F}^{*}+\mathrm{F} ;-\mathrm{H}=98 \mathrm{kcal} / \mathrm{mole}
\end{aligned}
$$

(where $\mathrm{F}$ denotes a free flourine radical and $\mathrm{HF}^{*}$ denotes a vibrationally excited molecule).

It has been verified ${ }^{4.5}$ that up to $72 \%$ (reaction 1) and $44 \%$ (reacion 2 ) of the reaction enthalpy could appear as vibrational excitation of the HF molecule. A simple calculation suggests that a properly prepared detonation of $\mathrm{H}_{2}+\mathrm{F}_{2}$ could yield $100-200 \mathrm{~kJ} / \mathrm{mole}$, all of which is potentially available for stimulated emission. One can be assured of efficient energy extraction if the HF production rate exceeds the fastest of the various deactivation rates. Typical deactivation processes can be represented by the following reactions:

$$
\mathrm{X} \cdot+\mathrm{HF}^{*} \rightarrow \mathrm{X} \cdot+\mathrm{HF} \text { (free radial deactivation) }
$$

where $X \cdot=F \cdot, H *$

$$
M+H F^{*} \rightarrow M+H F \text { (molecular deaclivation) }
$$

where $M=N_{3}, H_{2}, F_{2}$

$$
\mathrm{HF}+\mathrm{HF}^{* *} \rightarrow 2 \mathrm{HF}^{*} \text { (HF-HF deactivation). }
$$

Assuming that favorable rate competition can be realized, one is tempted to consider the construction of targe efficient laser systems employing chemical pumping. Chemical systems san operate with an efficiency that greatly exceeds $100 \%$. That is, one can expect to generate laser light output whose total energy exceeds the investment in initiation energy, if the energy to produce the reactants is ignored.

With the foregoing argument in mind, an experimental program wa's undertaken to assess the gain properties of a particular reactant system $\left(\mathrm{NF}_{3}+\mathrm{H}_{2}\right.$ ) that was known 6 to produse vibrationally exicted HF via chemical detonaticn. During the formulation phase of this stufiy, it wa's noticed that the jiterature 7,8 contained references to the laser properties of $\mathrm{HF}^{*}$ produced in so zalled "pin laser" configurations. Thesc devices were ali characterized by liot arc discharges between oppose's pairs if individually tallasted points. A schcmatic tiew of such a device appears in Fig. 1 .

Ballasted jin systems produce nonuniform and unrepeatable gain arross the active aperture. The nonuniformity becomes pronounced where the total reactant picsuce exceeds 150 Torr. In order to produce energeti; laser systems (one of the major inter-

-This tw:hnique was conceived by R. E. Kidder, B. Kranet2, D. W. Gregg, and patented in 1972.

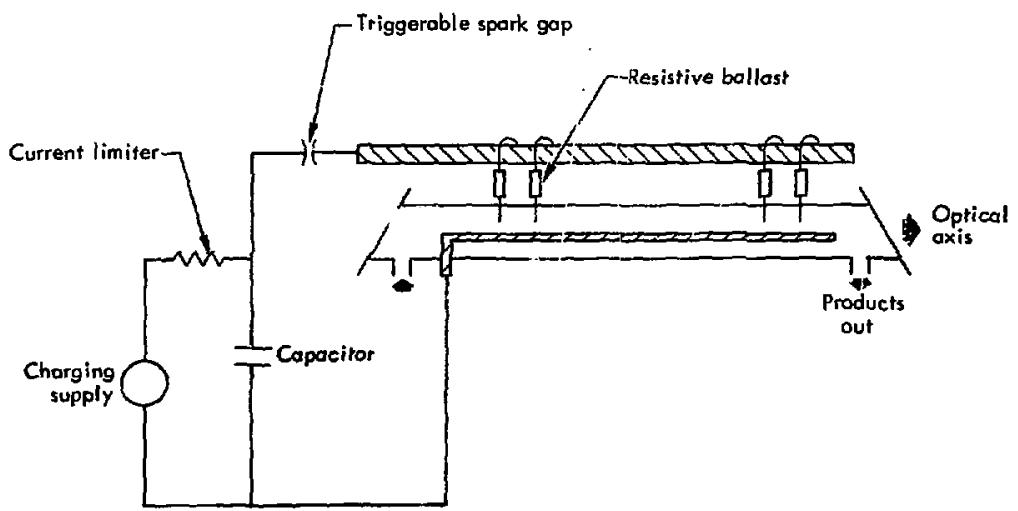

Fls. 1. Schematic representation of a pin discharge liser. 
ests of the A.E.C.) one has to postulate the extension of any initiation technique to large apertures (severa] tens of centimeters) and high reactant pressure (se:reral atmospheres). It is well known ${ }^{9}$ that pin discharges condense to hot arcs well velow 760 Tor and are therefore unacceptable. As the reactant pressure is increased, the characteristic time for bintry kineiic processes scales as (pressure) ${ }^{-1}$. One is, therefore, faced with the additional requirement of ninding initiation schemes suitable for high pressure operation. In this study a pulsed, relativistic, electron beam technique is employed for chemical initiation. The electron beam method is potentially useful for arbitrarily large gain apertures. Initiation pulse widths of several nanaseconds are well within the state of the art. Uniformity of initiation is assured if the electron range substantially exceeds the areal density of the reactants trayersed by the beam. (Range and arca density are normally given in units of $\mathrm{g} / \mathrm{cm}^{2}$.)

The value of uniform initiation is immediately seen when one realizes the effect of hydrodynamic shock waves on the homogeneity of the optical (gain producing) medium. The appearance of shock waves will terminate laser action by producing unpredictable density gradients and elevating the gas kinetic temperature of the exploding medium. The electron beam produces about $10^{15}$ initiations per gram of matcrial, consequently no discrete shocks form unili iong after the end of laser action.

The first step toward proving the feusibility of the electron beam initiation idea was to buidd a small criclosure run in an oscillator configuration. It was decided that $\mathrm{H}_{2}+\mathrm{F}_{2}$ was too hazardous a combination for our initial experiment. $A$ better choice was $\mathrm{H}_{2}+\mathrm{NF}_{3}$; it is readily mixed and not given to spontaneous detonation. Several combinations of hydrogen and flourine-bearing molecules were examined before reaching this conclusion $\left(\mathrm{N}_{2} \mathrm{~F}_{4} / \mathrm{H}_{2}\right.$, $\left.\mathrm{N}_{2} \mathrm{~F}_{4} / \mathrm{B}_{2} \mathrm{H}_{6}\right)$. Some details of this experiment are given in Ref. 6 .

Figure 2 outlines the arrangement of the test volume for this preliminary experiment.

The laser cavity shown in Fig. 2 was formed by one front surface gold coated, $10 \mathrm{~m}$ mirror with $97 \%$ reflectivity at $3.0 \mu$, and one $50 \%$ reflective (gold reflector), $\mathrm{NaCl}$ flat. The laser action observed on several

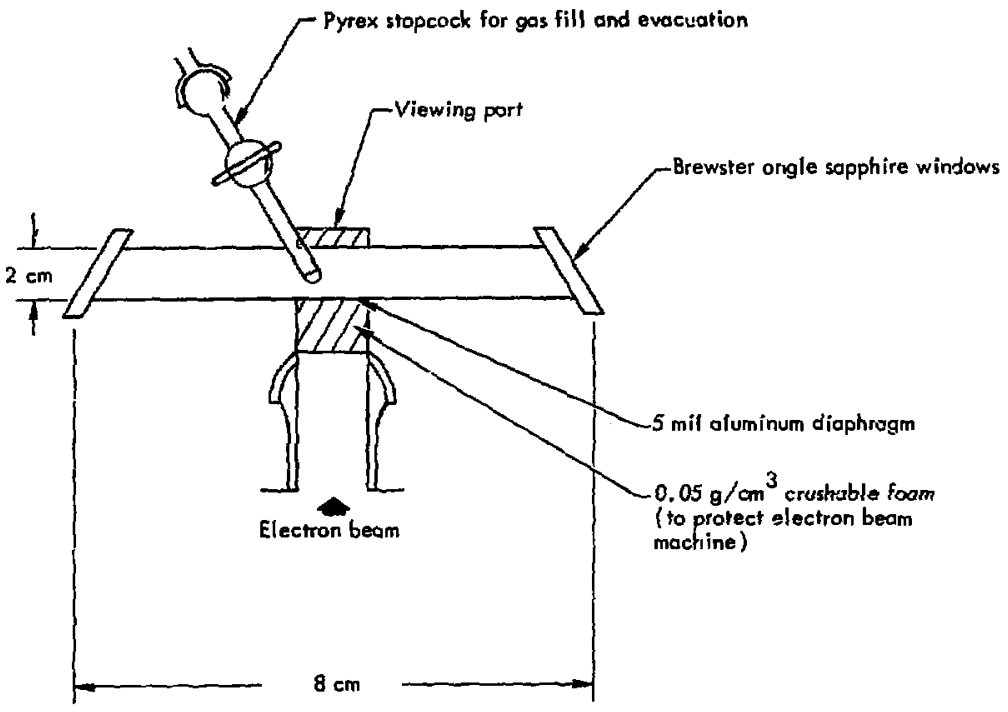

Fig. 2. Proof of principle appartitus 
vibration-rotation transitions of HF encourdged further experimentation. An objection to the initial experimental arrangement was that one could not conclude that electron beam effects alone were responsible for the excitation leading to laser action. One could reasonably expect the leading edge of the electron pulse to charge the far wall of the pyrex cell (because of the snall capacitance of thr structure, few elsctrons would be required to bring the potential of the pyrex surface up to that of the buam) thereby stopping the succeeding electrons in the small yolume. Subsequent arcing would certainly occur, thereby casting doubt on the spatial uniformity and character of the ignition mechanism. It was because of this doubt that the experiment to be described below was conceived. For the remainder of the study, the electron beam is run axially down a large volume reaction pipe made of Teflon and constrained by a magnetic field to a diameter small compared to the inside diameter of the reaction vessel $(6.35 \mathrm{~cm})$. The aspect ratio of the vessel was chosen such that end effects leading to captcitive charge buildup could be ignored (actual length/diameter $\simeq 10.5 / 1$ ). Finaliy, it wa: dccided to study the $\mathrm{NF}_{3}+\mathrm{H}_{2}$ system in an oscillatoramplificr configuration so that one could attempt the understanding of linear amplification characteristic of the syster rather than the necessarily nonlinear behavior characteristic of an oscillator alone.

"Linear amplifiention v"as not observed in this system at tot.l pressures above 15 Torr. (See Sec. II-B.)

\section{Description of Experimental Apparatus}

\section{A. ELECTRON BEAM GENERATOR}

\section{Principles of Operation}

This device is an 80-stage "Febetron" * Marx generator. Each stage (for this experiment) was charged to $35 \mathrm{kV}$, istucing $2.5 \mathrm{MV}$ gctoss a field emitting diode consisting of a thin ( $1.5 \mathrm{mil}$ ) titanium anode and a fork-like array of needles scrving as the cathode; the elfectiva impedance of the diode being solenoid that serves to guide the electron beam repeatedly through the titanium output window. The solenoid is driven by $700 \mathrm{~A}$ dc supply and is energized for abost $20 \mathrm{sec}$ at each firing. This extended "on" time lients the solenoid enough to limit the repetition rate for repeatable electron bears outputs to one firing every $7 \mathrm{~min}$. Overheating of the internal solenoid coupled with the necessity for pumping exploded gases out of the amplifier section resulted in a maximum repetition-rate of six firings/hr.

The temporal output of the machint as monitored by a capaci ive voltage divider connected across the field emittirs diode is represented by Fig. 3.

\footnotetext{
*Reference to a company or product name does not imply approval or acommendation of the product by the University of California or the U.S. Atomic Energy Cummission to the exclusion of others that may be suitable.
} ubout $400 \Omega$. The machina contains an internal dc

\section{Elèctron Beam Generator Output Cnaracteristics}

The effective electron energy as determine 1 by aft average penetrating power messurement, see Fig. 4 , is taken as $1.4 \mathrm{MeV}$. A peak charging voltage of 2.8 MV (35 kV/stage $\times 80$ stages) results in $2.5 \mathrm{MV}$ actuaily appearing across the tube.

The peak current $=\frac{2.5 \mathrm{MV}}{400 \Omega}=6.25 \mathrm{kA}$. Taking the pulse width to be $80 \mathrm{nsec}$ (FWHM) and the average current to be $4.5 \mathrm{kA}$, the energy delivered per puise is:

$$
\overline{t_{p}} \cdot \bar{I} \cdot \bar{V}=\text { energy } / p u l s e=475 \mathrm{~J}
$$

$$
\text { where } \begin{aligned}
\bar{t}_{\mathrm{p}} & =\text { average pulse length }=80 \mathrm{nsec} \\
\overline{1} & =\text { average total current }=4.5 \mathrm{kA} \\
\bar{v} & =\text { average electron voltage }=1.4 \mathrm{MeV}
\end{aligned}
$$

This figure agrees well with the $450-500 \mathrm{~J}$ stered in the capacitor stack. For firther calculations, the average current will be taken $4.5 \mathrm{kA}$ emitted in 4.9 $\mathrm{cm}^{2}$ beam.

Triggering of the machine is accompiished by a low jitter trigger amplifier consisting of a precharged length of coaxial cable switched by a hydregen filled thyratron. This airangement delivers a $20 \mathrm{kV}$ pulse to the trigger electrodes of the first Marx stage. The spark gaps of succeeding stages are illuminated by the first stage discharge photons (as well as being overvoltaged) resulting in lowered "staging time" jitter. 


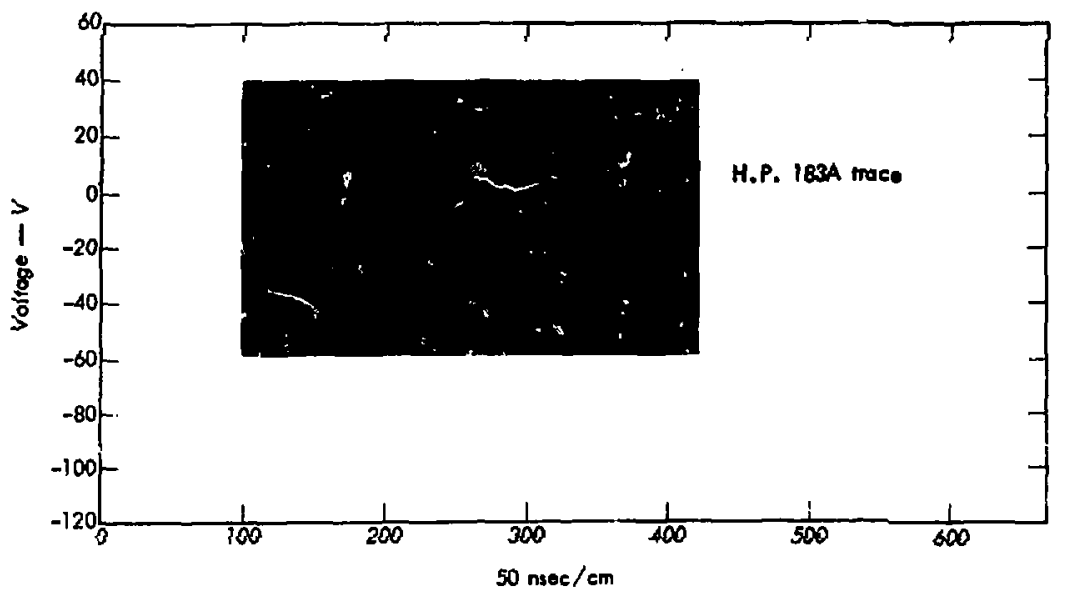

Fig. 3. Voltage vi uime acrow feld emititng diodo.

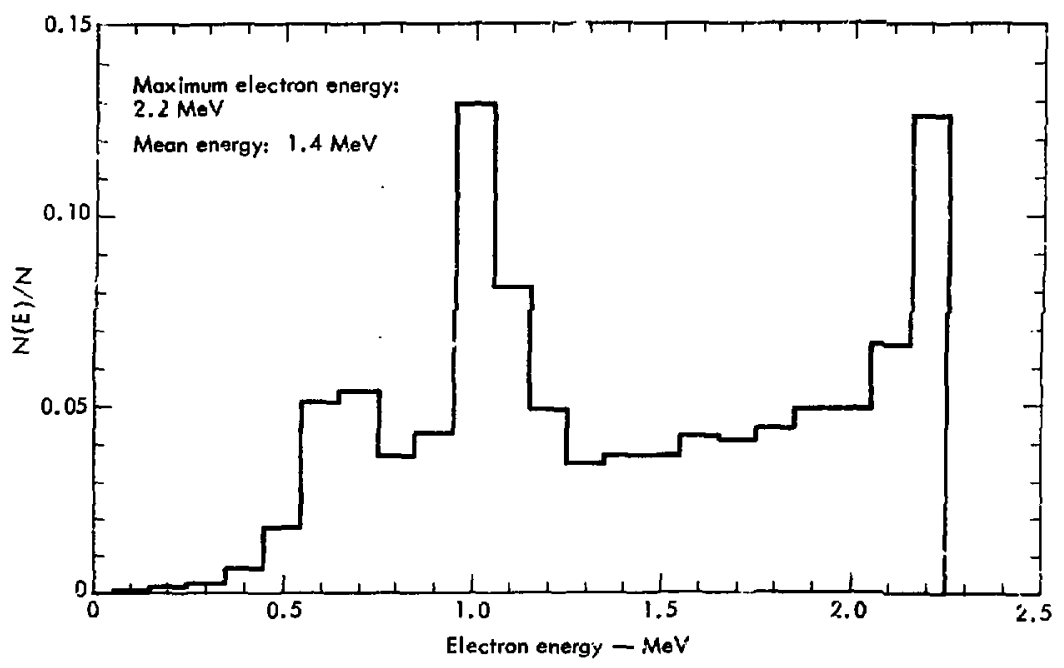

Fig. 4. Electron energv spectrum. 
The machine consistently produced triggering jitter of less than \pm 1.5 nsec, as measured on a 519 oscilloscope. Typical electron beam tube life was 1500 shots at $30 \mathrm{kV}$ ( $1.4 \mathrm{MeV}$ awerage electron energy). It was found from machine diagnostics data taken on each shot that when the tube failed it did not do so gradually. It was a simple matter to diagnose tube malfunction. replace it, and then repeat suspect experiments.

The machine is characterized by the following operating parameters:

- Jitter \pm 1.5 nsec.

- Propagation delay (Marx erection time) 425 nsec.

- Average ener $6 y /$ electron $=1.4 \mathrm{MeV}$ (as measured by a mean range parameter).

- Peak output current $6 \pm 0.3 \mathrm{kA}$ (as measured by Faraday (up).

- Current rise time $10 \mathrm{nsec} \stackrel{+5}{-0}$

Current width 80 nsec +10

(as measured by Faraday cup)

- Nominal internal magnet Feld $=4 \pm 0.4 \mathrm{kG}$

Electromagnetic Noise Envirorsraent

The inductance of the electron beam cursent path is of the order of a few microhenries. With $\mathrm{d} l / \mathrm{dt}$ calculated from the performance figures given above, one expects rudiated field strengths of several kilovolts/meter near the generator. Appropriate screen room and noise suppression procedures were therefore crucial to the attainment of acceptable signa!-to-noise ratios.

\section{Sanıple Calculation}

$$
\begin{aligned}
& V=L \frac{d I}{d t}=2 \times 10^{-6} \times 10^{9}=2 \mathrm{kV} \\
& V / L=2 \mathrm{kV} / 1 \mathrm{~m} \Rightarrow|\vec{E}|=2 \times 10^{3} / \mathrm{m}
\end{aligned}
$$

(1 $\mathrm{m}=$ characteristic size of system)

\section{B. OSCILLATOR}

The oscillator/power supply systems examined included all combinations of linear and spiral pin oscillators driven by high impedance reactive and Marx bank devices. For reasons of mude unifomity and energy delivered/pulse it was decided to use the spital system as shown in Figs. 5 and 6.

Pairs of opposed pins constructed of Kovar were arranged in interwoven helices such that 50 pin pairs. tompleting 3 revolutions of the helix placed $1 \mathrm{~cm}$ apart defined as active length of $70 \mathrm{~cm}$.

Each of the anode pins was ballasted with a $500 \Omega$. $20 \mathrm{~W}$ noninductive wire wound resistor giving an effective total ballast impedance of $10 \Omega$; this resistance proved adequate to stabilize the discharge without excessive source energy dissipation.

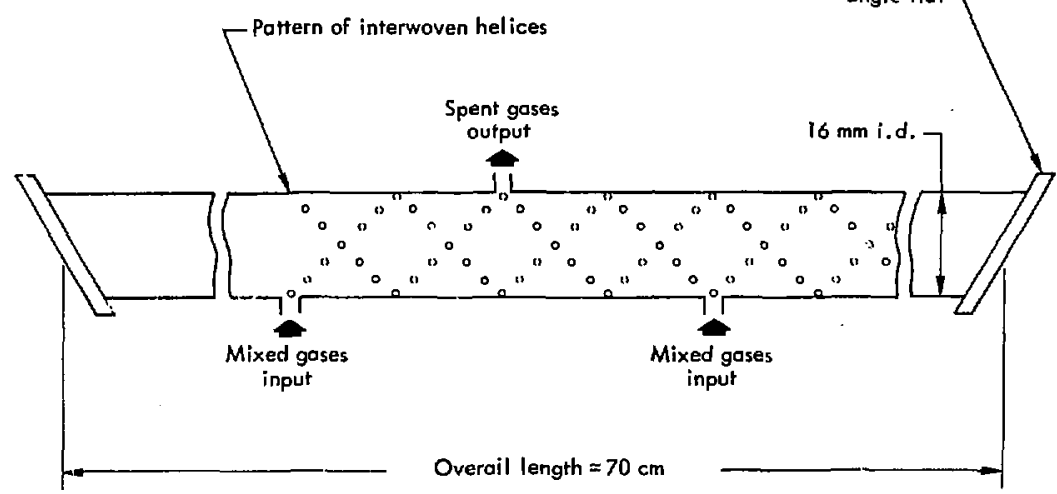

Fig. 5. Spiral pin array ascillato- 


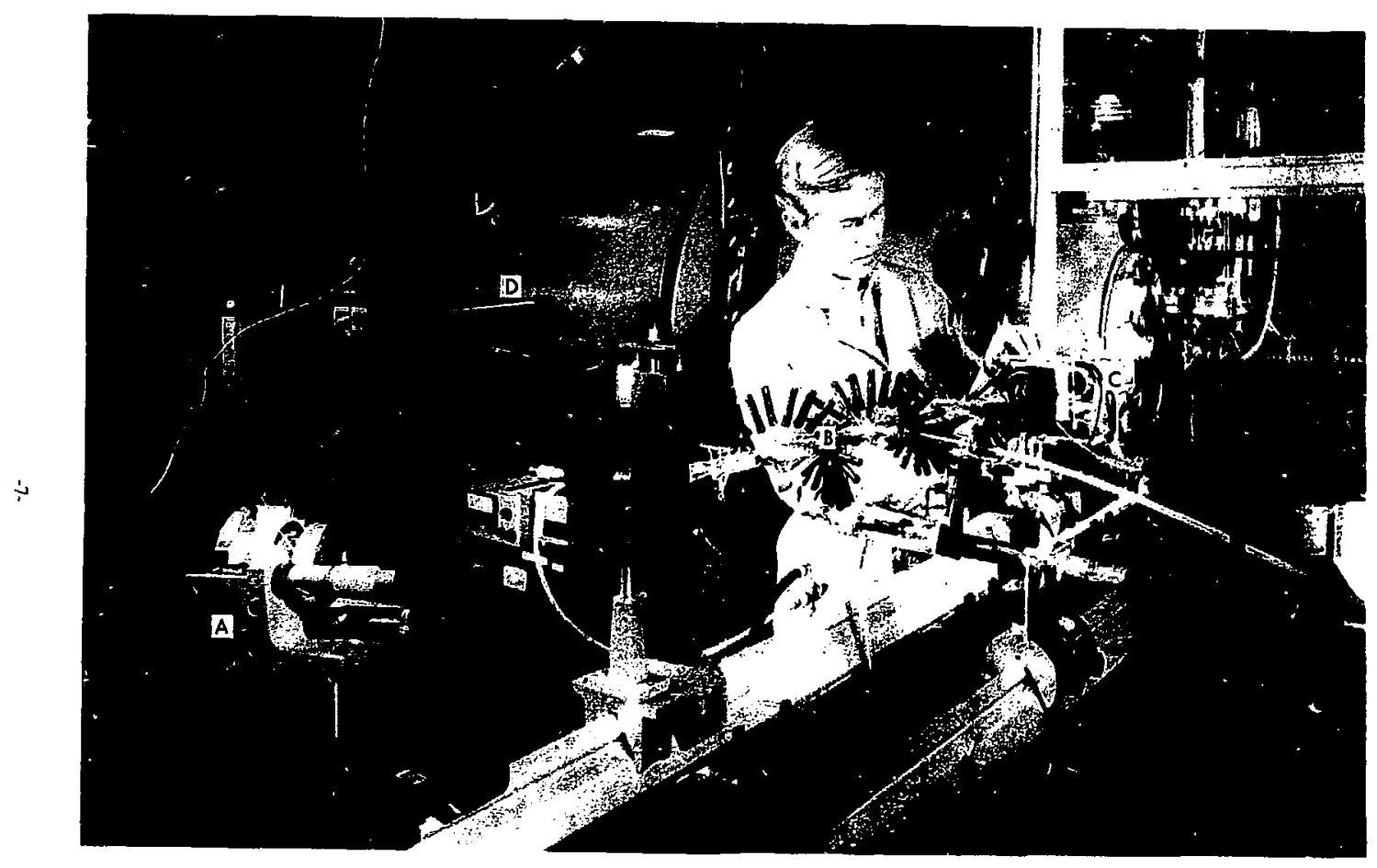

Fig. 6. $\mathrm{SF}_{6} / \mathrm{H}_{2}$ oscillator corvity.
A: Grating fixture
B: "Spiral" pin oscillator tube
C: Piezoelectric output mirror mount
D: Electron beam generator, Marx tank 
Gases $\left(\mathrm{SF}_{6}, \mathrm{H}_{2}\right)$ were introduces into a flow control manifold, mixed and fed into opposite ends of the tube labelud "input"; spent gas was extracted from the opposed centrally located fixture labeled "output", by a $2 \mathrm{cfm}$ mechanical pump. This arrangement permitted extended operating life ( $100 \mathrm{hr}$ ) without window fogging even when sunning with inputs of $40 \mathrm{~J} / \mathrm{pulse}$.

This particular tube diameter and electrode spacing was chosen as a compromise between excessive heating of the glass walls and mechanical pumping capacity when the system was operated in the mode requiring $40 \mathrm{~J} /$ pulse input energy.

\section{Powtr Supply}

For fow pressure, long pulse width applications the oscillator was cperated with the approximately-2-k $\Omega$ output-impedance, capacitor-SCR-transformer arrangement at $10-20$ qns. The valtage input to the arcillatur peaked at $14 \mathrm{kV}$ with $200 \mathrm{nsec}$ rise time. An adjustable width, scries spark gap was used to steepen leading edge. Typical outputs were $\curvearrowright 1 \mathrm{~mJ}$ in $1 \mu$ sec.

For high pressure, short pulse width applications the oscillator was operated $w$ :ith the Marx generation source; $40 \mathrm{~J} /$ pulse ( 2 stage, $20 \mathrm{kV} / \mathrm{stage}$ transmissionline coupled) with voltage rising to $\simeq 60 \mathrm{kV}$ at breakdown depending on pressure and stoichiometry of $\mathrm{SF}_{6} \mathrm{jH}_{2}$ mixture. This source was used in that portion of the study steking to assure the maximum likelihood of saturated aniplifier performance. Typical outputs were $25-30 \mathrm{~mJ} / \mathrm{pulse}$ when no dispersion was used in the cavity. Typical repetition rates were 1-2 pps.

Operation with the ivarx generator was characterized by 1.50 nsec pulses (FWHM) with peak power of $250 \mathrm{~kW}$

\section{Crvity}

The discharge tube described above was inserted in a $1.5 \mathrm{~m}$ cavity having two distinct configurations, agein depending on the mode in which data was being taken; see Figs. 7 and 8 .

In both cases the output mirtor is held in a piezoelectric mount to permit axial mode selection (Fig. 6). It sould be noted that in the high energy mode of operation, no experiments requiring single mode performance were attempted. Care and attention to single mode optration was attempted only in the low energy mode.

This particular oscillator arrangement, after careful alignment and adjustment of the cavity length to an integral multiple of $\lambda / 2$, provided stable operation for

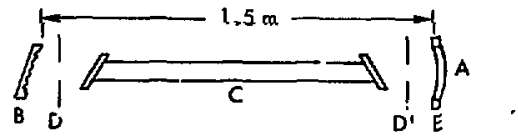

Fl. 7. Oscillator cavity, low energy, long pulse, single mode operation.

$C=$ Laser tube illustrated in Fis. J,

A = 3-m radius miniscus type silicon output mirror, $50 \%$ refletting.

$B=$ Grating blazed at $\left(61^{\circ} 10^{\prime}\right)$ useful range $2-4 \mu$; 625 lines/mm. The culing of the graling was sufficient to resolve adjacent rotational lines under all experimental conditions.

$D, D^{\prime}=$ Apertures used for alignment; $D^{\prime}$ provided transverse mode control as well.

$\mathbf{E}=$ Piexoelectric positioning device for axial mode costrol.

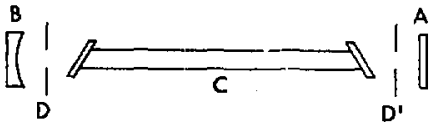

Fig. 8. Or jillator cavity, high energy, short pulse mode.

$C=$ Laser tube described in Fig. 5.

$D D^{\prime}=$ Apertures, $\left(D^{\prime}\right.$ used for transyerse un' Je control).

A $-1 / 4$ in. thick sapphire llat output mir - r.

$B=$ Front surfaced gold, $3 \mathrm{~m}$ mitror $97 \%$ reflecting at $3 \mu$

periods of $5.10 \mathrm{~min}$. This we defined as operation in which the amplitude of mode beats did not exceed $20 \%$ of the unpcrturbed pulse amplitude. After that time thermal cycling and associated strain of the cavity caused unacceptable intermode mixing forcing a ninor readjustment of the cavity length.

Amplified Spontancous Emission - Oscillator

The gain of an H-I. system is known to be very high. 10 In the experimental situation, high gain caused persisten: parasitic oscillations unless rather exireme precautions were iaken.

Low Pressure - Long Pulse Mode - This mode was defined by $0.5 \mathrm{~J} / \mathrm{pulse}$ (input) and typical output pisse lengtlı of several $\mu$ ses, reactant pressurs about 30 Torr. Care was taken to inatch tỉe TEM 00 modu size to the volume of the active region. Tis clearty is bencficial from the standpoint of maximizing tlac 
output of the system, but tov large a mode diameter carries with it the problem of the inlerently nonuniform gain distribution as measıred across the active volume. Thus, about hall the full gain diameter was used in this study.

Further, all mode controlling aperatures had to be fitted with some materiaj that was highly lossy for wavelengths in the emission region of $\mathrm{HF}^{*}(\lambda \simeq 3 \mu)$. This was done using cardboard sprayed with paint whose infrared absorption was measured at $>90 \%$ for $2 \mu<\lambda<30 \mu$. Optics at exterior surfaces were all antireflection coated. The succeeding amplifier stage and apertures necessary for detection had Brewster's angle windows and antireflection paint respectively. Under these conditions it was impossible to obserye amplified spontaneous emission. When under grating control, no oscillator emission 'sut that selected by the appropriate grating angle was observed. The detection senisitivity was $20 \mu \mathrm{V} / \mathrm{cm}$. For reference, the same detection arrangement gave $500 \mathrm{mV}$ signals when the grating was tuned to resonance with a trarksition exhibiting gain.

High Pressure - Short Pulse Mode - This mode was defined by $40 \mathrm{~J} /$ pulse (input) and typical output pulse length of 150 nsec, reactanit pressures were

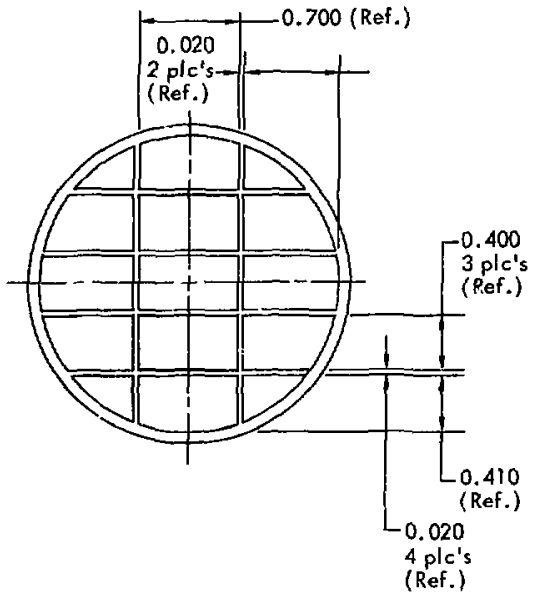

NOTE: Surface to be flot within 1 wavelength (sodium D) ahout 150 forr. It was experinientaliy determined that rptimum output coupling was achieved using a $\mathrm{NaCl}$ nat as an output nirror. In this configuration. en.ission peuked in energy hy a factor 6 over that in which no output mirror was used. In no case, quite independent of precuutions, was it possible to reduce the amplified spontaneous emission to unobservable Ievels.

Whth the grating detuned and the output mirror removed it was only possible to achieve attenuation of $10^{3}$ in emission of the strongest line $P(4) 2-1$. Thus, in this case, complete decoupling of the oscillatoramplifier regions was never achieved. By proper aperture selection it was possible to obtain TEM $_{\infty}$ performance as verified by observation of burn sputs on film and the use of a movable pinhole in conjunction with a calorimeter in the far field of the oscillator.

\section{AMPLIFIER}

\section{Turning Mirsor}

A speciat feature of the amplifier geometry is the tuming mirror shown in Fig. 9. This mirror serves two functions. First, it reflects the oscillator beam into the reaction vessel and second, it permits transmission of the electron beam through the mirror and

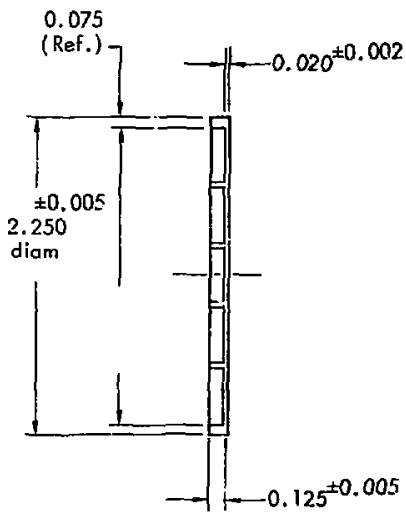

Dimensions in inches

Fig. 9, Beryllium tuming mirror. 


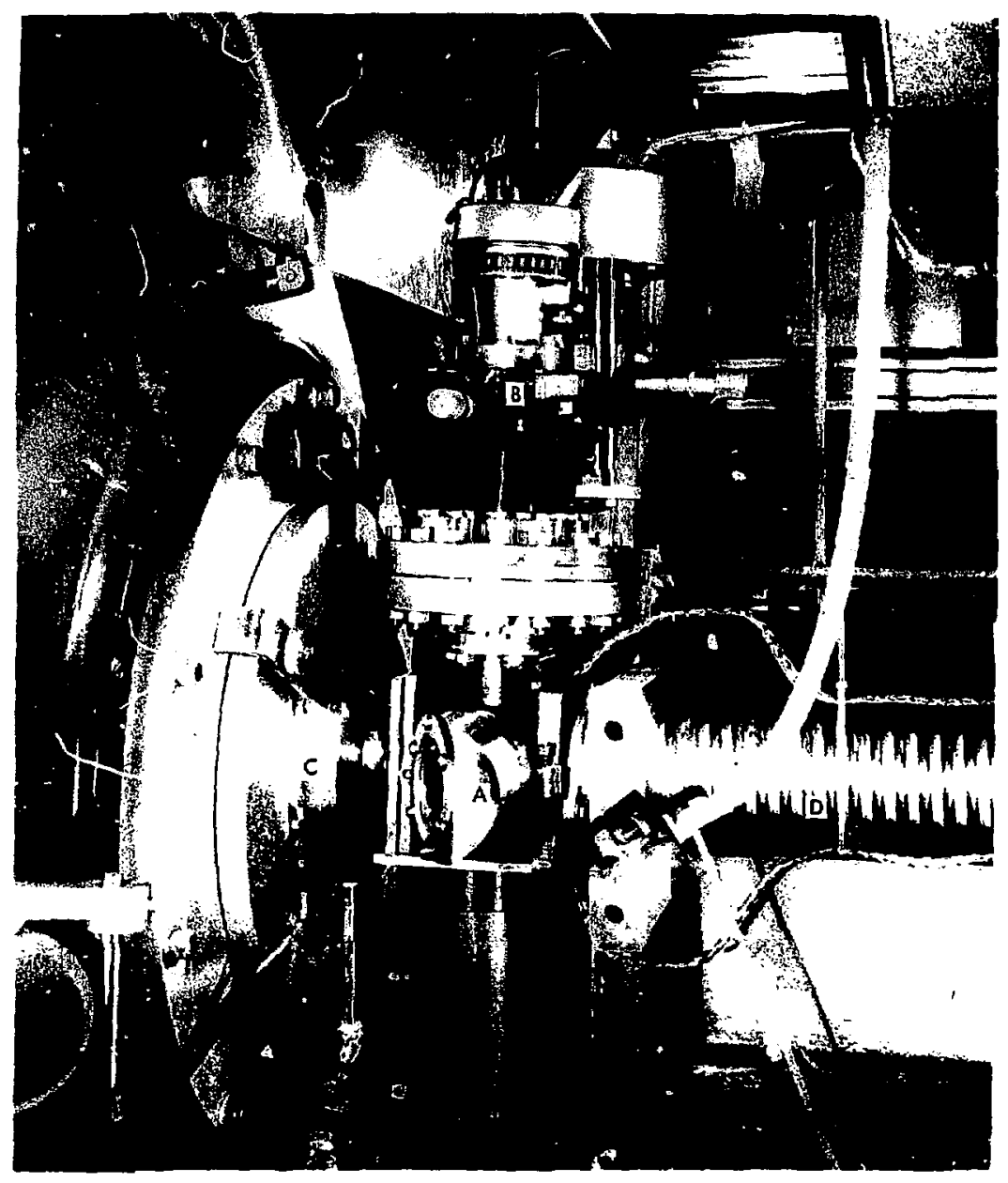

Fig. 10. Close-up of amplifier, mirror housing section.
A: Sapphire entrance window.
B: Mirror positioning fixture.
C: Electron beam output fixture.
D: Solenoid exasing teflon reaction pipe. 
down the axis of the amplifier tube. Beryllium was chosen for its obviously favorable density-to-strength ratio. The mirror was fabricated from a $1 / 8$ in. thick blank, $2.25 \mathrm{in}$. dia, with the back of the mirror being etched with a rib-like pattern. Etching was accomplished by electrolytic erosion.

The front face of the blank was then lapped and polished to \pm 1.5 wavelengths flatness (sodium-D). The structure was extremely rigid and calculation showed that no more than $\sim 10 \%$ transmission loss would be suffered. The mirror's cuntrihution to seattering losses was considered negligible when compared with the losses associated with the other scattering elements. The mirror and its associated housing were suspended on a $3 / 8$ in. dia stainless stee? shaft from a heavy-duty Varian rotation-translation fixture, Figs. 6 and 10, and was "'posed to the full impact of the chemical explosic curring in the renction pipe. After several hundsed firings, neither the flatness nor the infrared reflectivity of the mirror were seriously degraded by the effects of the explosive reaction. A light fillm produced by reaction products slightly degraded the mirror's reflectivity at $6328 \AA$.

The mechanical stability of the structure was examined using a He-Ne alignment beam directed onto the beryllium mirror. Fig. 11 , and then detected by an SDG- 100 photodiode, $15 \mathrm{ft}$ away from the mirror. The electron beam was made to penetrate the mirror and then the time for spot iraversal of the

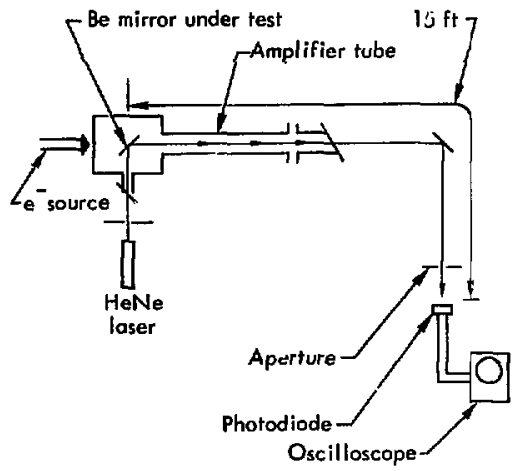

Fig. 11. Test geometry for mirror motion studies. sensitive area of the diode was measured. As shown in Fig. 12, no motion occurred during the first $8 \mu \mathrm{sec}$ after the beam fired. After $8 \mu \mathrm{sec}$, a slow drift of the reflected beam occurred with the spot retuming to its precise prefiring position within about $50 \mathrm{msec}$. The observed $8 \mu \mathrm{sec}$ interval of stability correlates well with the sound transit time across the diameter of the mirror.

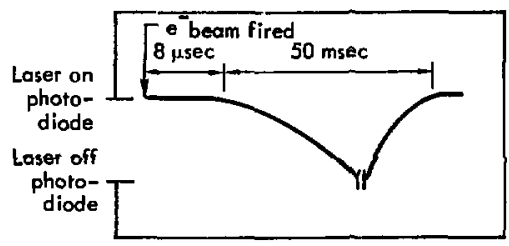

Fig. 12. Data on mirror motion.

\section{Amplifier Geometry}

The beryllium mirror serves the dual task of turning the oscillator beam down the pipe while at the same time causing minimum perturbation to the electron beam in its path down the tube.

All obstructions to the free electron motion down the tube contribute to beam spread and absorption. The influence of these effects will be assessed in the section on electron beam propagation below. In summary, the energy loss due to ionization is under $10 \%$ and the rms scattering angle is under $30^{\circ}$. In Sec. I-H it is shown that the mirror is a minor contributor to the electron loss. The scattering, being predominantly forward, is relatively insignificant because of the effectiveness of the longitudinal magnetic field in confining the divergent electrons.

The amplifier section is taken to ifclude the mirror housing section, the amplifier tube (reaction vessel), and the output housing, Fig. 13.

The mirror section, aside from containing the mirror, allowed for the attachment of the entrance Brewster window and for high speed pump-out of the exploded gases through a $5 / 8 \mathrm{in}$. air operated, $2 \mathrm{ksi}$, Nupro valve. The mirror section is shown schematically in Fig. 14. 


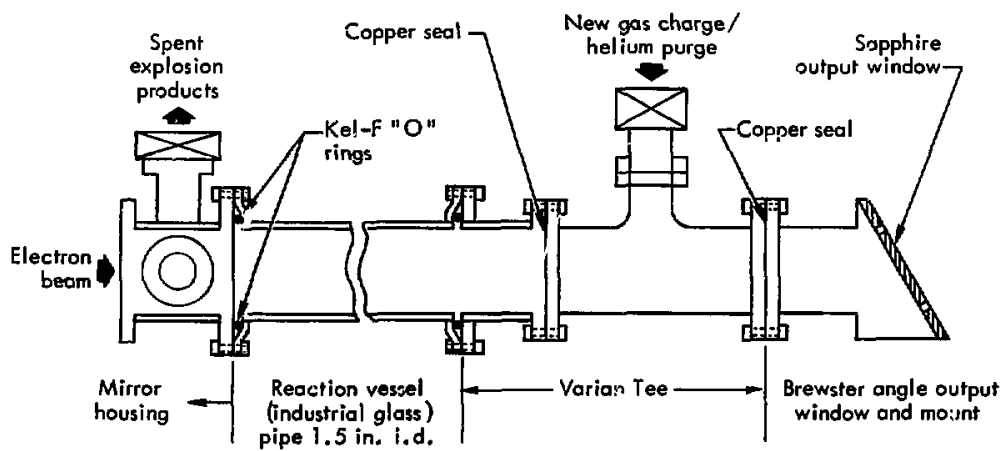

Fig. 13. Four major sections of the amplifier.

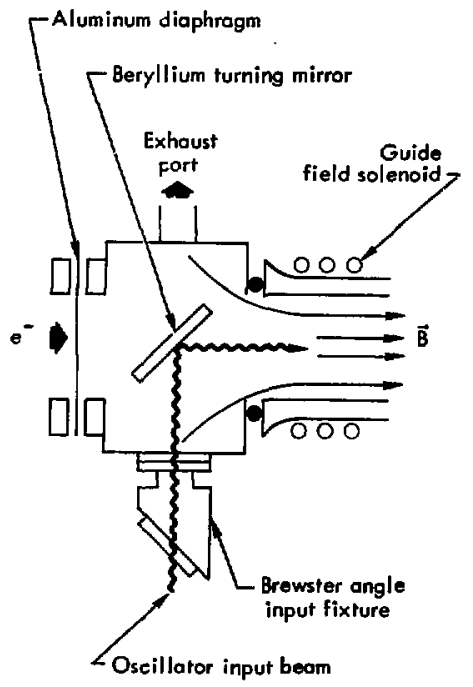

Fig, 14. Top view of input and mirror section.

\section{Ampifier Reaction Tube}

In early experiments the reaction tube was standard industrial glass pipe cleuned with ethyl alcohol and then pumped for several days until a base pressure of $<5 \times 10^{-7}$ Torr was attained. The glass was sealed with KEL-F (a fully flourinuted hydrocarbon) O-rings and secured with standard industrial glass pipe flanges. Gases were then introducid, exploded, and the amplifier output exumined. It was noticed that after each firing, $i$ : became increasingly difficult to pump the system down and the output became weaker and more erratic. This was especially true when the mixtures were near stoichiometric for the reaction:

$$
2 \mathrm{NF}_{3}+3 \mathrm{H}_{2} \rightarrow 6 \mathrm{HF}+\mathrm{N}_{2}
$$

Note: Reaction (5) is the ultimate result of complete combustion at $\mathrm{NF}_{3} / \mathrm{H}_{2}=2 / 3$ and is not representative of what actually oceurs during laser action.)

Post explosion mixtures were sampled by llowing explosion products into a previously evacuated ir cell built of Monel with $\mathrm{AgCl}$ windows." Spectrophotometer traces of post explosion mixtures showed a strong $\mathrm{SiF}_{4}$ band. evidence of a reaction between $\mathrm{HF}$ and the glass walls. The gain of tle system contaminated with $\mathrm{SiF}_{4}$ became small and generally unpredictable. Seversl alternative reaction vesse' materials were examined including ceramics and various metals

This cell was shown to be inert with respect to catalysis of the $\mathrm{NF}_{3} / \mathrm{H}_{2}$ reaction over periods of sevcral days. 11 
(e.g. stainless steel and Monel). Ceramics were rejected on the grounds of difficulty of fabrication and possibility of reaction with the HF formed in this reaction. All the metallics were rejected because of their conductivity. For reasonable tube thicknesses the magnetic field d:ffusion times art unacceptably long, see Sec. เ-H below.

The material finally chosen was Teflon machined to the same shape as the glass tube. Teflon did not react with the HF to any noticeable degree but did suffer the disadvantage of being more porous than glass, The best base pressure at : vinable was higher than that of glass $\left(\simeq 8 \times 10^{-7}\right.$ Torr). Teflon performed acceptably throughout the experiment. The magnetic field alignment relative to the reaction tube axis was important to prevent puncture of the tube, after several shots, by the formation of discharge tracks in the material.

The Teflon amplifier section was wrapped with copper tubing forming a solenoid that, when energized, provided an axjal magnetic field centered about the tube axis. The solenoid is effectively infinite (for the purpose of inductance calculations) with fringing of the field occurring at about one coil diameter away from the end of the solenoid. The magnetic field cir. cuit oscillates, essentially undamped, with a quarter period of $50 \mu \mathrm{sec}$. The electron bears is introduced into the amplifier section at about the time $( \pm 0.5$ $\mu$ sec) that the voltage induced in the pickup coil passes through zero ( $E_{\text {piskup }} a \mathrm{di} / \mathrm{dt}$ ) or equivalently, the current in the main solenoid is a maximum. This externally induced magnetic field was taken to be constant during and immediately after the electron beam was introduced (total duration of beam is $80 \mathrm{nsec}$ ). Figure 15 Jemonstrates the effectiveness of the confining field.

Figure 15a sliows the beam propagating in 300 Torr of argon with a containmen: field of $\sim 2.7 \mathrm{kG}$. The entire surface of the tube is illuminated. The visible emission is due to flourescence of the glass tube as well as bulk emission from the gas. Figure i 5 b depicts the same experiment with the containment field increased to $\sim$ kG. The illumination in this case is due solely to the thin pencil beam down the $a$ vis of the tube.

\section{Amplifier Exit Region}

This region consists of a Varian "tee" (stainless steel) that couples to the glars amplifier section on onc end; to the output Brewster angle fixture on the
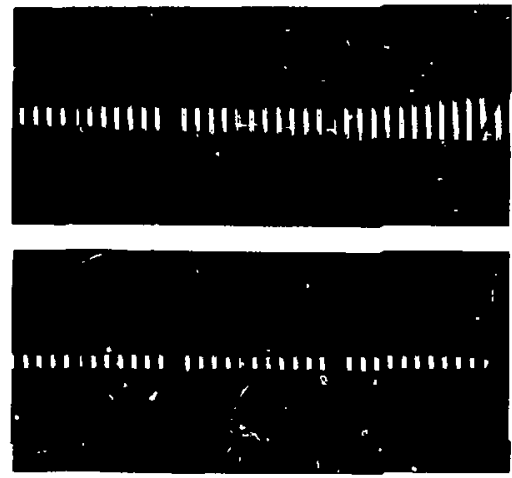

Fig. 15. Electron beam in alr

(a) with insufficient containment field (2.7 kG),

(b) with 8 kG containment fiekd.

other, and to the filling, purge and pressure monitoring hariware on the center of the "tee", Fig. 16.

A pair of braided copper straps, Figs. 10, 16.17. connect the output hcasing to the mirror housing forming a low inductance return path for the electron beam primary electrons. The outpu't tee also provides a sin!. iv seam primaries guided by the fringing fields to the tee walls. This protects the sapplire output window from any but a trivial exposure to direct slectrons from the beam. Even after about a one thousind firings there was no evidence of radiation damage to the windows.

\section{ruide Field Solenoid}

The magnetic field solenoid was constructed of 1/4 in. o. d. copper tubing. Hollow tubing is totally acceptable since even at tile design resonant frequency of $5 \mathbf{~ k H z}$ the skin depth is about $0.9 \mathrm{~mm}$. The tubing is wrapped on a lucite tube of $8.2 \mathrm{~cm}$ o. d. forming 42 turns in a length of $60 \mathrm{~cm}$. Another lucite tube, whose inside diameter was such that it could be slipped over tlie wound coil, was fitted and then cleai potting material was flowed between the windings and allowed to "set up". The coil, this ; inited, 'Nas held in a fixture that supported it indejendently of the amplifier tube.

This entire assembly is then slipped over the end of the amplifier and shimmed to be concentric with the teflon tube axis. The coil fixture was made fast to the granite optical bench by weighting with about 


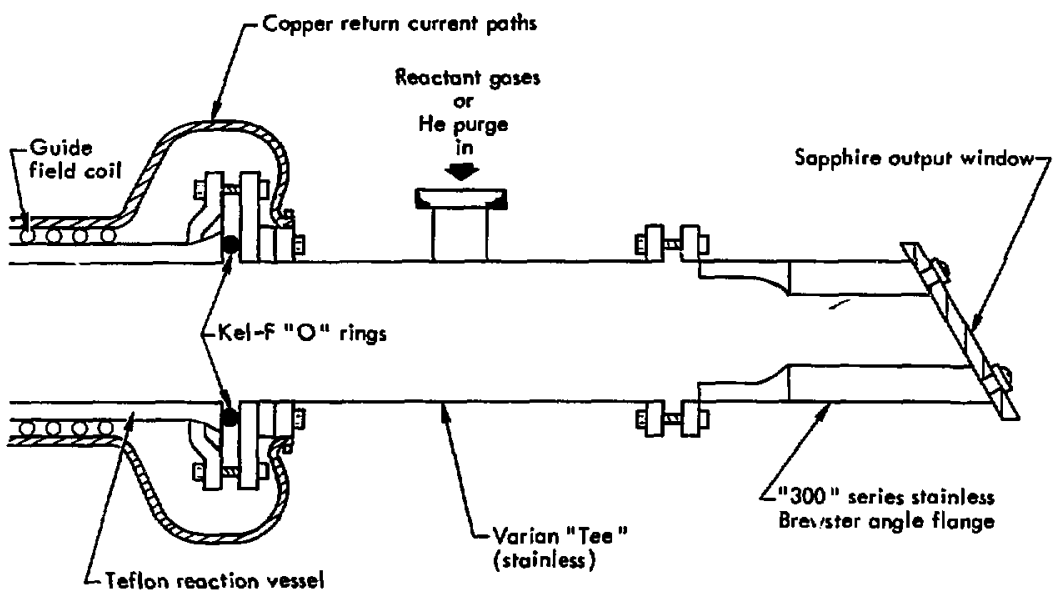

Fig. 16. Amplifier output section.

100 tb of lead bricks. The amplifier section was supported, to this point, at the mirror housing end only, and was subsequently pasitioned by b.ljusting its center to be coincident with a He-Ne alignment laser hesm shone into the input window and reflected down the tube axis by the beryllium turning mirror.

The final aliznment of the Teflon tuhe axis with the magnetic axis was checked by experimentally measuring the path of the electron beam using plastic cliscs nut in the beam path, see Sec. II $C$. The bleached center of this series of dises, when compared to the gtometric center of the tube, allows the final adjustment of the solenoid. No further alignnent was reyuired until an equipment malfunction required disassembly and complete realignment.

\section{INSTRUMENTATION}

The data tommonly gathered during this investigation consisted of:

1) Oscillator/amp!ifier pulse shupe data - Cu:Ge (liquid helium cool:ad).

2) Monochromatry - Perkin Elmer E-1.

3) Calorimetry - Scientech Inc. (Model 1602).

4) Electron beam performance data - capacitive voltage divider across field emitting diode.

5) Magnetic confinement field monitoring - JB/dt probe.
The pulse shape data acquisition system evolved in three distinct sta 35 . First, in the earliest experimenta! stage Au doped Gezmanium (rhilco-Ford 201A) was used for monitoring the oscillator input, amplifier output, and monochror.ator output. These detectors had the advantage of operating over a wide dynamic minge (saturation at $10 \mathrm{~V}$ output into $S 0 \Omega$ ) and requiring only liquid nitrogen cooling; their major drawback showed up as a rather low bandwidth resulting in poor resolution of pulse shapes, Fig. 18 . In addition the high- $Z$ dopant (gold) rendered the devices quite sensitive to the hard $x$-ray bremsstrahlung generated by the electron beam machine.

Next we tried InSb photo resistive detectors. These devices. produccd by Mullard, had the advantages of greater bandwidth (see Fig. 19), operation at room temperature, use of d.c. power supplies rather than batteries, and remarkable insensitivity to the hard $x$-ray environment mentioned above. Their only drawback was a limited dynamic range that resulted in saturation at signal levels of $200 \mathrm{mV}$ into $50 \Omega$.

The final configuration of detectors was liquid helium cooled, $\mathrm{Cu}$ doped, germanium (Cu:Ge). These detectors combined high sensitivity with wide dynamic range and the largest bandwidths of all detectors examined.

Thest crystals were originally intended for use at $10.6 \mu$ and were therefore peaked in sensitivity for this range. Due to an accidental overdoping of copper 


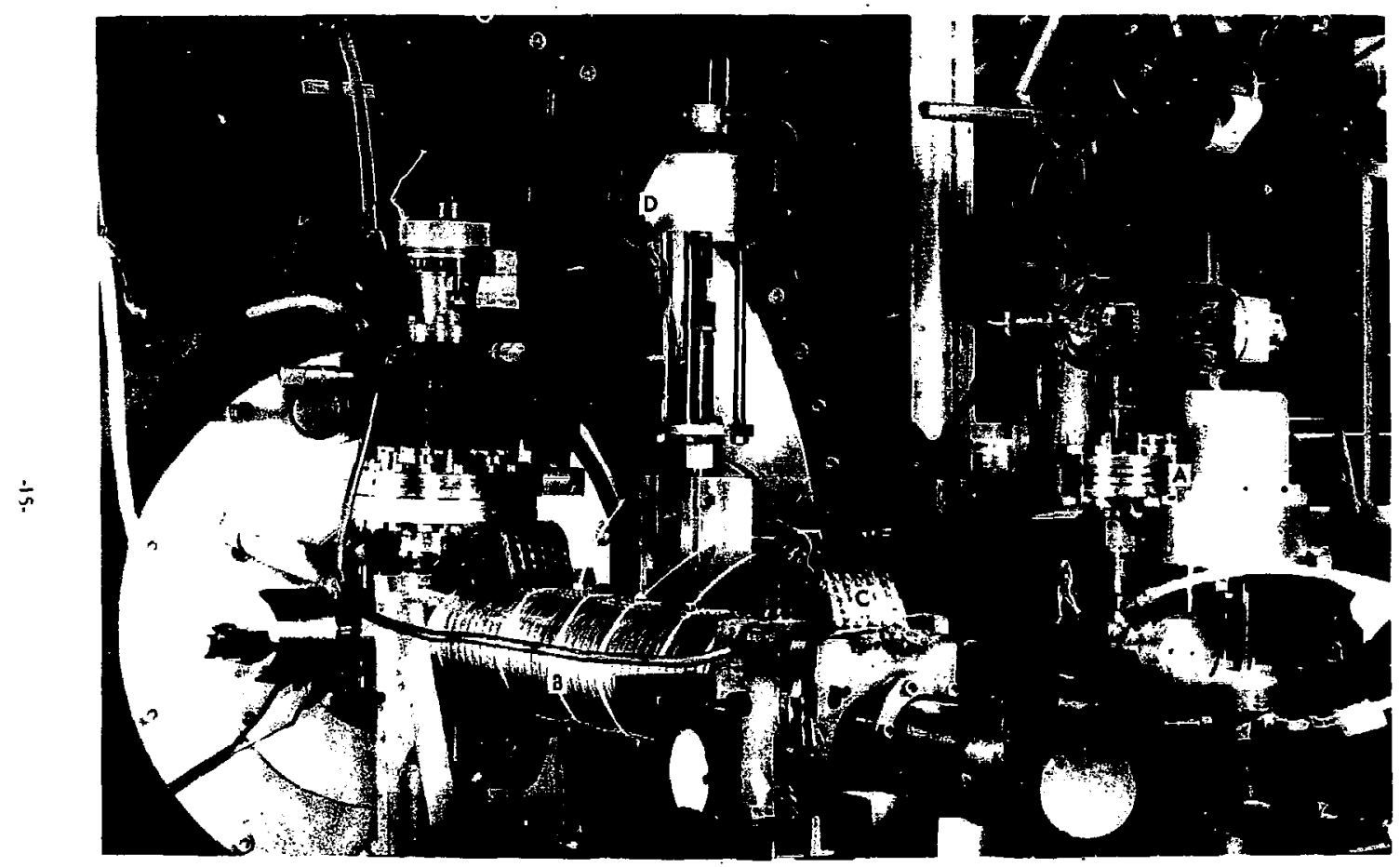

Fig. 17. Amplifier sectios.
A: Full/purge/prespure senting hardwars
B: Gulde field solenoid
C: Copper ground retum straps
D: Nupro 5/8" exhnust valve 


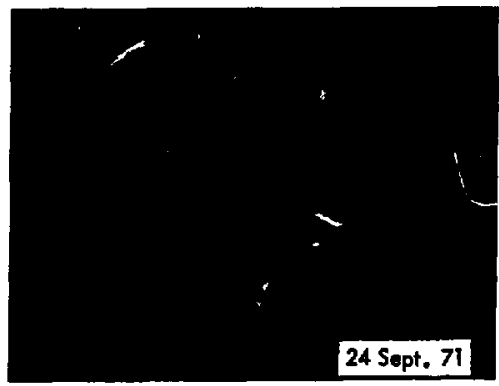

Fig. 18. Dual beam teconding comparing frequency rexponses of gold doped gemanium with copper doped germg. nium detectors, using $1 \mathrm{~A} /$ preamp, and 555 scope at 100 nsec $/ \mathrm{cm}$ and $0.02 \mathrm{~V} / \mathrm{cm}$. No electron bean.

Upper trace: Cu:Ge

Lower trace: Au:Ge

Note: Display is limited by the bandwidth of the 55S osciloscops.

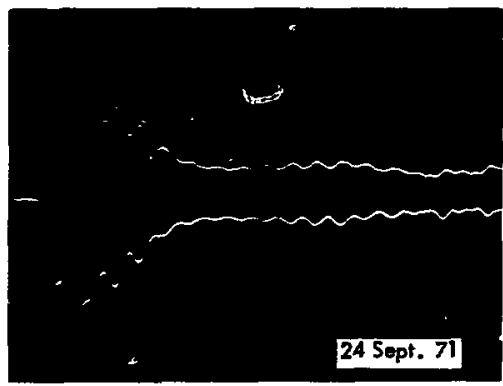

Fig. 19. Dual beam recording comparing frequency responses of indium antimonide with copper doped detector. using IAI preamp and 555 scope at .00 nsec/cm and $0.01 \mathrm{~V} / \mathrm{cm}$. No electron br $\mathrm{m}$.

Upper trace: Cu:Ge

Lower trace: InSb

Note: This display is limited by the bandwidth of the SSS oxcilloutope. however, their sensi- vity at $3 \mu$ was substuntially improved over the original design requirements. These devices, installed in liquid He Dewars, were shecked for response time with a 20 psec Nd:glass oscillator and found to have an inverse bandwidth corresponding to about 5.0 nsec. The data to be reported later will. unless otherwise specified, be exclusively that collected with the $\mathrm{Cu}$ :Ge devices. Figure 20 shows a typical arrangement of optical components used for detection and monochromatry.

\section{E. FAST FILL SYSTEM}

A particular hazard associated with clkemical lasers is a tendency for various mixtures of fuel and oxidizer to detonate spontancously. For this reason rather elaborate precautions were taken to permit complete remote control of all gas handling including filling the amplifier, mixing the gases, pressure monitoring, detonation, pumpout. and gaseous helium purge.

The key apparatus necessary to accomplish this task is a fast fill system. This device allowed precise pressure and stoichiometry control over a range of 20-80 Torr of explosive mixture. To permit the desired firing rate, it was necessary to introduce the fresh charge immediately before firing to minimize prercaction with incompletely removed explosion products from a previous firing. Simliarly immediate exhausting of spent gases. followed almost simultuncously with a clean helium gas purpe. was inecessary to eliminate the fesidente timt of the chicf reaction product, $\mathbf{H F}$.

The fast fill system was of a general purpose design that permitted mixing any pair of highl vapor pressure fuels and oxidizer by imposing a constant pressure on the upstream side of preset metering valves. Some of these fuels and oxidizers, not including $\mathrm{NF}_{3}-\mathrm{H}_{2}$. Werc unstable with respect to spontaneous exothermic decomposition. It was therefor: netessary to minimize any friction that might serve to detonate the gases. Figure 21 shows a simplified schematic of the system for a single gas. The symmetry of the system is such that it may be imagined extended to any number of gases.

The regulators for the pusher gas and fuel/oxilizer gas are set to the same pressure. The operation is quite simple. After remote evacuation of the storage and metering regions, valve $l$ is opened to allow fuel/ oxiaizer gas to filt the storage tube to the preset regulator pressure. Vals: 1 is then closed. The laser fill command the:i sinultaneously opens valves 2 and 3 for a preset length of time. The function of the pusher 


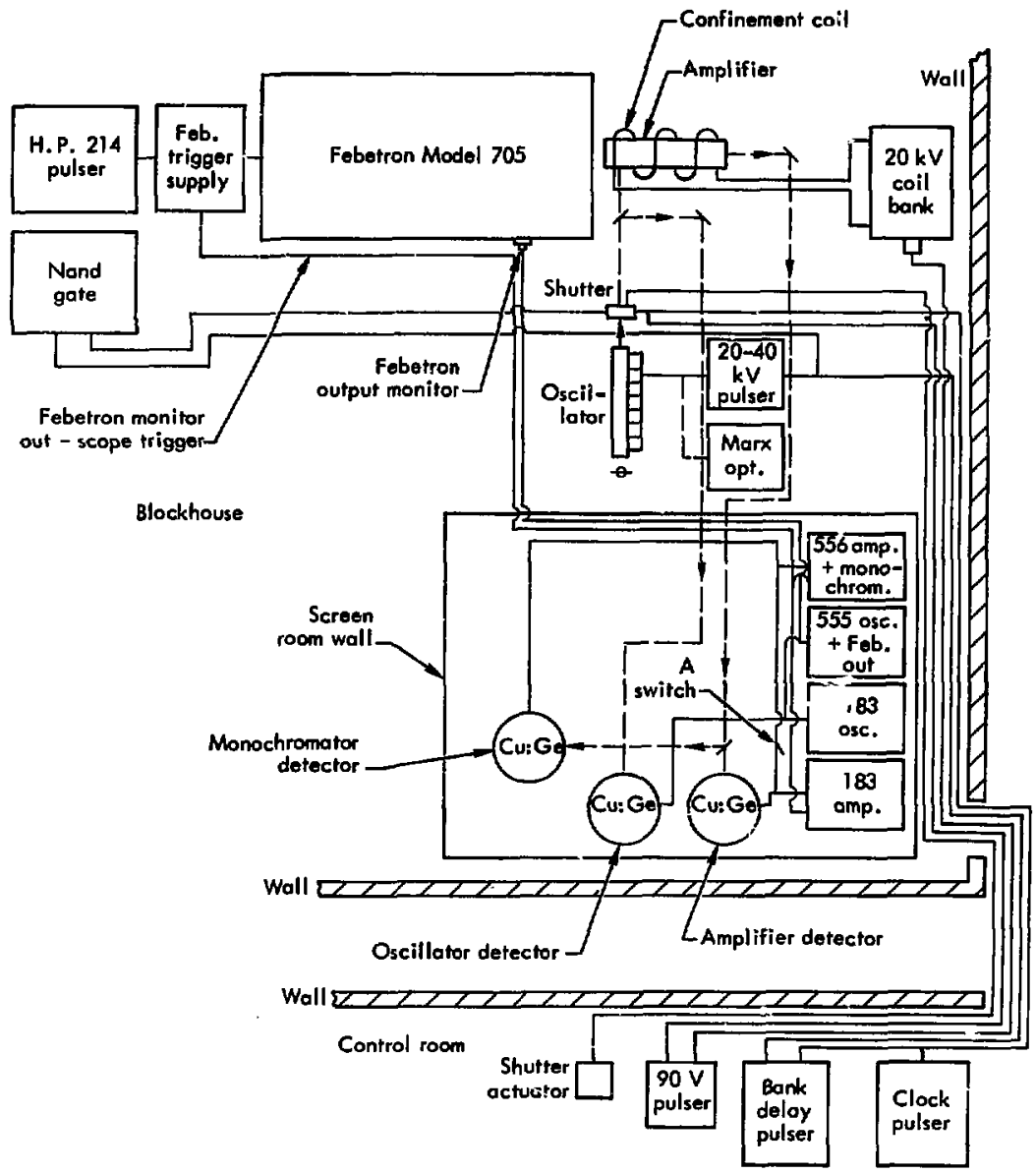

Fig. 20. Electron beim driven chemical laser synem. 


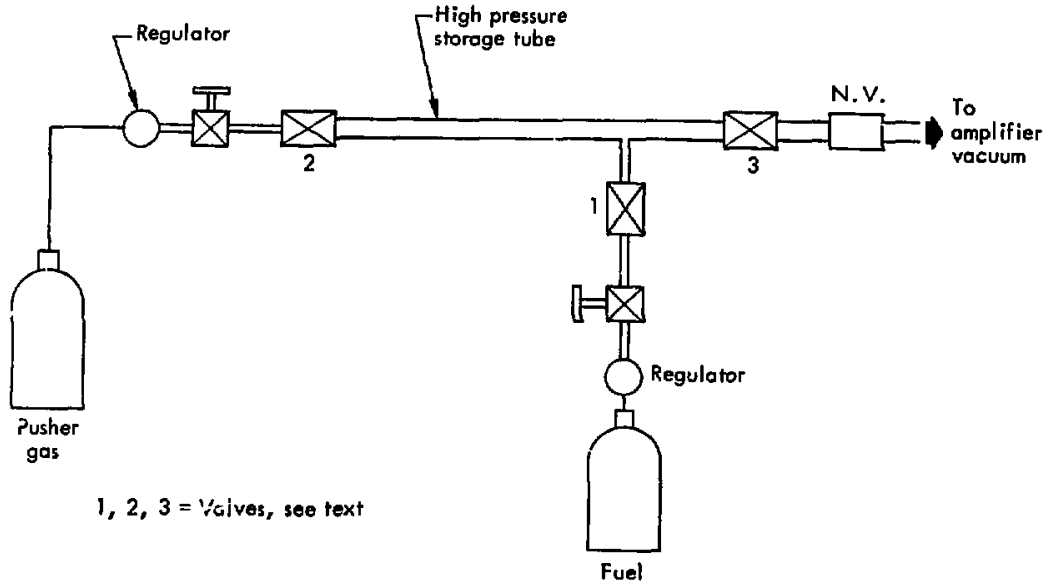

Fig. 21. Schematic of smallest functional part of fast fill system.

(argon gas) is to impress a fixed pressure of active gus on the high pressure side of the needle valve (N.V.) so as to keep a steady flow rate essentially independent of the amount of fuel/oxidizer exhausted. After the preset low period both valves 2 and 3 ulose simultaneously leaving the storage tube filled (in the optimum case) with only argon gas. The laser fill valve (not shown in this (igure) is then closed and the laser is fired. Exhausting through a separate punp-down path prevents explosion products from ever contaminating the fill section of the apparatus, Fig. 22.

Typical operating pressures in the slorage tube were 30-50 psia. Consequently for low pressurc laser fills this system was necessarily quite wasteful of reactants. At high pressure amplifier fills, however, this was not the case. The storage tubes as shown in Figs. 21-23 are long and slim in order to minimize mixing of the pusher gas with the pushed gas. The fact that argon impurities were quite small was verified by mass spectrometer studies performed for worst case conditions (long low times). Figure 23 schematically represents the system used in this experiment.

Valves with common numherings are always opera* ted in pairs (a single solenoid controls both valves).
Valves 4 facilitate pumpolt of the system by bypassing the necdle valves with a high conductance palit. The entire system is constructed from high pressure stainless steel tubing, valve bodies were all $200 \mathrm{psig}$ stainless steel, and all components with the exception of the needle valves could stand pressurization to 2000 psig. Needle valves were limited to only 150 psig across the seat to guarantee $1 \times 10^{-10}$ std $\mathrm{cm}^{3} / \mathrm{sec}$ helium leak rate. This was never a problem since pressure differencrs in excess of 50 psig were never used.

The system was carefully interlocked so that it was virtually impossible to raise the laser pressure to the 50 psig setting of the regulators. The system was fail-safe in the sense that either a power failure or air pressure leak rendered the system harmless with respect to leaking explosive or toxic gas into the experimental area.

The entire gas handling system, the laser amplifier, and the pressure detection systems were enclosed in a chemical hood that was capable of safely withdrawing and exhausting $5 \mathrm{lb}$ of $\mathrm{NF}_{3} / \mathrm{H}_{2}$ mixture.

Each arm of the gas fill system was individually calibrated for the particular gas under test so that mixture ratios could be preset by rotating the needle valve micromete;s to indicated numerical values. A typical calibration run is shown in Fig. 24. 


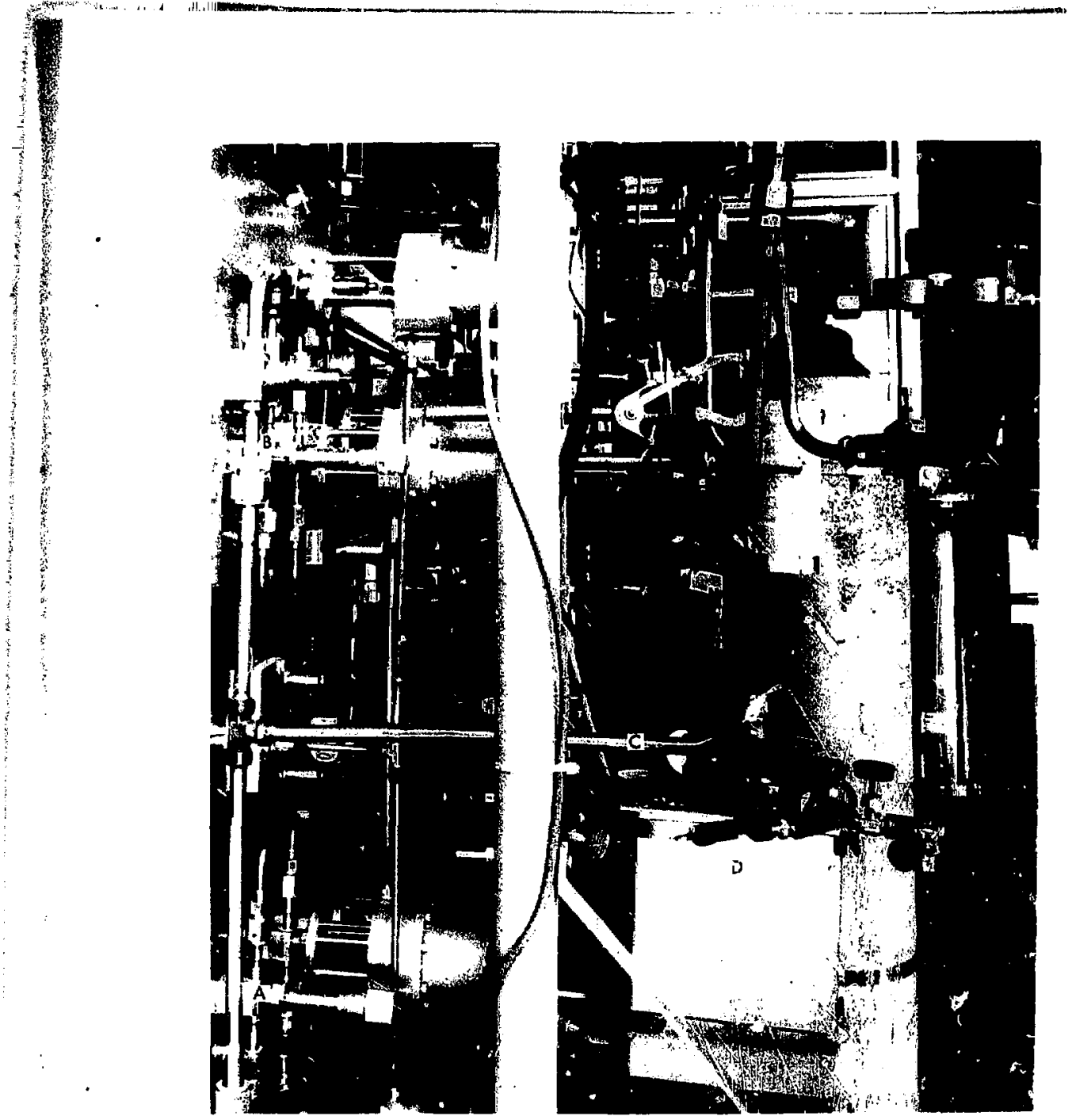

Fig. 22. Fast fll system/gas /uandlinz plumbing.

A: Hydrogen metering section (fast fill systern)

B: $\quad \mathrm{VF}_{3}$ metering c:action (fast fill system)

C: Fast fill outpul tule (mixed gases to amplifier)

D: Jarocull pressure moniloring dtvice 
fast fill system. The "fill" valve located at the amplifier was then closed, thereby isolating the amplifier. A sainple of the (unexploded) amplifier gas was flowed into an infrared cell and scanned in an infra red spectrophotometer for the dominant NF 3 peaks (1870 and $1800 \mathrm{~cm}^{-1}$ ). The peak absorption was then compared with previously calibrated samples to determine the quantity of $\mathrm{NF}_{3}$ in the amplifier gas. By subtraction it was then possible to verify that the ratio of $\mathrm{NF}_{3} \mathrm{H}_{2}$ was that determined by the calibrations shown in Fig. 24 above.

As a further check for the presence of the monatomic pusher gas, a sample whose pressure and volume was known was condensed $\left(\mathbf{N F}_{3}, \mathrm{Ar}\right.$ ) over liquid nitrogen and the uncondensed gas pressure $\left(\mathrm{H}_{2}\right)$ was then remeasured. This technique checked with spectroscopy to within $1.0 \%$ (the experimental error) thus indicating that at most $100 \mathrm{ppm}$ Ar was present in the amplifier sample.

In order to achieve higlı total pressure fills under strongly nonstoichiometric conditions, (e.g. $8 / 1$ $\mathrm{NF}_{3} / \mathrm{H}_{2}$ ) it was tuecessary to have large needle valve openings for $\mathrm{NF}_{3}$ and small openings for $\mathrm{H}_{2}$ becouse of its molecular size. The valve timers were typically set to operate for 5-8 sec. Under the strongly nonstoichiomet $i$ conditions discussed above, it was observed that the argon concentration rose to $25 \%$ of the total pressure as verified by mass spectrometer studics.

\section{F. ELECTRICAL AND MECHANICAL INTERCONNECTIONS}

The combination schematic and flow diagram shown in Fig. 25 illustrates the scheme used for coincidence timing of the oscillator pulse, electron beam pulse, and the guide field solenoid. It should be noted that the oscillator is run at a fixed repetition rate of about 2-5 Fulses/sec with $\mathrm{SF}_{6} / \mathrm{H}_{2}$ mixture ratios chosen to optimize the pulse shape for the particular investigation undertaken. The repetitively pulsed osejllator was decmed necessary in order to estaolish steady state thermal conditions and flow mixtures. The entire firing system was enabled by a mechanical (cameratype) shutter that served the dual functions of permitting only one oscillator pulse to traverse the amplifier and initiating the triggering sequence. The primary i eason for admitting but one oscillator pulse was to prevent the calorimetry from integrating a large number of pulses before the ampliffer fired.

Substantially all of the timing and triggering electronics were located in a control room area behind
3 ft thick interlocking concrete blocks. Exceptions to this rule were the oscillator firing pulser and the Febetron trigger generator. These were located inside the "block house" directly adjacent to their respective driven units. All the detection cquipment, oscilloscopes, monochromatry and calerimetry were located in a double walled copper mesh streen room with "portholes" cut in solid copper plates to allow the light signals to enter. The only nonoptical signals to enter the screen room were those of the capacitive voltage divder (potential across ficld emitting diode) and scope triggers from a monitor output on the electron beam triggering chassis. Screen room effectiveness is demonstrated by noting that peak-to-peak noise with the screen room closed was $<1.0 \mathrm{mV}$. With thi door open $\geq 20 \mathrm{~V}$ peak-to-peak signals were common.

In addition to the electrical squipment directly related to the last-fill system, a switching array permitted remote operation and monitoring of the entire fill and pumpout procedure. This equipment was designed in a master-slive configuration such that completely identical operations could be performed inside the experimental area and in the control room. A photo of the chassis involved appears in Fig. 26.

Figure 27 illustrates the overall mechanical/ physical arrangement of the experinental area. The high magnetic field strength, associated with the pulsed guide field and internal electron beam guide magnet, required that the entire amplifier be constructed of nonmagnetic material. The optical bench for the umplifier hardware was a tool-room-qualíy granite table isolated from the floor by a stack of altemated wooden blocks and rubber pads. The table supporting structure, of all steel construction, was far enough from the field sources to make the effects of magnetic forces unobscrvable.

The path length from the oscillator output mirror to the detector is of the order of $30 \mathrm{ft}$. For this rather sizable propagation distance it was necessary to etiminate air currents insofar as possibic. Failure to do so produced noticeable wandering of the oscillator beam caused by index of refraction variations along the optical path. With proper air baslles it was possible to reduce this motion to rms angular deviations of $10^{-4}$ rad (or $1 \mathrm{~mm}$ output spot excursions). The time variations of this effect were slow ( $\sim 1 / 2 \mathrm{sec}$ ) and therefore utterly negligible during the $1 \mu \mathrm{sec}$ over which the typical experiment was run.

The experintental area, as indicated in Fig. 27, was entirely enciosed by $3-f t$ thick concrete walls and a 16-in. thick wood ceiling. It therefore exhibited a 

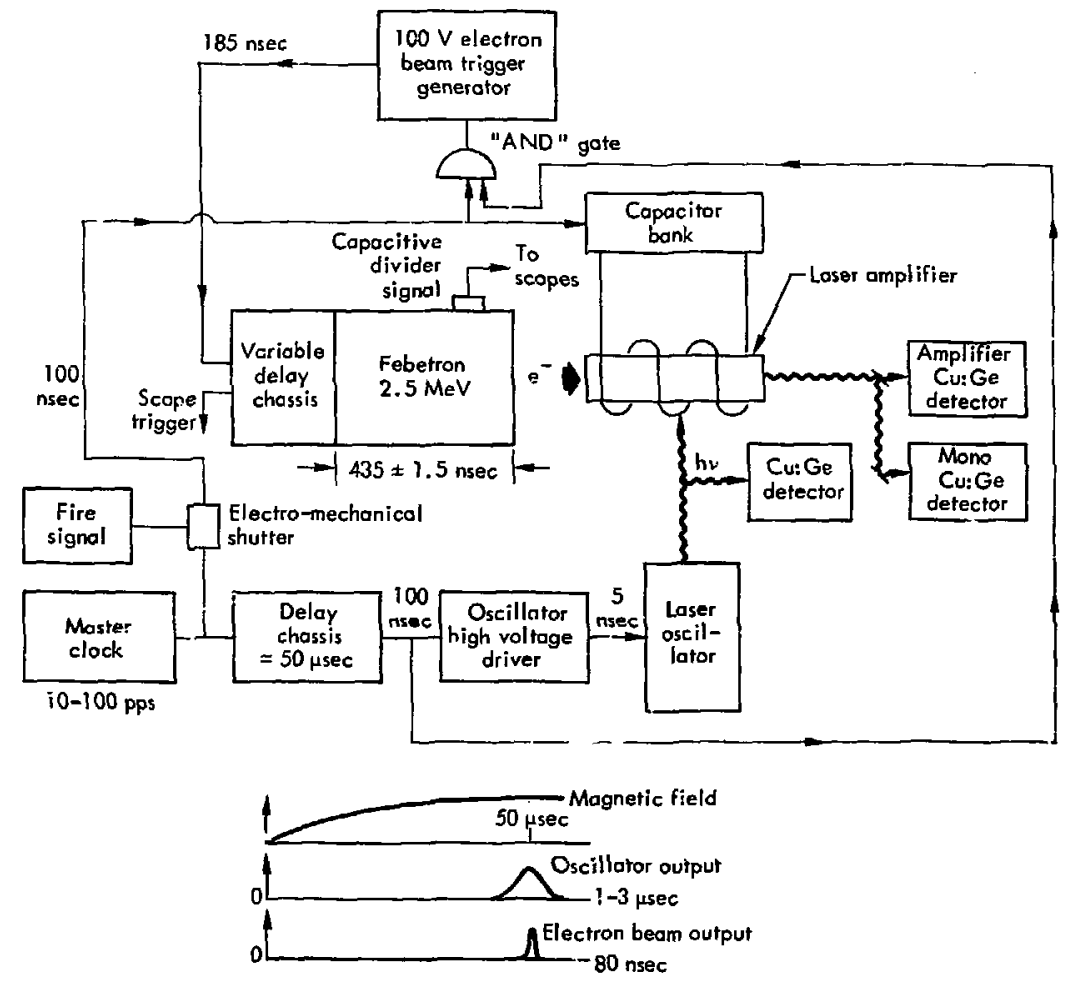

Fig. 25. Overall electrical tuming and interconnection scheme. 


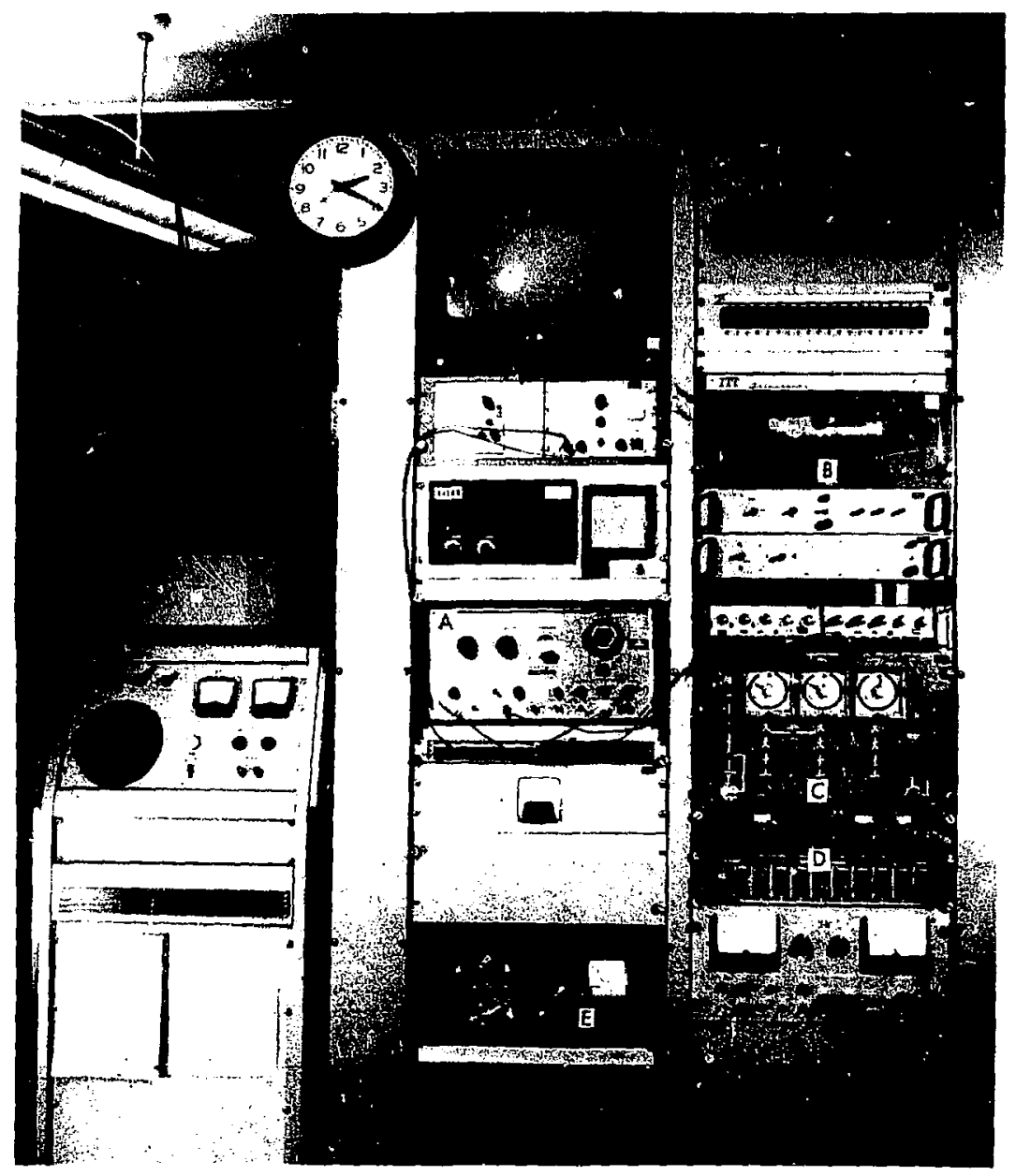

Fig. 26. Experiment control electronits
A: Master clock
B: Timing chassis
C: Fast fill system control panel
D: Remote value contrul panels
E: Amplifier yressure monitor 


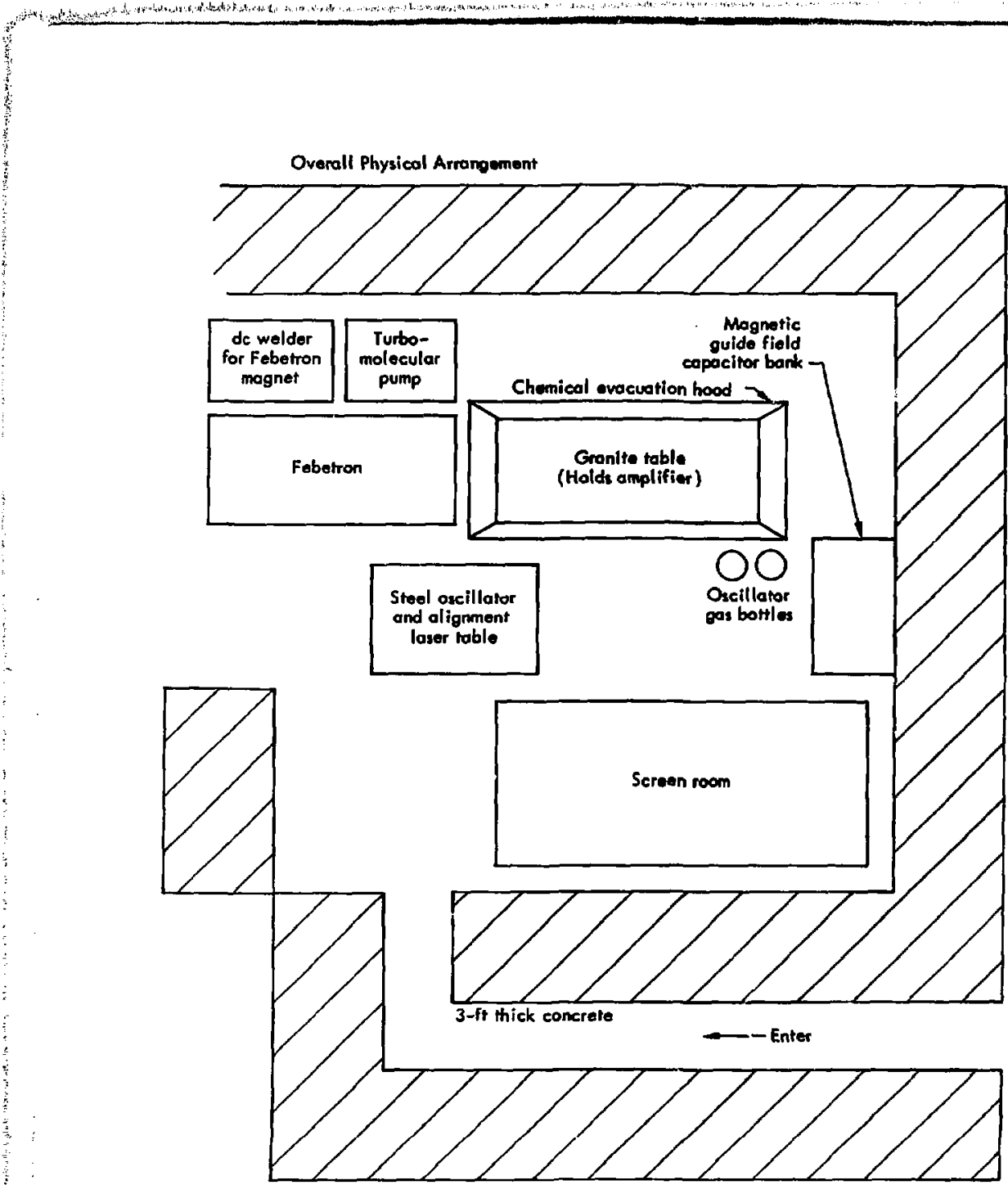

Steal oscillator and alignment laser rable oxeillaror Gronite table (Holde amplifier)

Fig. 27. Overall mechanical view of experimental area. 
"high Q" with respect to acoustic disturbances generated by passing trucks or loud noises generated in close proximity to the experiment. The oscillator cavity stability was the element most seriously affected by these phenomena. Active cavity stabilization was judged quite difficult for a pulsed laser and therefore not attempted. It was necessary to resort to working with the system during its stable periods. These would last several minutes at a time, after which we restabiliesd by piezoslectrically adjusting the eavity length.

The usual frecautions attendant with operating in high noise envilonment were taken. For example:

- Line filters. These included both the lumped LC variety and the inductive common-mode rejection techniques used to discriminate against ground noise carried by ground sheaths.

- Signal isolation by $1: 1$ isolation transformers.

- Single point grounding.

- Specially designed high level (t I5 V) digital Jogic.

- Physical shielding (lead) of sensitive thectronics and detectors.

- Careful selection of oscilloscopes, trigger generator, ctc., for their inherent resistance to electromagnetic effects.

\section{G. VACUUM SYSTEMS}

It was originally intended to use liquid-nitrogentrapped mercury diffusion punsps to evacuate the amplifier and fast fill systems. These pumps were soom rejected because of the appearance of inercury vapor throughout the system and the lrazard of occasional contact between unexploded gases and the diffusion pump traps. This error required careful warming of the traps to remove the condensed gases and then restarting the 1rap cooling and pumring process. This would constime the better part of a working day.

Fortunately a 400 //sec turboinolecular pump hecame available. The diffusion pumps were runoved from the system and a new vacuum manifold was constructed. The virtues of the turbomolecular pump were that it produced its rated pumping speed independent of pressure from $10^{-3}-10^{-9}$ Torr, was insensitive to momentary large gas loads (c.g., exposure to the ambient atmosphere), had negligible back diffusion of lubricating oils, required no down time ror maintenance. After about $\mathbf{2 0}$ exposures to explosion products (the amplifier tube was never tumed on to the lurbo pump system unil the system was roughed out to $\simeq 50 \times 10^{-3}$ Torr) pumping speed did suffer in the sense that the pump throat pressure levelled off at high pressure $\left(10^{-7}\right.$ Torr) for about twice as leng as after the first exposure of the day. This effect was accentuated thr, nearer to stoichiometric the explosive mixtures became. This indicated that HF produced some product of rather low volatility in and around the pump manifold. The primary cause of the temporary pressure plateau was a glass. enctr xed ionization gauge mounted on the pump inlet manifold, with $\mathrm{SiF}_{4}$ the reaction product.

\section{H. Calculations}

\section{Low Energy Oscillator Mode}

The cavity length was set as near to $1.50 \mathrm{~m}$ as possible. A grating (Baush and Lomb \#35-63-05-720) functioned as the back $(>90,5)$ mirror and a $3.0 \mathrm{~m}$ silicon 50\% mirror as the output device. The output mirror was of a menistus type, the output fate of which was antireflection costed $3 \mu$

The cavity mode sinucture can bit represented by the following equation: 12, 13

$$
\Delta u_{\text {contly }}=\left[q+(m+n+1)^{1 \cos ^{-1}\left(g_{1} B_{2}\right)} \pi^{-\frac{c}{2 L}}\right.
$$

$$
\begin{aligned}
& \text { where } \mathbf{g}_{1}=1-\frac{L}{\mathbf{R}_{1}} \\
& B_{2}=1-\frac{L}{R_{2}} \\
& c=\text { velocity of light }
\end{aligned}
$$

For this case:

$$
\begin{aligned}
g_{2}=1 ; g_{1}=1-\frac{L}{2 L}=1 & ; B_{1} g_{2}=\frac{1}{2} \cdot \cos ^{-1} \frac{1}{2}=\frac{\pi}{3} \\
\Delta v_{\text {cavily }} & =\left(q+(m+n+1) \frac{2}{3}\right) \frac{C}{2 L} \\
& =\left(q+(m+n+1) \frac{1}{3}\right) 10^{8} \mathrm{~Hz} .
\end{aligned}
$$

giving axial mode spacing of $10^{8} \mathrm{~Hz}$.

Atso of interest are the spot sizes it the grating and output mirrors as well as the diffraction limited beam spread. The general equations for Gaussian beam propagution in a cavity of length $\mathbf{L}$ and mirror radii $R_{1}$ and $R_{2}$ are: 


$$
\begin{aligned}
& w_{1}^{2}=\frac{L \lambda}{\pi} \sqrt{g_{1}\left(1-B_{1} B_{2}\right)} \\
& w_{2}^{2}=\frac{L \lambda}{\pi} \sqrt{\frac{B_{2}}{B_{2}\left(t-B_{1} B_{2}\right)}} \\
& g_{1}=1-\frac{L}{R_{1}}=1-\frac{1.50}{3.0}=\frac{1}{2} \\
& g_{2}=1-\frac{L}{R_{2}}=1-\frac{1.50}{\infty}=1
\end{aligned}
$$

Substituting thes values for $g_{1}, g_{2}$ into Eqs. $(8),(9)$ ahove gives

$$
\begin{aligned}
& w_{1}=\left(\frac{2 L \lambda}{\pi}\right)^{1 / 2}=1.70 \mathrm{~mm} \\
& w_{2}=w_{0}=\left(\frac{L \lambda}{\pi}\right)^{1 / 2}=1.20 \mathrm{~mm}
\end{aligned}
$$

where $w_{1}=$ spot size at output mirror, $w_{2}=$ spot size al grating, where $w_{0}=$ minimum beam diameter; defining the diffraction angle $\theta_{d}=\frac{\lambda}{T w_{0}}$ gives $\theta_{i}=8.0 \times 10^{-4}$
rad.

Since the oscillator output window is approximately I. 0 in from the entrance to the amplifitr section, and the amplifying section is $60 \mathrm{~cm}$ leng, the average output spot diameter as it traversed the amplifier was taken as $\simeq 2.7 \mathrm{~mm}$. At various times during the course of this study, reflecting and refracting telescopes were used to enlurge the beam diameter to fill the entire atmptificr aperture. The experimental rusults with and without beam expansion devices revealed no qualitative lifferences. The extra optics were difficult to align sid were of such suspect quality that their use was discontinued. In cascs where large nyertures were required (e.g. thc high power oscillator mode for saturation of amplifier to extract total energy) it was found that high order oscillator moles did the job adequately.

\section{Cavity Losses}

Using the tables given by Fox and $\mathrm{Li}^{14}$ one can testimate the cavity diffraction losses due to:

The Unapercurud (avity The mirrors are $5.08 \mathrm{~cm}$ diameter; cavity lingth 3.0 meters; wavelength $=3.4$ $\times 10^{-4} \mathrm{~cm}$.
The Frusnel number $(N)$ of the cavity is $\frac{a^{2}}{\lambda L} \simeq 70$ where $\mathrm{a}=\mathrm{d} / 2 ; \mathrm{d}=$ mirro; diameter : $\lambda=$ wavelength : $L=$ cavity length. The losses for this high Frosind number wity cun be neglected (loss <.01\%).

Thu Aptrt ured Cavity Aperturing is requirsd to constrain the oxcillutor to the TEM 00 mode. Experimentally the aperture diameter nequined for TEM 00 performance was masured to be $4.5 \mathrm{~mm}$.

Thus the fresnel number for this ense is:

$$
N=\frac{(.225)^{2}}{3 \times 10^{-4} 3 \times 10^{2}}=0.562
$$

$N=0.562$ implics a toss of about 3\%jpass.

\section{Cavity Polarization}

The gruting was placed in the holder with the rulings vertical; this produced a preferred horizontal polarization. The oscillator and amplifier Brewster angle windows were aligned relative to the horizontal polarization so as to minimize reflection losses throughout.

\section{Brewster Window Losses}

These lasses for sapphire at $3 \mu$ are cstimated to be ubout $1 \% /$ window; 2 windows imply $2 \% / p a s s$.

\section{Grating Losses}

The grating is blazed at 2.81 with a manufacturer's quoted efficiency in excess of $90 \%$. The transitions studied were at approximately $\lambda=2.76 \mu$. It is reasonable to estimate the grating losses at $<10 \%$.

The total tavity losses (excluding output coupling) are therefore estimated to be $\simeq 15 \% /$ pass.

The silicon output mirror was coated to allow $50 x$ reflection at $\mathbf{3} \boldsymbol{\mu}$.

\section{Oscillator Linewidths}

The oscillator was run in two separte configumations: lo"' pressure, low energy input (0.5 J/pulse); high pressure, high energy input ( $30 \mathrm{~J} / \mathrm{pulse}$ ). Low pressure mixtures: 20 Torr total with 16 Torr $\mathrm{SF}_{6} ; 4$ Torr $\mathrm{H}_{2}$. High pressure mixtures: 120 Torr total with 96 Torr $\mathrm{SF}_{6}$; 24 Torr $\mathrm{H}_{2}$. 
The Doppler width for the oscillator is tesily talculated from the expression

$$
\Delta w_{\mathrm{D}}=\left(\frac{8 k \operatorname{Tn} 2 v_{0}^{2}}{M_{0} c^{2}}\right)^{1 / 2}
$$

where $\mathrm{M}_{0} \mathrm{c}^{2}$ is the molecular wejght of HF in MeV = $18620 \mathrm{MeV}$,

$\mathbf{T}=$ translational temperature,

kT $\left(T \simeq 300^{\circ} \mathrm{K}\right)=0.025 \mathrm{eV}=2.5 \times 10^{-8} \mathrm{MeV}$, $v_{0}\left(\lambda=2.7(004 \mu)=1.087 \times 10^{14} \mathrm{~Hz}\right.$.

Substituting, onc obtains

$$
\Delta v_{D}=0.297 \times 10^{9} \mathrm{~Hz}
$$

which. when compared to the axial mode spacing from Eq. (6) above shows that approximately 3 axial modes exist within the Doppler linewidth. The need for axial mole control is clearly demonstrated.

The homogeneous tinewidths for oscillator and amplifier are calculated from the equations which follow and the use of Table 1 below.

The collisional linewidth is given by

$$
\frac{1}{\tau_{i}} \equiv n_{i} \sigma_{i} \overline{v_{i}}
$$

where $n_{i}=$ density of $i$ th species with which the HF collides, $a_{1}=i$ s corrected collision cross section for the hard sphere collision approximation between HF and species $(i), \bar{y}_{i}=$ relative velocity of encounter.

The ideal gas law, $n=\frac{P}{k T}$, gives $n=\frac{P_{\text {Tor }}}{760} \frac{10^{6}}{k T} \# / \mathrm{cn}^{3}$

$$
\sigma_{i}=\frac{\pi}{4}\left|d_{H F}+d_{j}\right|^{2} \cdot\left[C F \mid \mathrm{cm}^{2}\right.
$$

where $[C F]=$ correction fuctor $^{15}$ for deviation from gas kinetic collision diameters

$$
\begin{aligned}
d_{i} & =\text { gas kinetic diameter }(\mathrm{cm}) \\
\bar{v}^{2} & \times\left(\overline{v_{1}+v_{2}}\right)=\overline{v_{1} \cdot v_{2}+v_{2} \cdot v_{2}+2 v_{1} \cdot v_{2}} \\
& \simeq \bar{v}_{1}^{2}+\bar{v}_{2}^{2}
\end{aligned}
$$

where $\bar{v}_{i}=$ mean speed $\equiv\left(\frac{8}{\pi} \frac{k T}{M_{j}}\right)^{I / 2} \mathrm{~cm} / \mathrm{sec}$

$$
v=\left(\frac{8}{\pi} k T\right)^{1 / 2}\left[\frac{M_{1}+M_{2}}{M_{1} \cdot M_{2}}\right]^{1 / 2}
$$

$M_{1}=$ molecular weight of molecule $i$.

Combining Eqs. (15), (16), and (17) gives

$$
\begin{aligned}
\frac{1}{\tau_{i}} & \left.=11.03-\frac{\left(P_{\text {Ton }}\right)_{i}}{\sqrt{T}} \mid d_{H F}+d_{i}\right]^{2}\left[\frac{M_{H F}+M_{i}}{M_{H F} \cdot M_{i}}\right]^{1 / 2} \\
& \times[C F] M H z
\end{aligned}
$$

where $\mathrm{T}$ is given in ${ }^{\circ} \mathrm{K}$

$d_{i}$ is in $A$

$M_{i}$ is in amu $\quad\left(P_{\text {Tor }}\right)_{i}=$ pressure of ith constituent

The parameter values for sibstitution into Eq. (18) above for various collision processes are given in Table 1.

Recalling that

$$
\frac{1}{r}=\sum \frac{1}{1}
$$

and substituting from Table $\mid$ into Eq. (19) for: $S F_{6} / H_{2}=4 / 1$ at 20 Torr, gives

$$
\begin{aligned}
\frac{1}{T_{\mathrm{H}_{2}-\mathrm{HF}}} & =11.74 \mathrm{MHz} / \mathrm{Torr}\left(\mathrm{H}_{2}\right) \\
\frac{1}{T_{\mathrm{HF}_{-S F}}} & =13.16 \mathrm{MHz} / \mathrm{Torr}\left(\mathrm{SF}_{6}\right) \\
\frac{1}{\tau} & =12.9 \mathrm{MHz} / \text { Torr at } 4 / 1 \mathrm{SF}_{6} / \mathrm{H}_{2}
\end{aligned}
$$

Similarly for the amplifier $1 / \tau$ becomes

$$
\frac{1}{r}=10.3 \mathrm{MHz} / \text { Torr at } 4 / 1 \mathrm{NF}_{3} / \mathrm{H}_{2}
$$

Thus the homogeneous linewidth for the oscillator is about $90 \%$ of the Doppler width at this pressure.

The HF-HF collision contribution has been neglected because of the very low concentrations of HF formed in the times of interest. This assumption is justified by the calculation which follows. 
Tahle 1. Purameter values for calculation of pertinent collisional linewidths. $\mathrm{F}-\mathrm{N}-\mathrm{F}$ angle $=102.9^{\circ}, \mathrm{N}-\mathrm{F}$ lenght $=1.37 \mathrm{~A} . \mathrm{F}-\mathrm{F}$ lengt $\mathrm{l}=2.14 \mathrm{~A}$.

(F molecular radius taken as radial distanct at which $2 \mathrm{p}$ shell charge distribution peaks $=0.38 \AA .16$ )

\begin{tabular}{|c|c|c|c|c|c|}
\hline Collision type & $\mathrm{d}_{\mathrm{A}}$ & d(collision partner) & $\begin{array}{c}\text { M(HF) } \\
\text { amu }\end{array}$ & $\begin{array}{c}M \text { (partner) } \\
\text { amu }\end{array}$ & Correction factor \\
\hline$H F-S F_{6}$ & 4.35 & $4.96^{\mathrm{a}}$ & 20 & 146 & 1.0 \\
\hline $\mathrm{HF}-\mathrm{H}_{2}$ & 4.35 & 2.70 & 20 & 2 & 0.5 \\
\hline$H F \cdot N F_{3}$ & 4.35 & $3.50^{b}$ & 20 & 71 & 1.0 \\
\hline$H F \cdot H F$ & 4.35 & 4.35 & 20 & 20 & 2.5 \\
\hline
\end{tabular}

${ }^{a}$ Cakculated from viscosity data using $\sigma_{0}=\pi d^{2}=\frac{.377}{\eta}(\mathrm{mkT})^{1 / 2}$ where $\eta$ is viscosity in poise. 15

${ }^{b}$ Estimated from known bond angles and lengths for $\mathrm{NF}_{3}$.

Let us assume that in a gain length of $60 \mathrm{~cm}$, a small signal enhancement of $10^{40}$ is observed (this is consistent with computer results to be presented in a later section).

Thus $\mathrm{e}^{\mathrm{B}_{0} 60}=10^{40}=\mathrm{e}^{92}$ where $\mathrm{B}_{0}$ is small signal gain

$$
\mathrm{g}_{0}=\frac{92}{60}=(1: 66)(92) 10^{-2}=1.53 \mathrm{~cm}^{-1}
$$

but $B_{0}=\left.\frac{8 \pi^{2}}{h c}\right|_{\mu} P^{2} \frac{\nu}{\Delta \nu} \Delta n$.

Using $\mu=0.1$ Debye $=10^{-19}$ esu-cm

$$
\begin{aligned}
\Delta \nu_{D} & =\Delta v=1 \mathrm{GHz} \\
\nu & =1.1 \times 10^{5} \mathrm{GHz} \\
h & =1.05 \times 10^{-27} \mathrm{erg}-\mathrm{sec} \\
\mathrm{c} & =3 \times 10^{10} \mathrm{~cm} / \mathrm{sec} \\
\Delta \mathbf{n} & =\mathrm{N}_{2}-\mathrm{N}_{1} \frac{\mathrm{g}_{2}}{\mathrm{~g}_{1}}=\text { inversion density }
\end{aligned}
$$

which when substituted gives an upper bound on $\Delta \mathrm{n}$ as:

$$
\Delta \mathrm{n} \simeq 1 \times 10^{14} / \mathrm{cm}^{3} .
$$

Thus at 100 Tor total reactant pressure the HF concentration (not all of which is excited) is $\simeq 50 \mathrm{ppm}$. This justifies the assumption of negligible contriburtion to the homogeneous width by HF-HF collisions.

The natural linewidth (spontaneous width) is given, for completeness, by:

$$
\frac{\mathrm{g}^{\prime}}{\tau_{\text {pont }}}=\frac{4 \mathrm{e}^{2} \omega^{3} \mid \mathrm{X}_{\left.\mathrm{y}^{\prime} \mathrm{v}^{\prime}\right|^{2}}}{h c^{3}}
$$

where $\omega \simeq 6.28 \times 10^{14}(\lambda=3 \mu)$ and

$$
\left|X_{v^{\prime}}\right|^{2}=v^{\prime}\left|X_{10}\right|^{2} S_{j} \cdot F_{v j}^{\prime^{\prime} J^{\prime}} \text { (Ref. 17) }
$$

$$
\begin{aligned}
X_{10} & =0.105 \text { Debye } \\
g^{\prime} & =\text { degeneracy (multiplicity of upper state) } \\
S_{J} & =J \text { for } P \text { transitions } \\
\text { and } &
\end{aligned}
$$

$$
\frac{1}{\tau_{\text {spont }}} \simeq 128 \mathrm{Jv}^{\mathrm{t}}\left(\mathrm{sec}^{-1}\right)
$$

which for $P$ (4) $2 \rightarrow 1$

$=1.02 \mathrm{kHz}$

\section{Mechanical Stability}

As discussed above, the oscillator for the experiment was mounted on a $1.5 \mathrm{~m}$ Ealing rail (aluminum). If one assumes the stability criterion that the cavity not change length by more than one wavelength due to thermal expansion of the rail (conservative) one calculates

$$
\Delta \mathrm{T}\left({ }^{\circ} \mathrm{F}\right) \leq \frac{\Delta \mathrm{L}}{\mathrm{L}} \frac{1}{\mathrm{a}} \cong 0.15^{\circ} \mathrm{F}
$$

$$
\begin{aligned}
& \text { where } \\
& \begin{aligned}
\Delta \mathrm{L} & =3 \mu \mathrm{m} \\
\mathrm{L} & =1.5 \mathrm{~m} \\
\mathrm{a} & =\text { coeflicient of thermal expansion } \\
& \simeq 13 \times 10^{-6} /^{\circ} \mathrm{F}
\end{aligned}
\end{aligned}
$$


A temperalure stability of $\pm 0.1^{\circ} \mathrm{F}$ was quite diffcult to achieve and its control was therefore not attempted. One was forced to take stability where it came and retune the cavity after each liring.

\section{Dose-Depth Calculations}

Assumptions:

- Range of the electrons is large compared to areal density through which electrons are made to pass.

- Electrons travel unperturbed by pulsed guide field until they enter the containment region as delined by the entrance plane of the reaction pipe.

- Eiectrons proceed in the gaseous medium in such a way as to suffer predominantly small angle scatters. This is equivalent to saying that they remain relativistic throughout their traversal and that ionizing collisions with valence electrons represent the dominant transfer mode to the chemical medium. Tlus also implies that the integrated path length is of the order of the geometric length of the tube and that deviations from simple $d E / d x$ absorption can be explained by other than straight line trajectories.

Under these assumptions; one can give an expression for the range of these electrons $3 \mathrm{~s}^{20}$

$$
R\left(\mathrm{gm} / \mathrm{crn}^{2}\right) \cong 0.542 \mathrm{E}-0.133 \mathrm{E}>0.18 \mathrm{MeV}
$$

for $E=1.40 \mathrm{MeV}$

$$
\mathrm{R} \simeq 0.626 \mathrm{gm} / \mathrm{cm}^{2}
$$

Since reactant pressures never exceeded 200 Torr in the case of $\mathrm{NF}_{3} / \mathrm{H}_{2}$, it is a conservative approximation to calculate the areal density of 200 Torr of pure $\mathrm{NF}_{3}$

$$
\begin{aligned}
& \begin{aligned}
(\text { At wt }) \mathrm{NF}_{3}=71 \mathrm{amu} & \\
\text { Molecules } / \mathrm{cm}^{3} @ 200 \text { Torr } & =\frac{200}{760} 2.4 \times 10^{19} \\
& =6.3 \times 10^{18}
\end{aligned} \\
& \rho_{\mathrm{NF}_{3} @ 200 \text { Torr }=0.74 \times 10^{-3} \mathrm{gm} / \mathrm{cm}^{3} .}
\end{aligned}
$$

Taking $75 \mathrm{~cm}$ as the total length through which the beam most traved is $\mathrm{NF}_{3}$

$$
\rho_{\mathrm{NF}_{3}}^{*}=5.55 \times 10^{-2} \mathrm{gm} / \mathrm{cm}^{2}
$$

where $\rho^{*}$ is areal density.

The berryllium mirror is $43.2 \times 10^{-3} \mathrm{~cm}$ thick and is inclined at $45^{\circ}$ with respect to the beam axis. The siructural ribbing of the mirror completely shadows $10 \%$ of the beam.

\section{Calculation of rms Scattering}

Various obstructions to free electron beam propagation necessarily exist between the beam source and the entrance to the amplifier section. These are itemized as

- The electron tube output window (1.5 mil titariums.

- The pressure seal separating explosive gases from the electron tube face (4 mil titanium)

- The reactants contained in the "dead region" prior to effec. ive electron containment by the magnetic guide field. A worst case condition for the purposes of calculation is 200 Torr of $\mathrm{NF}_{3}$. The "thickness" of the $\mathrm{NF}_{3}$ layer is $10 \mathrm{~cm}$.

- The beryllium turning mirror $\left(43.2 \times 10^{-3} \mathrm{~cm}\right.$ beryllium).

The equation for sms scattering angle for relativistic electrons is given by $\mathrm{Fermi}^{20}$ as:

$$
\sqrt{\theta^{2}}=\left\{\frac{8 \pi N D Z^{2} z^{2} e^{4}}{v^{2} p^{2}} \text { In }\left[\frac{a_{0} v p}{2 Z^{4 / 3} z e^{2}}\right]\right\}^{1 / 2}
$$

where $D=$ distance of traversal

$$
\begin{aligned}
N & =\text { number of atoms } / \mathrm{cm}^{3} \\
z & =\text { charge units of projectile ( } 1 \text { for electrons) } \\
Z & =\text { charge units of target } \\
e & =\text { electrunic charge } \\
v p & \simeq c p \simeq \text { kinetic energy of projectile } \\
a_{0} & =\text { Bolu radius }
\end{aligned}
$$

Calculations show ${ }^{20}$ that for materials of interest, the logarithmic factor is of order 10.0. Simple manipulation produces

$$
\theta_{\mathrm{mns}}=1.77 \frac{\mathrm{Z}}{\overline{\mathrm{E}}}\left(\frac{\rho \mathrm{D}}{\overline{\mathrm{A}}}\right)^{\mathrm{I} / 2} \mathrm{rad}
$$

where the units are:

$$
\begin{array}{ll}
\mathrm{E} \text { in } \mathrm{MeV} & \mathrm{Z}=\text { atomic number of target } \\
\rho \text { in } \mathrm{gin} / \mathrm{cm}^{3} & A=\text { atomic weight of target in a:cu } \\
\text { Cis } \mathrm{cm} &
\end{array}
$$


For $4 \mathrm{mil} \mathrm{Ti}=3.8 \times 10^{-3} \mathrm{~cm}$ one obtains

$$
\Delta \theta_{\mathrm{mms}}=0.907 \mathrm{rad}=51.8^{\circ} .
$$

For $43.2 \times 10^{-3} \mathrm{~cm}$ Be one obtains

$$
\Delta \theta_{\mathrm{rms}}=28.6^{\circ} .
$$

For $10 \mathrm{~cm}$ of $\mathrm{NF}_{3} @ 200$ Tor one obtains

$$
\Delta \theta_{\mathrm{ms}}=0.115 \mathrm{rad}=6.2^{\circ}-(\text { negligible }) .
$$

Thus for a 4 mil titanium diaphragm placed 3 in. from the onset of the guide field, taken as 1 coil diameter in from the coil start, one can consider that the energy lost in arriving at the reaction tube is simply a beam divergence effect with the energy lost in scattering in 200 Torr $\mathrm{NF}_{3}$ and in the Be nimor being initially neglected. Figure 28 shows the geometry for this calculation.

\section{Magnetic Guide Field Design}

It is assumed that, in the event of a $90^{\circ}$ scatter by : $1 \mathrm{MeV}$ electron, a sufficiently strong axial B field would be present to constrain the scattered electron to a circular path whose diameter would be $\leq 1.0 \mathrm{~cm}$. In this calculation it is assumed that the scattered electron is free and that during an orbit it is not rescattered. This assumption is poor and results in a requirement for higher fields than those calculnted below. On the other hand, assuming a $v_{\perp}$ corresponding to $1 \mathrm{MeV}$ is extremely conservative and the field thus calculated will be, experimentally, entireby adequate. Force balsnce

$$
\frac{q(v)(B)}{c}=\frac{m v^{2}}{R}
$$

or

$$
B=\frac{c}{q} \frac{m v}{R}=\frac{c}{q} \frac{p}{R} .
$$

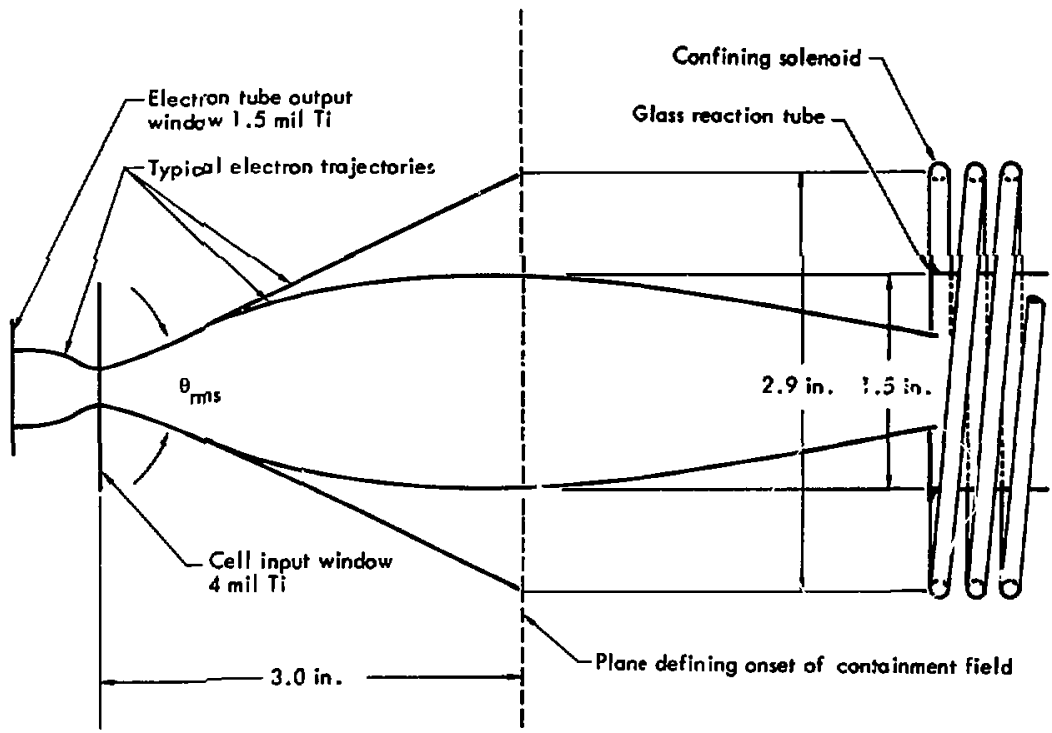

Fig. 28. Geometry for scattering loss calculation. 
But recalling

$$
w^{2}=p^{2} c^{2}+\left(m_{e} c^{2}\right)^{2}
$$

with $W=1.0 \mathrm{MeV}$

$$
m_{e} c^{2}=0.511 \mathrm{MeV}
$$

one obtains

$$
p c \sim 0.86 \mathrm{MeV}=1.37 \times 10^{-6} \mathrm{ergs} .
$$

Thus

$$
B=\left(\frac{1}{q R}\right) 1.37 \mu \mathrm{G} .
$$

Using

$$
\begin{aligned}
& q=4.8 \times 10^{-10} \mathrm{esu} \\
& R=0.5 \mathrm{~cm}
\end{aligned}
$$

the $B$ resulting is

$$
B \simeq 6 \mathrm{kG} \text {. }
$$

The circuit to give such a field is the simple R-L-C arrangenent shown in Fig. 29.

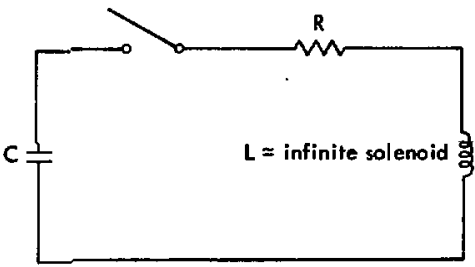

Fig. 29. Lumped circuit used to generate guide field.

where $L$ is an excellent approximation to an infinite solenoid (length to diameter ratio $(10 / 1)$ ) whose inductance is given by:

$\mathrm{L}=19.2 \mu \mathrm{H}, \mathrm{R}-\mathrm{L}-\mathrm{C}$ Bridge ELI Model \#2500A

$R=50 \mathrm{~m} \Omega, R-L-C$ Bridge ELJ Model \#2500A

$C^{\prime}=5.0 \mu \mathrm{F}$ (Note: There are 4 capacitors of $5.0 \mu \mathrm{F}$ each in parallel, each with an internal inductance of $80 \mathrm{nH}$. Thus $\mathrm{C}=4 \mathrm{C}^{\prime}=20 \mu \mathrm{F}$ ).

$$
H \text { (gauss) }=\frac{4 \pi n l}{10} \quad(\text { Ref. 19) }
$$

where $\mathrm{n}=\mathrm{turns} / \mathrm{cm}=0.688$.

\section{Using $6 \mathrm{kG}$ for $\mathrm{H}$ gives}

$$
1=7.3 \mathrm{kA} \text {. }
$$

The solution for the R-L-C circuit in Fig. 29 above is straightforward and satisfies the well known differential equation

$$
\ddot{Q}+\frac{R}{\mathbf{L}} \ddot{Q}+\frac{1}{2 C} \mathbf{Q}=0,
$$

subject to the initial conditions

$$
Q(0)=Q_{0}=C V_{0} \text { and } Q(0)=0
$$

The method of Laplace transforms gives

$$
Q(s)=\frac{Q_{0} s}{s^{2}+\nu s+\omega^{2}}+\frac{Q_{0} V_{0}}{s^{2}+\nu s+\omega^{2}}
$$

where

$$
\nu=R / L, \quad \omega=\frac{1}{L C} .
$$

The time domain representation for $i(t)=\frac{d Q(t)}{d t}$ is:

$$
i(t)=\frac{Q_{0}}{2 \omega^{\prime}}\left(\omega^{\prime 2}+\frac{\nu^{2}}{2}\right) \exp \left|-\frac{\nu t}{2}\right| \sin \omega^{\prime} t(36)
$$

where $\omega^{\prime} \equiv\left(4 \omega^{2}-\nu^{2}\right)^{1 / 2}$.

Taking the derivative of $i$ with respect to tine, setting it to zero, and solving for $t_{\max }$ gives $i_{\max }$ as

$$
\begin{aligned}
i_{\max } & =\frac{C v_{0}}{2 \omega^{\prime}}\left(\omega^{\prime 2}+\frac{\nu^{2}}{2}\right) \exp \left[-\frac{\nu}{2 \omega^{\prime}}, \tan ^{-1}\left(\frac{\omega^{\prime}}{\nu}\right)\right] \\
& x \sin \left[\frac{1}{2} \sin ^{-1}\left(\frac{\omega^{\prime}}{\nu}\right)\right] .
\end{aligned}
$$

Assuming $\nu<\omega$ implies $\frac{L \omega}{R} \gg 1$ for $|L|=|C|$, which is very nearly true in this case, results in the requirement:

$$
\frac{1}{\mathbf{R}} \gg \mathbf{1}
$$

But $\frac{1}{R} \simeq 20$, therefore in this approximation $\omega^{\prime} \rightarrow 2 \omega$

$$
\begin{aligned}
i_{\max } & \simeq C V_{0} \sin \left(\frac{\pi}{4}\right)=0.707 \frac{C V_{0}}{L M} \\
& =0.707 \frac{C}{L} V_{0} .
\end{aligned}
$$


For this system, where $15 \mathrm{kV}$ charging voltage was routinely used, Eqs. (37) and (34) give:

$$
\begin{aligned}
& i_{\max } \lesssim 10 \mathrm{kA} \\
& B_{\max } \lesssim 8.2 \mathrm{kG} .
\end{aligned}
$$

It is shown in Sec. II-C. that the diameter of the clectron beam exceeds by $50 \%$ that inplied by the $B_{\max }$ of result (39) above. This result is to be expected because of the effects of scattering and, to a lesser degree, electrostatic repulsion generated from the net nezative charge of the beam interior during plasma formation times. Experimentally it is observed that $r \tilde{a}\left(\frac{1}{B}\right)^{1 / 2}$.

Formation of Flourine Redicals

The details of the dynamic interaction of intense, magnetically guided, relativistic, election beams with high pressure (20-200 Torr) complex molecular systems like $\mathrm{NF}_{3}$ is not understood in minute detail. It is known, ${ }^{21}$ however, that during the formation and propagation of such a beam the secondary electrons produced by direct interaction of $\mathrm{NF}_{3}$ with $1.2 \mathrm{MeV}$ primaries generate substantial collisional jonization, are accelerated to produce avalanche effects due to nonuniform ionization density, and, in this case, are inhibited from normal diffusion by the existence of an incense $(\simeq 10 \mathrm{kG})$ axial magnetic freld. It was not the intent of this study to produce detailed information (e.g., electron density vs. tine) on the state of this plasma, but rather to produce an inituition scheme that could reasonably be expected to be uniform throughout the volume of the laser vessel.

In Secs. I and II it is shown, through the use of open shutter photography, calorimetry, and isodensitometry, that a uniform energy deposition $( \pm 20 \%$ along the tube axis) was achieved. For future comparisons with calorimetry, however, some calculations of the energy delivered are presented. The average energy per electron is $\sim 1.4 \mathrm{MeV}$ when it leaves the electron tube exit plane; passing through the burst diaphragm and the beryllium turning mirror degrade that average to $1.2 \mathrm{MeV}$.

If one assumes that the integrated electron path length in the amplifier is large compared to the electron range and that the total path length is approximately the geometruc length, one calculates the energy lost per electron in traversing the amplifier as:

$$
\frac{\rho}{R}\left(1.2 \times 10^{6}\right) \mathrm{MeV} / \mathrm{cm} \text { electron }
$$

where $\rho$ is the gas density $\left(\mathrm{gm} / \mathrm{cm}^{3}\right.$ ) and $R$ is the range of the electrons $\left(\mathrm{gm} / \mathrm{cm}^{2}\right)$. Recalling that the number of electrons generated is

$$
\frac{I_{w}}{4} t_{p} A=\frac{2.25}{4} \times 10^{15} \text { electrons }
$$

where $I_{w}=4.5 \mathrm{kh}$

$t_{p}=$ average electron pulse length $=80$ nsec.

$A=$ No. of electrons/Coulomb $=6.25 \times 10^{18}$.

The factor of $1 / 4$ in Eq. (41) above is to account for geometric factors and attenuation before the beam arrives at the entrance region. One obtains, for the total dne oy loss

$$
E_{\text {lost } / \mathrm{cm}^{3}}=2.14 \times 10^{20} \frac{\rho}{R} \mathrm{eV} / \mathrm{cm}^{3}
$$

Using the range ( $R$ ) appropriate to $1.2 \mathrm{MeV}$ electrons, and recalling that about $30 \mathrm{eV}$ is spent for each ionelectron pair, the number 0 . econdary electrons of $\approx 15 \mathrm{eV}$ average energy is gives. S

$$
\text { Ion pairs } / \mathrm{cm}^{3}=1.33 \times 10^{19} \mathrm{\rho} .
$$

Thus for 100 Torr $\mathrm{NF}_{3}$ (neglect secondaries generated by $\mathrm{H}_{2}$ ) in a samole amplifier charge, the secondary electron density becomes:

$$
\begin{aligned}
N_{e} & =5 \times 10^{15} \text { electrons } / \mathrm{err}^{3}\left(p_{100 \text { Tor }}\right. \\
& \left.=0.37 \mathrm{mg} / \mathrm{cm}^{3}\right) .
\end{aligned}
$$

With fractional ionization

$$
\frac{N_{e}}{N_{A}}=\frac{5 \times 10^{15}}{\left(2.7 \times 10^{19}\right)\left(\frac{100}{760}\right)}=1.4 \times 10^{-3}=0.14 \%
$$

where $\mathrm{N}_{A}=$ No. density of atoms at 100 Torr.

\section{Calculation Pertinent to Magnetic Field Diffusion}

In Sec. I-C it was mentioned that inetallic substances were rejected for the chemical reaction vessel. The calculation given below justifies that rejection. Consider the Maxwell equations

$$
\vec{\nabla} \times \vec{E}+\frac{1}{c} \frac{\partial \vec{B}}{\partial t}=0
$$




$$
\vec{\nabla} \times \vec{B}=\frac{4 \pi}{c} \vec{J}
$$

I where $\vec{\nabla} \cdot \vec{J}=0$ has been assumed or equivalently, neglect displacement current ] and Ohm's Law:

$$
\vec{J}=u\left(\overrightarrow{\mathbf{E}}+\frac{\overrightarrow{\mathbf{V}} \times \overrightarrow{\mathbf{B}}}{\mathrm{c}}\right) .
$$

Combining Lqs. (45-47) so as to eliminate E gives

$$
\frac{\partial \vec{B}}{\partial t}=\vec{\nabla} \times(\vec{v} \times \vec{B})+\frac{c^{2}}{4 \pi \sigma} \nabla^{2} \vec{B}
$$

Considering the raction tube at rest, then

$$
\frac{a \vec{B}}{\partial t}=\frac{c^{2}}{4 \pi \sigma} \vec{\nabla}^{2} \vec{B}
$$

Relation (49) is the diffusion equation, where

$$
\frac{4 \pi a L^{2}}{c^{2}}=r=\text { characteristic diffusion time. }
$$

$L=$ characteristic length over which 1s:c field must diffuse. Take $0.3 \mathrm{~cm}$ for wall of reaction vessel. $\sigma=$ conductivity (in seconds) for iron ${ }^{19} \simeq 9.27 \times 10^{16}$ sec

$c=$ velocity of light $=3 \times 10^{10} \mathrm{sm} / \mathrm{sec}$

$$
=\frac{4 \pi\left(9.27 \times 10^{16}\right)(0.3)^{2}}{9 \times 10^{20}}=116 \mu \mathrm{sec}
$$

Recall however that the magne tic field is near its maximum value for only about $20 \mu \mathrm{sec}$. Thus field diffusion cannot take place fast enough for electron beam containment.

\section{Results of Chemical Studies}

\section{A. LÍNEAR GAIN CALCULATIONS AND P, $R$ BRANCH GAIN RATIOS}

Measurements in the linear amplification regime $\left(\mathrm{J} / \mathrm{I}_{0}=\mathrm{e}^{\mathrm{z}_{0}} \mathrm{~g}_{0}\right.$ 三 small signal gain cocfficient $)$ were useful in extracting overatf rate data for formation of gain in the $N F_{3} / H_{2}$ bystem and, in comparing corresponding $P$ and $R$ branch populations, to arrive at the relative rate of chemical pumping into the $\nu=1$ and $\nu=2$ vibrational levels. Careful measurements of gain properties normally require oxcillators of high stability which, preferably, operate in a continuour wave mode. Stable oscillators were not available for this study so that an approximation to the idteal was necessary. The spiral pin laser described earliter satisfied these constraints when operater in low power, long pulse mode. The long pulse mode (several microseconds of slowly decreasing amplitude) perınitted stabilization of the cervity mode structure which enabled extraction of the amplifier gain history. Low power operation restricted operation to the $\Delta y=2 \rightarrow 1$ vibrational transition. In this mode $\Delta v=3 \rightarrow 2$ was rarely observed. It is noted that $\nu=1 \rightarrow 0$ performance yas possible but the osejllator output was always tharacterized by a series of short pulses as a result of relaxation of the directly pumped $\nu=1$ vibrational level and relaxation of the $\nu=I$ population formed by spontancous emission from the $\nu=2$ vibrationa! state.

In sumnary, the peculiarities of the oscillator/ amplifier and in tercavity coupling restricted the systematic s:valuation of the gain history to low lying $\nu=2 \rightarrow 1$ transitions and to stoichiometries not too different from $N F_{3} / H_{2}=4 / 1$. The higher-lying rotational triusitions suffered from too high a gain, making suppression of amplified spontaneous emission impossible.

Figure 30 summarizes the small signal behavior of $P(4) 2 \rightarrow 1$ transition in the range 4-20 Tor, $\mathrm{NF}_{\mathbf{3}} / \mathrm{H}_{\eta}=4 / 1$. The plot is peak gain vs $1 / P$. This curve is described by the relation:

$$
p r=8.3 \pm 1.0 \text { nsec-atm }
$$

where $p=$ pressure of reactants $\left(N_{3} / H_{2}=4 / 1\right)$ in itmosphers $\tau=$ time to maximum gain in nanosictonds.

Data for small signal gain ceases at pressures in excers of IS Torr for the reason that amplified spontuneous emission could no longer be suppressed. Cain data was verified as linear by testing $l / l_{a}(I=$ output intensity, $1_{0}=$ input intersity) for values of $I_{n}$ larger than those used for the data taking; in all cases below 15 Torr $1 / \mathrm{J}_{\mathrm{c}}$ was independent of $\mathrm{I}_{\mathrm{o}}$. 


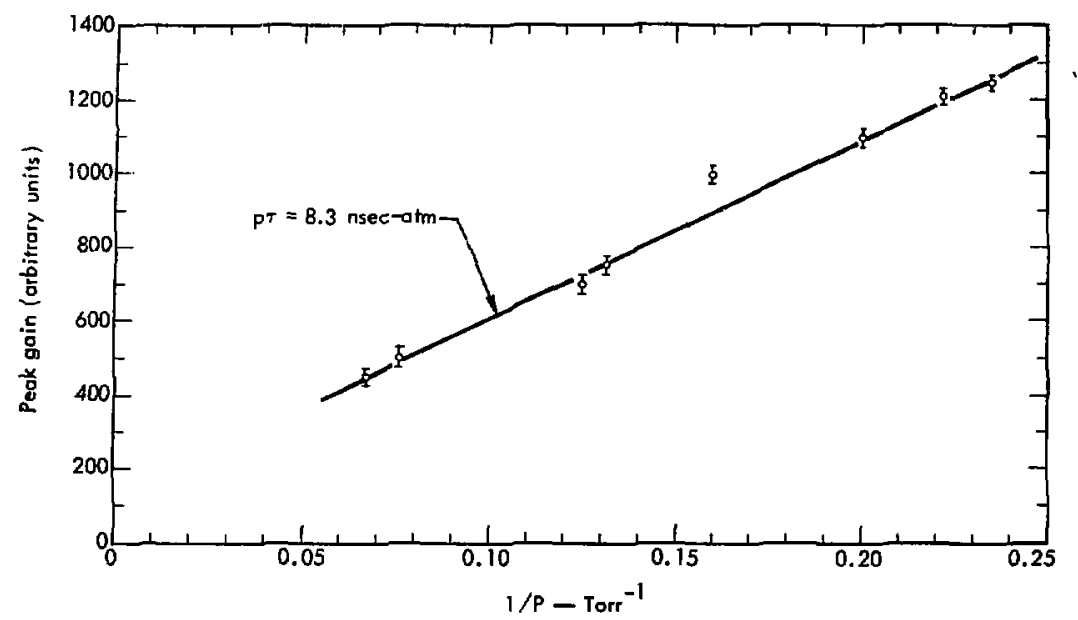

Fig. 30. Small signal gain rise time vs $I / P$.

\section{Chemical Rate Ratios}

With some care, it was possible to cause the oscillator to operate on at least one R-branch transition $\mathbf{R}(2) 2 \rightarrow 1$ under grating control. It was observed that this line when repeatable was quite weak and required large concentrations of $\mathrm{H}_{2}$ relative to $\mathrm{SF}_{6}$ (approximately $\mathrm{H}_{2} / \mathrm{SF}_{6}=1 / 2$ ). As the data in Fig. 31 demonstrate, it was possible to study the gain history of the R-branch transition only for times shorter than the onset of P-branch superradiance (amplified spon(aneous emission) by the amplifier. If superradiance of the $\mathbf{P}$ transition corresponding to this $\mathbf{R}$-line (P(4) 2-1) occurred, it simply served to diminish the population of the upper lasing level $\nu=2, j=3$, (see Fig. 32). For a given ratio of upper state density/ lower state density, P-branch gain always exceeds $R$-branch gain and no R-branch gain appears until $\mathrm{N}_{2}>22.23$

This explanation is completely consistent with the experimental observation that the disappearance of R-branch emission was exactly coincident with the appearance of spontaneous emissic: inot $\mathbf{R}$ branch).

Measurements of corresponding P-, R-branch small signal gain at the same time after reaction initiation permitted the direct calculation $\mathrm{N}_{2} / \mathrm{N}_{1}$, where $\mathrm{N}_{2}$ is the population density of the $\nu=2$ vibrational level and similarly $\mathbf{N}_{1}$ is the density of the $\nu=1$ level. The data presented graphically in Fig. 31 gives the normalized P-, R-branch gain as a function of pressure with stoichiometry as a parameter.

\section{Calculation of Vibrational Occupation Numbers}

The following calculation exhibits the theuretical relation between $N_{2}$ and $N_{1}$ as a function of the $P$ and $\mathbf{R}$ branch gain. This calculation is performed for a pressure of 15 Torr with $\mathrm{NF}_{3} / \mathrm{H}_{2}=4 / 1$ and at a time of 120 nsec after the onset initiations. Assumptions pertinent to this calculation are

- Rotational equilibrium.

- Temperature of $300^{\circ} \mathrm{K}$.

These assumptions are reasonable when the diluent concentration is high. (Diluent here is considered the undissociated $\mathrm{NF}_{3}$ at early times.)

The rotational term values for the vibrating rotator given by 18

$$
F_{\nu}(J)=B_{v} J(J+1)-D_{v} J^{2}(J+1)^{2}
$$
are used, but the approximation $D_{\nu}=D e=\frac{4\left(B_{e}{ }^{3}\right)}{e^{2}}$
is employed where 


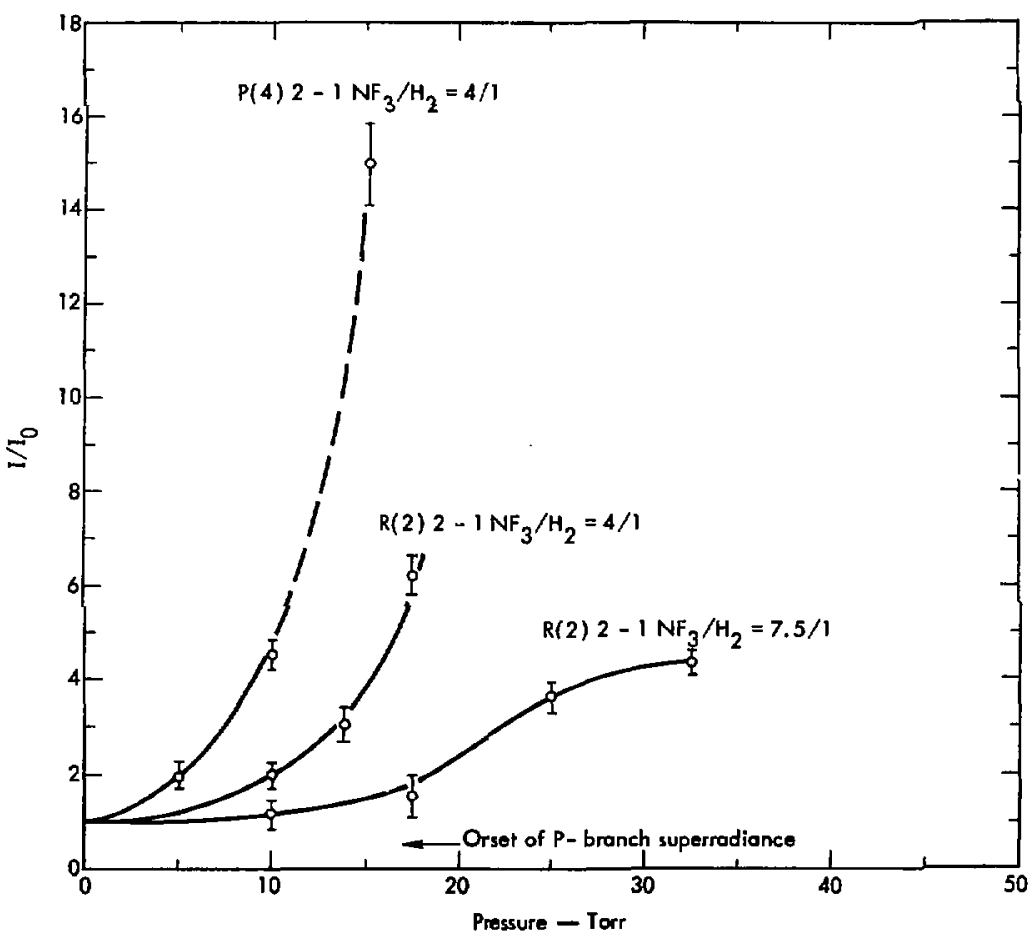

Fig. 31. Gain vs pressure for corresponding $P$ and $R$ branch tranations.

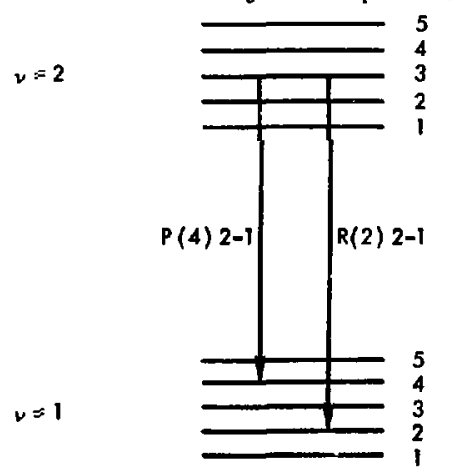

$$
B_{v}=B_{e}-a_{e}\left(\nu+\frac{1}{2}\right)
$$$$
B_{e}=20.939 \mathrm{~cm}^{-1}, a_{e} \simeq 0.23 \mathrm{~cm}^{-1}, \omega_{e} \approx 4138.52
$$
$\mathrm{cm}^{-1}$. In can be shows ${ }^{23}$ that the optices goin coesrcient for a vibration-totation transition $\nu=2, \mathrm{~J} \rightarrow 1=1$. $\mathbf{J + 1}$ in the Doppler broadened approximation is given by:

$$
\begin{aligned}
a_{2, I_{j+l}} & =\frac{3 \pi^{3} c^{4} K_{12}}{3 k T}\left(\frac{2 \pi k T}{M}\right)^{1 / 2} \\
& x(J+I)\left\{N_{2} B_{2} \exp \mid-F_{2}(J) \frac{h c}{k T}\right] \\
& \left.-N_{1} B_{1} \exp \left[-F_{1}(J+1) \frac{h c}{k T}\right]\right\}
\end{aligned}
$$

Fig. 32. A pair of corresponding $P$ and $R$ branch transitiona. $-35-$ 
and

$$
\begin{aligned}
a_{2 J} l_{J-1} & =\frac{8 \pi^{3} c^{4} K_{12}}{3 k T}\left(\frac{2 \pi k T}{M}\right)^{1 / 2} \\
& (J)\left\{N_{2} B_{2} \exp \left[-F_{2}(J) \frac{h c}{k T}\right]\right. \\
& \left.-N_{1} B_{1} \exp \left\{-F_{1}(J-1) \frac{h c}{k T}\right]\right\}
\end{aligned}
$$

where $a$ is the gain coefficient: $K_{12}$ is the vibrational part of the matrix element, squared. Forming the ratio of Eqs. (\$5) and (56) above gives,

$$
\begin{gathered}
\frac{a_{p}}{a_{1}}=\frac{(I+1)}{(J)} \\
\times\left\{\frac{N_{2} B_{2} \exp \left[-F_{2}(J) \frac{h c}{k T}\right]-N_{1} B_{1} \exp \left[-F_{1}(J+1) \frac{h c}{k T}\right]}{N_{2} B_{2} \exp \left[-F_{2}(J) \frac{h c}{k T}\right]-N_{1} B_{1} \exp \left[-F_{1}(J-1) \frac{h c}{k T}\right]}\right\}
\end{gathered}
$$

Notice that forming the ratio $\frac{a_{p}}{a_{r}}$ removes assumptions about the sources of linewidth.

$$
\text { Let } \frac{a_{p}}{a_{r}}=a^{\prime} \text {; and using the following definitions }
$$$$
\mathrm{e}^{-F_{2}(J) h c / k T}=\xi_{1} \mathrm{e}^{-F_{1}(J+1) h c / k T}=\delta . \mathrm{e}^{-F_{2}(I-1) h c / k T}=\eta,
$$

also assume $\mathrm{N}_{2}=\mathrm{pN}$.

Solving for $p$ produces

$$
P=\frac{1}{\left(B_{2} / B_{1}\right) E}\left\{\frac{\frac{a^{\prime} J}{J+1} \eta-\delta}{\frac{a^{\prime} J}{J+1}-1}\right\}
$$

$$
\begin{aligned}
& a^{\prime}(\text { experimental })=3.43 \\
& \frac{\mathrm{J}}{\mathrm{j}+\mathrm{I}}=0.75 \\
& B_{2} / B_{1}=0.988 \\
& \xi=0.31 \\
& \delta=0.1309 \\
& \eta=0.557 \\
& p=2.67=N_{2} / N_{1} \text { (15 Torr, } \\
& \mathrm{NF}_{3} / \mathrm{H}_{2}=4 / 1, \tau=170 \pm 10 \\
& \text { nsec after rise of electron } \\
& \text { current). }
\end{aligned}
$$

Figures 33 and 34 show typical traces from which $\mathbf{R}$ and $P$ branch gains were calculated.

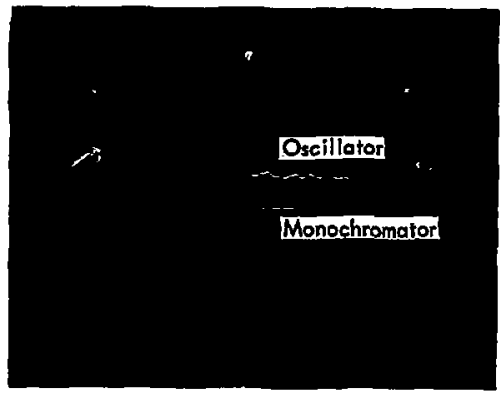

Fig. 33. Typical "R" branch date.

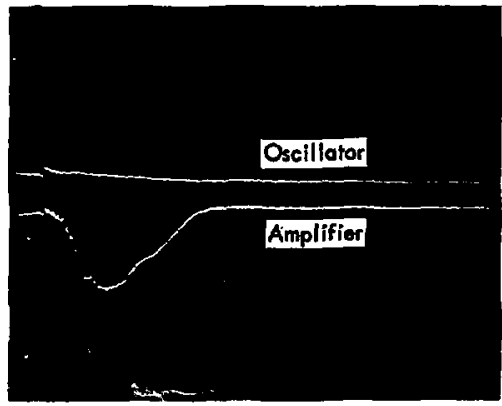

Fig. 34. Typical "P" branch data.

\section{B. NONLINEAR AMPLIFITATION}

Il was desired to compare the results of the experimentation in the nonlinear regime with the current llicory developed by Hopf and Rhodes. ${ }^{24}$ The current state of this theory places certain restrictions on the oscillator:

- The oscillator emission is to be composed of a single cavity mode.

- The etimulating wave entering the amplifier is to be nearly planc.

- The oscillator is to be tuned to a vibrationrotation transition exhibiting gain irs the amplfits medium. 
The fundamental reason for these restrictions is that the equations used to describe the process are necessarily nonlinear. One does not, therefore, expect the principle of superposition to apply. If, experimentally, one scts up a condition such that the oscillator light is composed of a linear combination of signals of differing phase and amplitude, it follows that coherent (phase sensitive) processes will tend to be averaged out. It :s noted that when the oscillator was tuned to allow simulianeous, high $\mathbf{Q}$ oscillations for a number of modes and transitions the effects to be described below were completely absent.

As described in Sec. I-B the oscillator was built and operated in a mode-beat-free, single transition manner. Stability could be achicved in the relatively hostile experimental environment for several minutes at a time. The quality of the plane wave approximation could not be directly measured because the operating characteristics of the oscillator required very low output energy pulses to achieve the required temporal purity. Furtler. the geometry of the amplifier test volume ant: the severe mechanical demands placed on the beryllium turning mirror made it cxperimentally impossible to examine in detail the spatial properties of the stimulating heam.

As was mentioned above in Sec. I-B it was necessary to prepare the same oscillator in a high energy output pulse con (iguration ( $\simeq 30 \mathrm{~mJ} /$ pulse) to attempt, in a different phase of this experiment entirely, to extract the maximum possible energy from the exploding $\mathrm{NF}_{3}-\mathrm{H}_{2}$ gas. With the oscillator thus prepared, it was possible to qualitatively examine the spatial behavior of the oscillator bcam as it entered the amplifier and as it emerged. These data suggest that the pulse at the input to the oscillator had a $3 \mathrm{~mm}$ diam anci roughly gaussian shape. The output pulse emerged with about a $15 \mathrm{~mm}$ effective diam; substantially larger than the diffraction limited divergence. The high beam divergence is attributed to the deviation from flatness of the beryllium turning mirror resulting from hundreds of exposures to the shock wave generated by the detonating explosives. Thus the "effective" average beam diameter is taken to be about $8 \mathrm{~mm}$. Figures 35-38 exhibit the oscillator input at the left and the amplifier output at the right. The second "hump" in the oscillator pulse is a result of direct $x$-ray induced conductivity in the $\mathrm{Cu}$ :Ge detector crystal and was unavoidable even with some substantial lead shielding of the detector, (Fig. 39). The oscillator in Figs. 35 and 36 was being operated at quite a low output energy $<10^{-4} \mathrm{~J} /$ pulse and in Figs. 37 and 38 with $10^{-5}$ to $10^{-6} \mathrm{~J} /$ pulse, requiring maximum vertical sensitivity on the oscjlloscopes for signal detection.

The signature of the amplified signal is a short, $\lesssim 10$ nsec (FWHM) high intensity pulse fo llowed by a weaker second peak and long 50-100 nsec tail. Typically the fraction of the energy contained in the leading edge spike is from $5 \%$ - $30 \%$ of the total output energy (depending on the detailed operating conditions). When the noise due to $\mathrm{x}$-ray effects is removed the remaining oscillator output signal is a decaying triangular pulse that changed slowly on the time scale of the amplifier output. The detection and display equipment were a jiquid-He-cooled Ar:Ge detector and a Hewlett-Packard 183A oscilloscope with overall bandwidth capable of displaying pulses of

$$
P=47 \text { Torr, } \mathrm{NF}_{3} / \mathrm{H}_{2} 4 / 1
$$
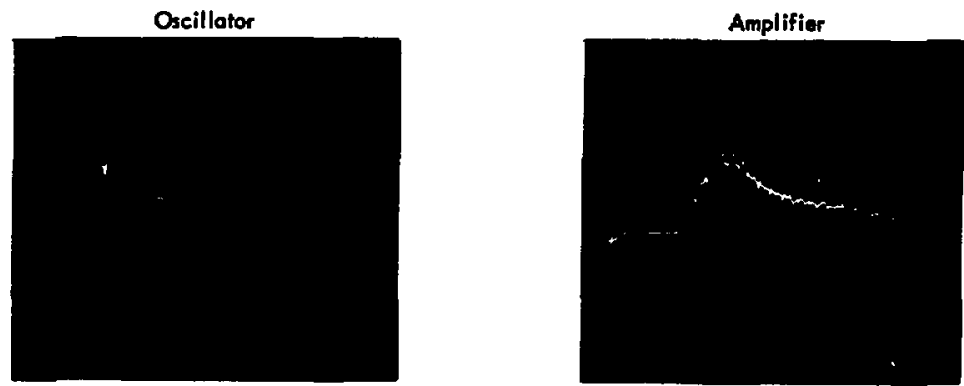

Time seole: 100 nec/div

Fis. 35. Oxcillator/amplificr inces showing nonllnear behavbor at 47 Torr $\mathrm{NF}_{3} / \mathrm{H}_{2}=4 / 1$. 


$$
P=95 \text { Torr, } \mathrm{NF}_{3} / \mathrm{H}_{2} 4 / 1
$$

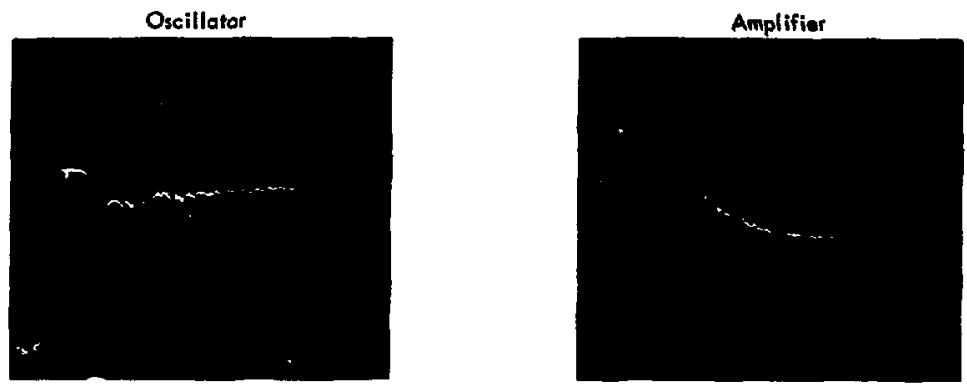

Timo seoles $100 \mathrm{nsec} / \mathrm{div}$

Fig. 36. Oscillator/amplifier tmes at 95 Torr $\mathrm{NF}_{3} / \mathrm{H}_{2}=4 /$.

99 Torr $\mathrm{NF}_{3} / \mathrm{H}_{2} 4 / 1$ low level oscillator

Oscillator

Ampiifier
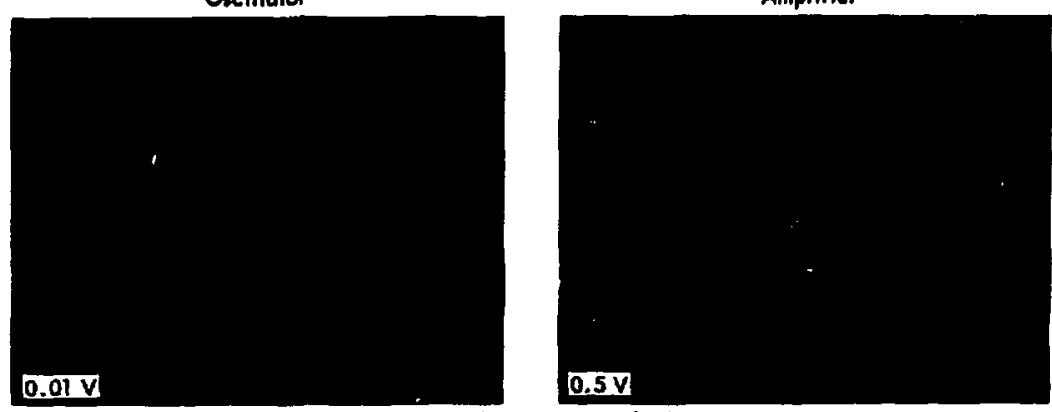

$50 \mathrm{msec} / \mathrm{div}(100 \mathrm{nsec} / \mathrm{cm})$

Fig. 37 Oecilator/amplifler traces at 99 Torr $\mathrm{NF}_{\mathbf{3}} / \mathrm{H}_{2}=\mathbf{4} / 1$ 
108 Torr $\mathrm{NF}_{3} / \mathrm{H}_{2} 4 / 1$ low level oscillator

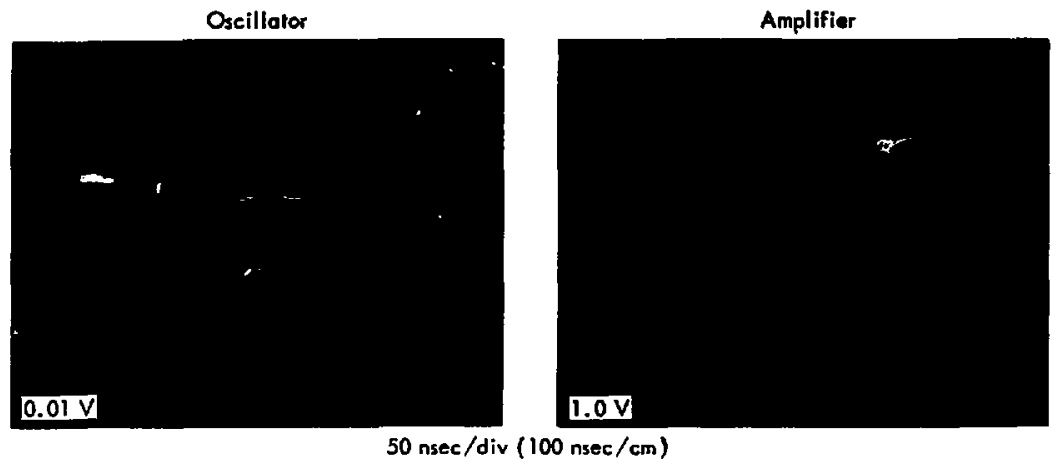

Fig. 38. Oscillator/amplifier traces at $108 \mathrm{Ton} \mathrm{NF}_{3} / \mathrm{H}_{2}=4 / 1$.

about 6-10 nsec duration. The system rise time was limited, not by the bandwidth of the 183A scope, but by the inductive nature of the circuitry associated with the detector Dewar.

The data presented below characterize the oscillator inpul, amplifier output features and pertinent gain paramelers that result from taking ratios of peak heights and artus. All correction factors ass ciated with filters are given for reference only and have been factored into the figures appearing in Tables 2-5.

Data stected from Tablec 2 through 5 have been plotted in Figs. 40 and 41 to permit later comparison witl the theoretical calculations on a code developed by Hopf and Rliodes. ${ }^{24}$ Figure 40 shows typical gain versus pressurc curves indicating that saturation has defiaitely occurred; that is, intensity in the nonlinear effect regime grows linearly with the amount of material traversed, (or linearly with pressure at a (ixad amplifier length) rather than exponentially as in the range $0<p \leqslant 20$ Torr. It is noted that the $P(5) 2 \rightarrow 1$ data is suspect because of the inordinately high oscillator and amplifier coupling experienced. The $P(4) 2 \rightarrow 1$ data suffered no detectable coupling and is therefore to be trusted.

Figure 41 shows the characteristic time between the first and second "spikes" as a function of pressure Again it is seen that the time scalc of events depends very nearly on $I / p$ as is to be expected from a situation that is controlled by binary collision processes. The discussion below will explain more fully the significance of these data.

Tahle 2. Chenical laser operation data extracted iron oncillosione traces (nonlinear amplitication): $\mathrm{P}(4) 2-1 \lambda_{\mathrm{vak}}=2.7604 \mu$ : stoichiometry $\mathrm{NF}_{3} / \mathrm{H}_{2}=4: 1$.

Pressure (Torr)

Spikc are:a insoc-V)

Oscillator arej" (nsec-V)

Ampliticer arciad (nsico-v)

Arè gain (dimensionless)

Peak gain (dingensiouless)

Contrissl raltiob (dintensionless)

$\Delta \mathrm{l}$ (time between two peaks) (nsec)

$\tau$ ducity final decily (nsis)

$\begin{array}{ccc}47 & 95 & 14.3 \\ 105 & 200 & 660 \\ 14 & 14 & 14 \\ 1.371 & 1870 & 208.5 \\ 98 & 134 & 174 \\ 300 & 714 & 2500 \\ \geq 1.65 & \geq 1.60 & \geq 2.60 \\ 130 & 72 & 50 \\ 470 & 300 & 100\end{array}$

\footnotetext{
${ }^{3}$ Nurmalization: An area of $1.0 \mathrm{nsec}-\mathrm{V}$ corresponds to $1.2 \times 10^{-4} \mathrm{~J}$ of oscillator energy entering the amplifier section.

h'ont rast ratio: Defined as ratio of spike amplitude to second pulse amplitude.
} 


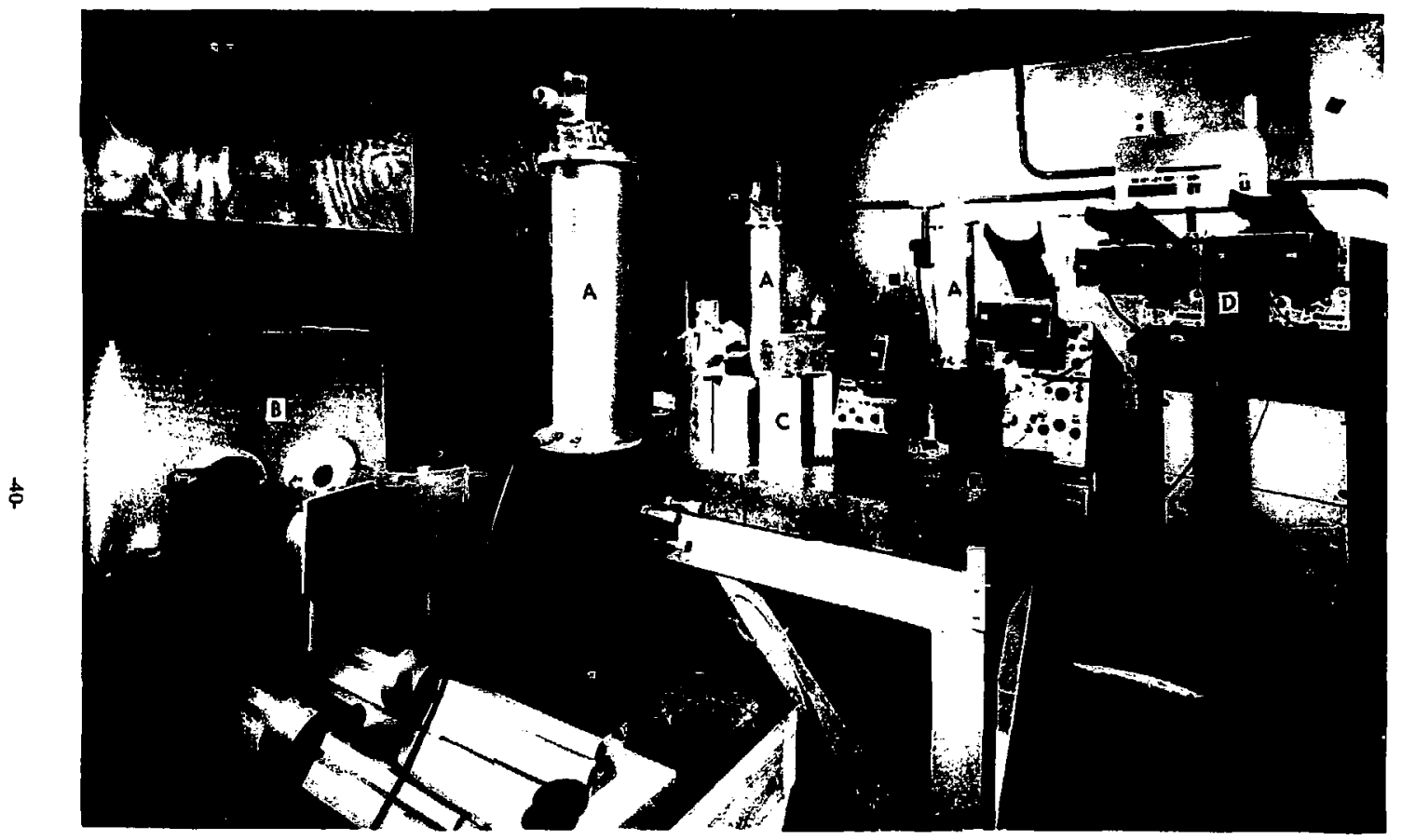

Fig. 39. Datu collection area (screen room).

A: Liquid helium cooked, coppat doped germanium detectors

B: Perkin-Elmes E-1 monochrouator

C. Leab bicks for $X$-ny thieling

D: Hewlett-Packard 183A oacillowopes 
Table 3. Chemical laser operation dela extracted from oscilloscope traces (nonlinear amplification): $P(5) 2-1 \lambda_{\operatorname{vac}}=2.7951 \mu$ : stoichiometry $\mathrm{NF}_{3} / \mathrm{H}_{2}=4 / 1$.

Pressure (Torr)

Spike area (nsec-V)

Oscillator area (nsec-V)

Amplifier area (nsec-V)

Area gain ${ }^{\mathbf{a}}$ (dimensionless)

Peak gain" (dimensionless)

Contrast ratio (dimensionless)

$\Delta r$ (time between two peaks) (nsec)

$\begin{array}{cccc}19.8 & 36 & 96 & 130 \\ - & - & 1420 & 1400 \\ 2.2 & 3.3 & 2.14 & 1.74 \\ 738 & 1940 & 4220 & 4140 \\ 39.4 & 50.6 & 201 & 237 \\ 34.3 & 68.0 & 506 & 733 \\ - & - & 2.0 & 1.83 \\ - & - & 60 & 35\end{array}$

a Jain on this transition was high enough to permit use of a narnow hand transmission filter (OCLI) that passes

$2.79 \rightarrow 2.84$. Even so, it was impossible to completely decouple the oscillator and amplifier sections.

Table 4. Chemical laser operation data extracted from nscilloscope traces (nonlinear amplification): $P(5)$ 2-I $\lambda_{\text {vac }}=2.7951 \mu$ : stoichiometry $\mathrm{NF}_{3} / \mathrm{H}_{2}=7.5 / 1$.

Pressure (Tarr)

Spike area (nsec-V)

Oscillator area (nsec-V)

Amplifier area (nsec-V)

Area gain ${ }^{a}$ (dimensionless)

Peak gain a (dimensionless)

Contrast ratio (dimensionless)

$\Delta r$ (time between two peaks) (nsec)

$\begin{array}{cc}31 & 70.8 \\ 25.2 & 1248 \\ 2074 & 20.25 \\ 82.3 & 6240 \\ 31.1 & 375 \\ \geq 1.86 & 138.6 \\ 380 & \geq 1.5\end{array}$

$\begin{array}{lc}108 & 150 \\ 1440 & 1200 \\ 17.25 & 21.2 \\ 7740.0 & 9890 \\ 548 & 561 \\ 240 & 300 \\ \geq 2.02 & \geq 1.85 \\ 100 & 80\end{array}$

aSame footnote as with Table 3 .

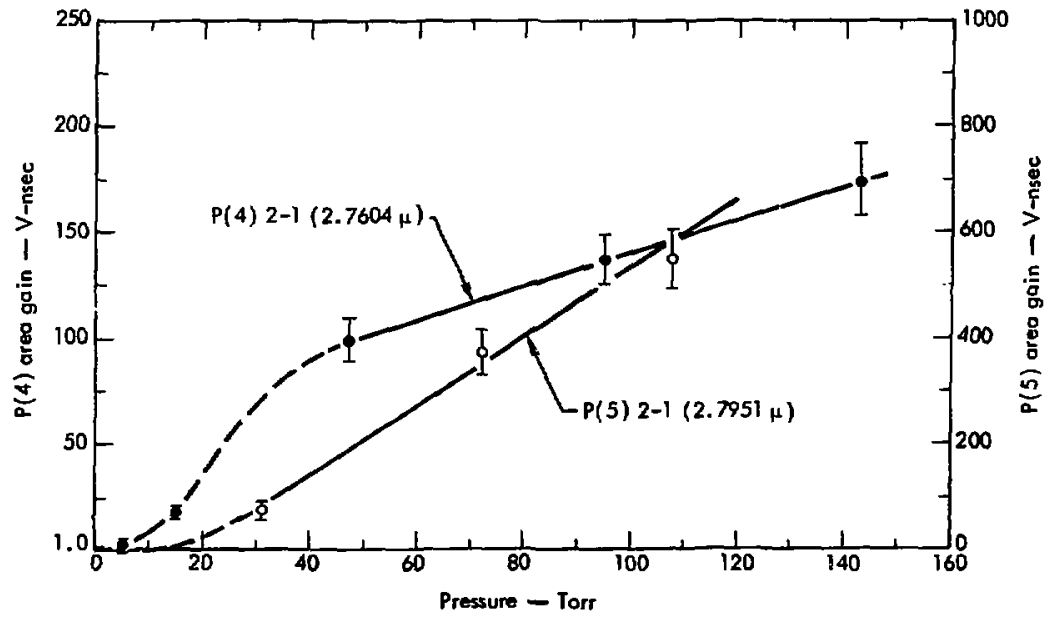

Fle 40. Ares pin ve preauro for lorge cecllatos input. 
Table 5. Chemical laser operation data extracted from oscilloscope traces (nonlinear amplification); $P(4)$ 2-I $\lambda_{\text {ne }}=2.7604 \mu$ : stoichiometry $\mathrm{NF}_{3} / \mathrm{H}_{2}=7.5 / 1$

Pressure (Tort)

Spike area (nsec-V)

Oscilloscope area (nsec-V)

Amplifier area (nsec-V)

Area gain" (dimensionless)

Peak gain" (dimensionless)

Contrast ratio (dimensionless)

$\Delta t$ (time between two peaks) (nsec)

$\begin{array}{cc}30 & 72 \\ 192 & 460 \\ 1.6 & 1.4 \\ 524 & 2020 \\ 153.5 & 675.6 \\ 130.0 & 657.1 \\ - & 2.55\end{array}$

$\sim 100$

$\begin{array}{cc}124 & 267 \\ 800 & 300 \\ 2.1 & 1.94 \\ 1600 & 600 \\ 378.7 & 148.0 \\ 1000 & 1111.0 \\ 3.13 & 3.67 \\ 40 & 20\end{array}$

II order to minimize the effects of oscillator-umpliffer coupling, two narrow pass filters were pluced at the osclintor cutput. The effective band pass was between $2.74-2.77 \mu$; the transmission of the two filters was $23 \%$ for $2.7604 \mu$

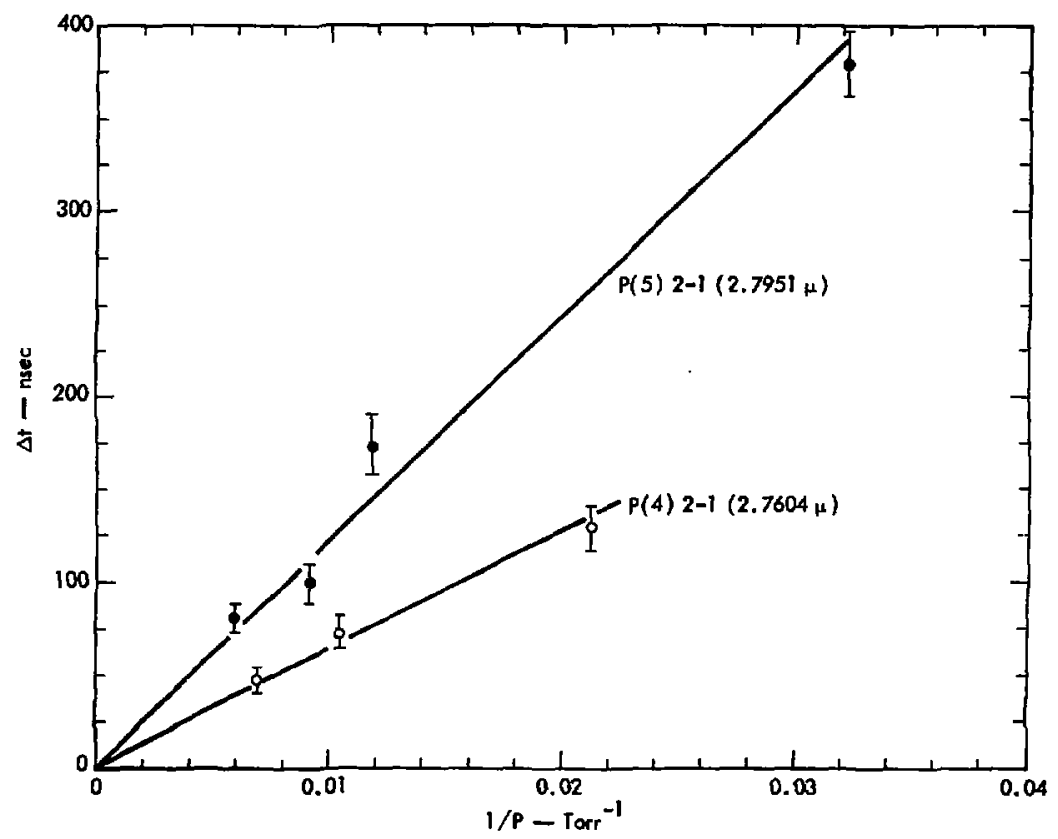

Fig. 41. $\Delta t \mathrm{ve}$ 1/p for two transition. 


\section{ELECTRON BEAM DOSIMETRY}

Figure $\mathbf{4 2}$ is a scan of a thin, sensitive plastic disc that bleaches proportional to the encrgy absorbed. The isodensitometer records density variations by a coded sequence of single dots, double Jots, dashes, spaces anu color changes and represents time integrated energy absorption. ${ }^{25}$ The figure was obtained with the amplifier charged with $1 \mathrm{~atm}$ air at $15 \mathrm{kV}$ charging voltage on the magnetic capacitor bank (about $8 \mathrm{kG}$ ).
The limb regions are at reference density and the center corresponds to a region of highest absorbed dose (or minimum density). There is a $50 \%$ density change from center to edge.

Figure 43 shows that $\sim 90 \%$ of the total dose is absorbed in a circle of diameter $=2 \mathrm{~cm}$. This diameter may also be obtained approximately from a to-scale measurement of the emission diameter in the open shutter photograph Fig. 15b. Compare this result with the calculation on Eq. (33) and the conclusion on beam diameter in the discussion following $\mathrm{Eq}$. (39).

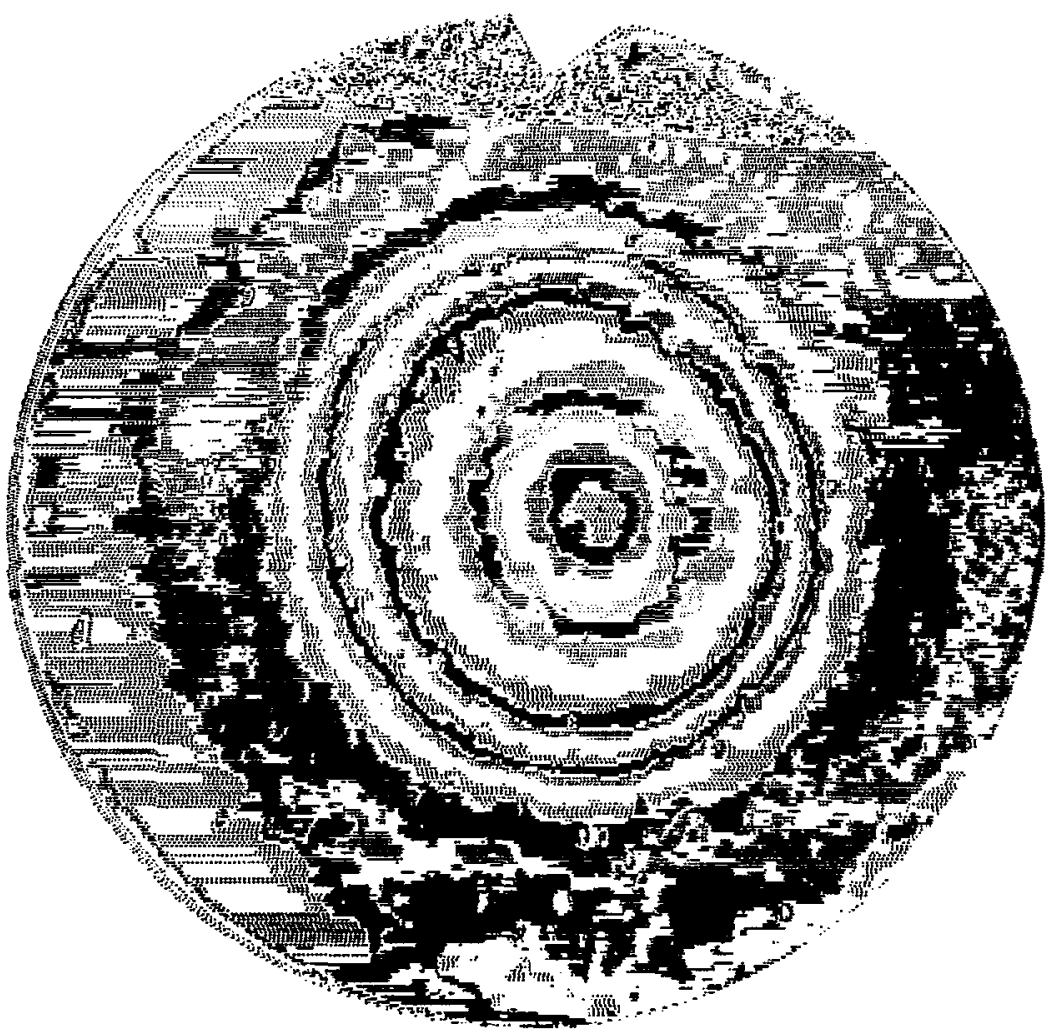

Fig. 42. Time integraled lsodose profite of electron beam. 


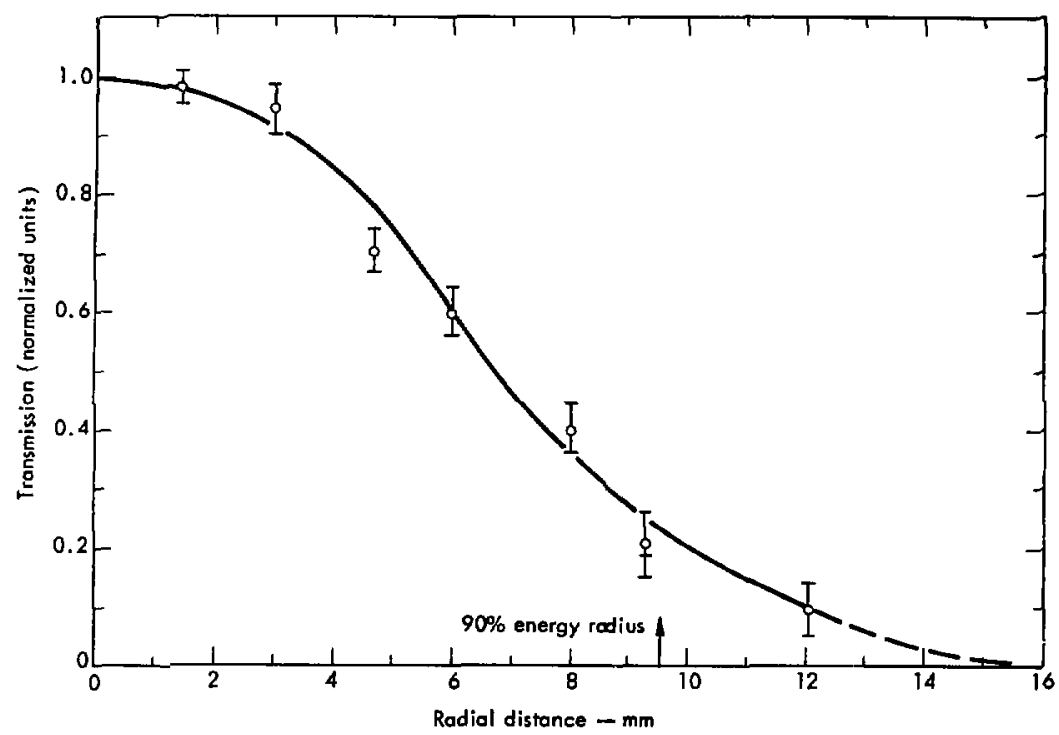

Fig. 43. Dose distribution across amplifier diameter.

To obtain a time-integrated picture of deposition versus length dow'n the amplifier, a sequence of experiments were nin with a separate disc at each of five stations down the amplifier tubc. The stations correspond to positions in the tube as pictured in Fig. 44. Figure 45 shows the result. The beam center may be seen 20 drift $+3.5 \mathrm{~mm}(\mathrm{x})$ in horizontal deflection and $-3.0 \mathrm{~mm}(y)$ in vertical deflection. This represents a motion along each axis of about (0.I) diamcter of biari.

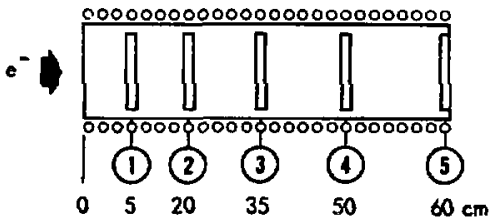

Fif 44. Experimentsl placement of bleachable dises.
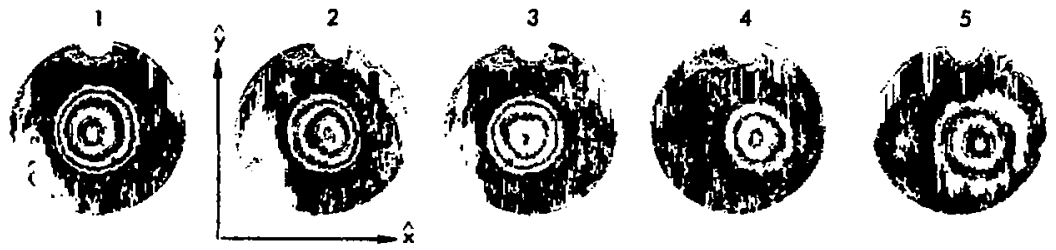

Fig. 45. Results of exposure of diasic restron beam. 
In addition to discovering the spatial distribution of the bearm versus distance from the source, the beam size versus magnetic guide field strength at a tixed position was alsu determined and is shown in Fig. 46.

The linear decrease of beam diameter with magnetic field follows the simplified analysis represented in Eq. (33). There was never any evidence of beam nonuniformity or "anomalous" absorption of the beam as might occur with a rapidly growing (e.g. I wostream) plasma instability. ${ }^{26}$

\section{CALORIMETRY}

A carbon block calorimeter with an iron-constantan thermocouple was constructed to get a rough measurement of the energy content of the electron beam as it traversed the amplifier reaction vessel.

Parameters of carbon block: $\quad 1 / 3 \mathrm{in}^{3}=2.047 \mathrm{~cm}^{3}$

$$
\mathrm{Cp}=0.170 \mathrm{cal} / \mathrm{gm} /{ }^{\circ} \mathrm{C}
$$

$$
\text { (a) } 25^{\circ} \mathrm{C}^{27}
$$

$$
\mathrm{p} \simeq 2.267 \mathrm{gm} / \mathrm{cm}^{3}
$$

$$
\text { (a) } 25^{\circ} \mathrm{C}^{27}
$$

This calorimeter has an energy of sensitivity $=\mathbf{0 . 7 5}$ $\pm 15 \% \mathrm{cal} /{ }^{\circ} \mathrm{C} @ 25^{\circ} \mathrm{C}$. The thermocouple generated $61 \mu \mathrm{V} /{ }^{\circ} \mathrm{C}$. Therefore the overall sensitivity factor is $\simeq 53 \mathrm{~J} / \mathrm{mV}$.

Based on these data one sers that approximately $65 \mathrm{~J}$ are absorbed by the gas in the amplifier chamber ( $\mathrm{atm}$. air). The effective path length of the average electron can then be simply calculated by assunting that whatever the "real" path length is, it is small compared to the classical range'.
The effective length $\mathrm{X}$ is given by

$$
\stackrel{p}{R} \times\left(E_{i n}\right)=E_{\text {absorbed }}
$$

where $E_{\text {in }}=$ input energy $=151 \mathrm{~J}$

$$
\begin{aligned}
E_{\text {wbsorbed }} & =E_{\text {in }}-E_{\text {out }}=65 \mathrm{~J} \\
\rho & =1.3 \mathrm{mg} / \mathrm{cm}^{3} \text { (air at STP) } \\
R & =\text { range of } 1.2 \mathrm{MeV} \text { electrons } \\
& =0.517 \mathrm{gm} / \mathrm{cm}^{2}
\end{aligned}
$$

$X$ is thus

$$
X=171.0 \mathrm{~cm}
$$

Taking the geometric path length to be $60 \mathrm{~cm}$ we ste that the magnetic confinement increased the absorption by $171 / 60=2.85$ fold. The energy deposited ; $\mathrm{cm}^{3}$ in $100 \mathrm{Torr}^{\mathrm{NF}}$ is then

$$
\frac{\mathrm{PNF}_{3}(171)}{R} \times(151) \cong 100 \mathrm{~mJ} / \mathrm{cm}^{3}
$$

This agrees with Eqs. (26) and (27) which assumed a pain length of $75 \mathrm{~cm}$.

Figure 47 shows the results obtajned with this calorineter. They agree within $15 \%$ with the calculation presented above.

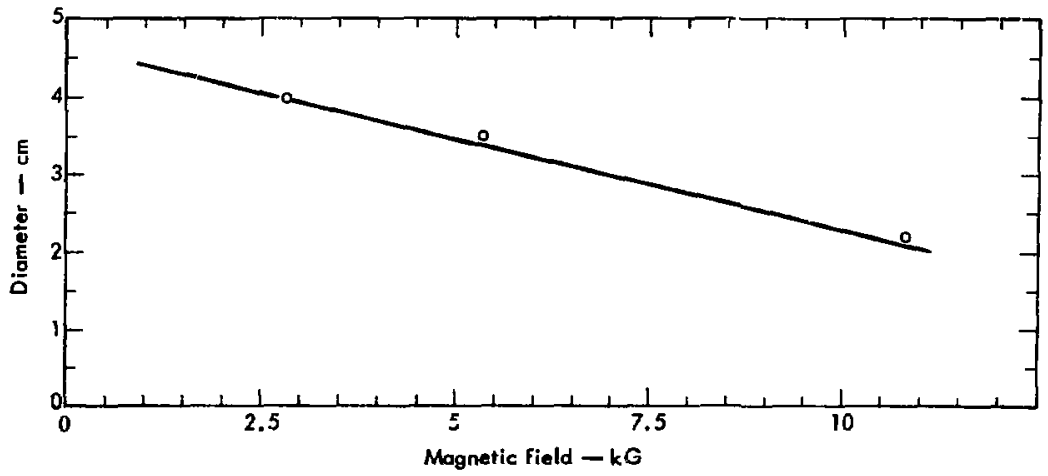

Fig. 46. Amplifier beam diameter ss magnetic field sitrength. 


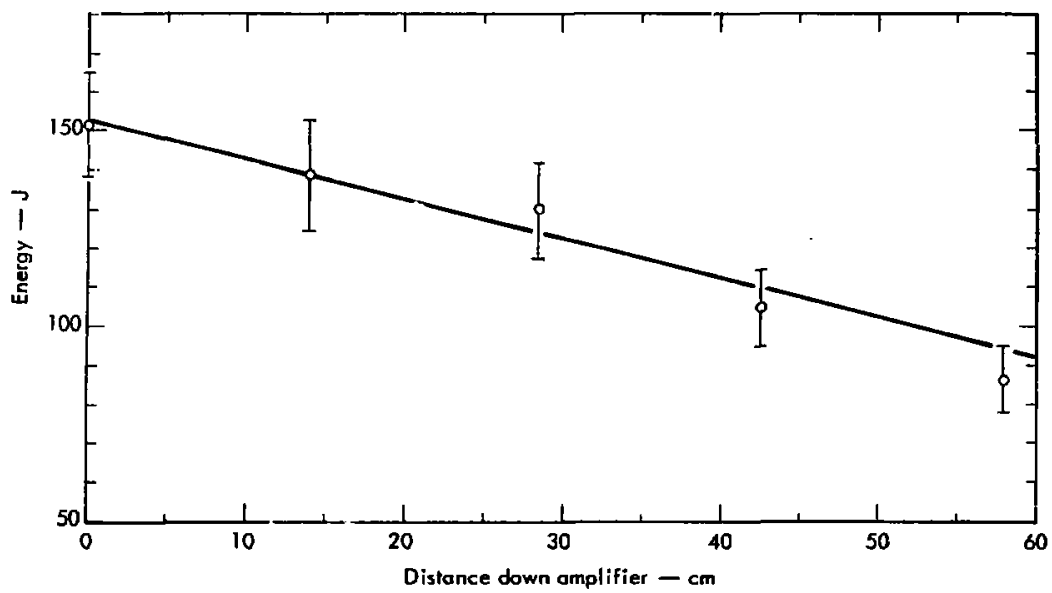

Fig. 47. Phot of calorimeier reading vs distance down tube.

\section{E. MAXIMUM ENERGY EXTRACTION}

The oscillator described above was fitted with a gold toated back mirror and a sapphire flat for an output coupler and operated in the high energy, short pulse moule. In this modt. typical inputs to the amplifier were ubout $20 \mathrm{~mJ} / \mathrm{pu} / \mathrm{se}$ with a pulse width of about 250 nset (FWHM).

The amplilite was tharged to about 275 Tor $\mathrm{NF}_{3} \cdot \mathrm{H}_{2}=7.5 / 1$. At high pressurc it was impossible to operate ut near stoichiometric proportions; mechanical failure of the prossure ves iel woukd hrve been certain. Meisurements indicated that at 25 Torr the chemical reaction resulting in liser attion lasted for about 250-300 nsect.

The oscillator and amplifiner wire timed so that the stimulating light was on when the amplifie themistry began a $\alpha$ was off just after the amplifitr yain disappeared. The calorimeter was placed directly at the output of the amplificr so as to receive ail of tho output light. Under these corkditions the miximum encrgy extratted was $\simeq 90 \mathrm{~mJ}$, an enurgy gain $I / I_{u}=90 / 20=4.5 i$ (saturated operation).

It is noted for completeness that if the amplifier is allowed to radiate sponiancously (i.c., oscillator blockel off under the conditions described above the walorimeter ruading decreased to $\simeq 40 \mathrm{~m}$. 


\section{Discussion of Chemical Studies}

\section{A. REACTION RATES}

The pteceding suttion presinted calculations and data that resulted in an experimental value of $\mathrm{N}_{2} / \mathrm{N}_{1}$ $\left(N_{i}=\right.$ population of the jth vibrational level) given by

$$
\frac{N_{2}}{N_{1}}=2,67
$$

The relative populations of 1 wo hevels at any time depend both nn activation and deactivation processes; thus one can sonclude that

$$
\frac{k_{2}}{k_{1}}>\frac{N_{2}}{N_{1}}=2.67 .
$$

where $k_{i}=$ reaction rate associated with population of the ith vibrational livel. This value is to be compered with the work of Jaffe and Anderson ${ }^{4}$ who gave $k_{2} / k_{1}=1.88$ and Polyani and Tardy $y^{5}$ who gave $k_{2} / k_{1} \geq 3.5$ at $300^{\circ} \mathrm{K}$. The work of these authors was concemed with the specific reaction:

$$
\mathrm{F}+\mathrm{H}_{2} \rightarrow \mathrm{HF}^{*}+\mathrm{H}
$$

It is thus reasonable to assert that the dominant gain producing reaction in the $\mathrm{NF}_{3} / \mathrm{H}_{2}$ system is in fact reaction (52). This result is significant in that it is extracted directly from analysis of the luser output of the $\mathrm{NF}_{3} / \mathrm{H}_{2}$ system. The experiniental procedure used to extract $k_{2} / k_{1}$ will be similarly useful in obtaining information about $k_{j} / k_{i}$ in the event that stahle cw H-F prohe oscillitors become available.

\section{B. GAIN ACIIVATION RELATION}

The study of rarious deactivation processes contributing to the loss of stored energy has been undertaken by varict s suthors. Among the reactions studied are radical deactivation described by Eqs. (63) ar I (64), and molecular deactivation described by Eqs. (65) and (66).

$$
\begin{aligned}
& \mathrm{H}^{*}+\mathrm{HF}^{*} \rightarrow \mathrm{H}^{*}+\mathrm{HF} \\
& \mathrm{F}+\mathrm{HF}^{*} \rightarrow \mathrm{F} \cdot+\mathrm{HF} \\
& \mathrm{HF}+\mathrm{HF}^{*} \rightarrow \mathrm{HF}+\mathrm{HF} \\
& \mathrm{H}_{2}+\mathrm{HF}^{*} \rightarrow \mathrm{H}_{2}+\mathrm{HF}
\end{aligned}
$$

Each of these processess desicribed above are binary in nature and can he destribed by a relation of the form

$$
p r=k \text { (nsect-atm) }
$$

where $p=$ pressure of deactivating constituent in atmuspheres

$\tau=$ collision deactivation timc in manoseconds $k=$ a constant.

This study permitted tike exanination of the binary assumption in the small sipnal gain formation process. It was found that. indecd, activation coula be described by the relation.

$$
\mathrm{p}_{\mathrm{a}}=8.3 \pm 1.0 \mathrm{~ns} \cdot \mathrm{i}-\mathrm{tan}
$$

where $\tau_{\mathrm{a}}=$ tinic constant for gain buildup.

$\tau_{a}$ is an effective time resulting from a complex interaction of various excitation und Juactivation processex. A detailed calculation. following the presiription of Curry and Kidder, ${ }^{28}$ has been pertormed under the assumptions:

- $\mathrm{F} \cdot+\mathrm{H}_{2} \rightarrow \mathrm{HF}^{*}+\mathrm{H}$ is the primary energy producing réaction.

- No linear claaining or chain branching chemistry acurs after the initial production of $F$ - radicals by the electron beam.

- Reations (63) through (66) are the only significant deactivitors.

- The amplificr is operating in the small signal gain regine.

- $k_{2} / k_{1} \geq 2.67$ (see Sec. Ill-A).

The ealculation predicts the tinte to maximum small signal gein as a function ol pressure at the stoichiometry of interest $\left(\mathrm{NF}_{3} / \mathrm{H}_{2}=4 / 1\right)$ as

$$
p r=8.5 \mathrm{nswalln} \text {. }
$$

This is in sxcetlent agreconent with the $8.3 \mathrm{nsec}$ figure yuoted in Eq. (52). A disappointing consequence of this resuft is that assumption (2) above is correct. The absence of chain brancling severely limits the chergy extractable from the reactants. Pearson ") liat. reporled that energy densities achicved cxperismentally are $~ 210$ joules/liter at one atmusphere $1300^{\circ} \mathrm{K}$. On these grounds, this chemical system is a poor crmmutitor lo existing $\mathrm{N}_{2}-\mathrm{CO}_{2}$ laser systerins. 


\section{r. MAXIMUM I:NI:RC;Y EXTRACTION}

The results on enirgy textraction at high pressure inclicute that the quin of the system was so high that stimulation of t/a amplificr produced only moderate enhancemert of the yisld from spontaneous emission alone. It can only be concluded that one must resort (1) wine sort of traveling wave ievict to achieve an criderly removal of stored energy. A difficulty with kng wavelength (far infrared) light is that most surIaces ant excellent reflectors. Excellent reflectivity, coupled with the severe restrictions placed hy the chemist:y on any vexsel, seriously limit conditions under wlyich high encrgy HF cmission can be obtained.

\section{KINETIC JROCFSSES}

Once the primary beam is off one mus! cansider N11. wecondary clectron plasina and how it decays. The primary difficulty is such a consideration is the reaction

$$
\begin{gathered}
\mathrm{c}^{-}+\mathrm{NF}_{3} \rightarrow \mathrm{F} \cdot+\mathrm{NF}_{2}+\mathrm{e}^{-} \\
\rightarrow \mathrm{F} \cdot+\mathrm{NF}_{2}
\end{gathered}
$$

etc.

(Litle is known in this regard about the $\mathrm{NF}_{3}$ moleculc.)

The hot stiondary plasma immediately cools by ionization and dissociation producing collisions to a tomperature of about $\leq 1 \mathrm{eV}{ }^{28}$ If it is assumed that the dissociation energy of $\mathrm{NF}_{3}$ is about $4 \mathrm{eV}$ (the energy below which an electron cannot form $\mathrm{F} \bullet$ ) one conclu:'es that the figure of $10^{15}$ electrons $/ \mathrm{cm}^{3}$ [Eq. (44)], if taken as the number of free flourine aldicals forned, will certainly be an over-estimate. Io this author's knowledge no evidence of chaining exists in the $\mathrm{NF}_{3} / \mathrm{H}_{2}$ system. Several authors have obtained satisfaciory agreement with experiment ${ }^{29-31}$ assuming that the following reaction scheme is dominant

$$
\begin{aligned}
& \mathrm{e}^{-}+\mathrm{NF}_{3} \rightarrow \mathrm{F} \cdot+\mathrm{NF} \mathrm{F}_{2} \\
& \mathrm{~F} \cdot+\mathrm{H}_{2} \rightarrow H \mathrm{~F}^{*}+\mathrm{H} \\
& H F^{\star}+\gamma \rightarrow 2 \gamma+\mathrm{HF}
\end{aligned}
$$

and that neither the $\mathrm{NF}_{2}$ nor hydrogen radical contribute to further linear (thermal) chaining or chain branching. ${ }^{30,32}$ Results of experiments on gain his- tory suggest thet either the equilibrated plasina electrons continute to produce nourine radicals as in reaction (72) above or that cold HF may be re-xcited to produce lingering sources of $\mathrm{HF}^{*}$ for periods of 200-300 nsec al 100 Torr $\mathrm{NF}_{3} / \mathrm{H}_{2} \curvearrowright 4 / 1$ or equivakently, several $\mu \mathrm{sec}$ ist pressures $\mathbf{2 0 - 4 0}$ Tort.

\section{E. NONLINEAR AMPLIFICATION}

Many authors, among them Hoff. el. al.$^{33}$ and Hopf and Rhodes. ${ }^{24}$ have concemed themselves with the investigation of the nonlinear interactions that occur when an inhomogeneously broadened amplifying modium interacts simulaneously with an intense, coherent field and the polarization of an ensemble of radiators (the active medium). Substantial experimental work has been accomplished with negative amplifiers (absorbers). Evidence of "optical-nulation" of the effective material polarization has been observed in $\mathrm{CO}_{2}$ by Hofr, et. al. ${ }^{33}$ The class of effects that can be understood by the theoreticul formalism (carricd over from the field of nuclear magnctic resonance) applied to this problem include photon spin echo and self-induced trassparency. ${ }^{34}$ The comparison of experiment and theory achieved in this stidy established the first evidence for the so called quasisteady state " $\pi$ "-pulsc 35 propagation in high gain media.

The calculational model with which the experiment was compared was built by Hopr and Rhodes. ${ }^{24}$ The reader is commended to Rof. 24 for specific details of the code. Essential features of the code, in the version that existed prior to the results given in this study, are presented below:

1) The code treats the field classically (justificd by the high photon fux for this problem) and the molecular system quantum mechanically. The coupled Maxwell and Schroedinger tquations are solved numerically using the density matrix formulation under conditions that the phase and amplitude of the stimulating pulse change slowly in space and timc. (Slowly is defined relative to $1 / \omega$ for the time seale and $1 /|\vec{k}|$ for the space scale; $\omega=$ optical frequency; $1 /|k|=$ wavelength.)

2) The input speciried:

- Initial inversion density (or small signal gain).

- Various characteristic times (e.g. $T_{2}=$ homogeneous dephasing time $\simeq 1 /$ nov, $T_{1} \equiv$ natural lifetime; $T_{1}=$ intra-rotational relaxation time, $T_{1}{ }^{\prime \prime}=$ inter-rotational rejaxation time $=$ degeneracy $\times T_{1}$ e) 
3) $T_{1} \cdot$ specified the maximum rate at which encrgy tould be withdrawn from the upper level rotational reservoir. Thu ratio $T_{1} \prime / T_{1}$, spectified tht tolal energy stored in the bath that was potentially availuble for extraction.

A monent's reflection reveals that this initial version of the code could not properly specify the physical mechanisnts it work within the cheınical amplifier. For the experimental situation it is clear that at $t=0$ the gain was zero. fi.c., the themistry had not yet been initialed). Furtler, the stimulating liuld was established in tlic almplifier just prior to the turn-on of the chemistry therchy further inhibiting llac accumulation of inversion density. (These points will reccive more detiviled distussion juter on in this section.)

The code was modified to account for physically reasonable gain build-up profiles by allowing the specificution of a time dependent inversion density. Figure $\mathbf{4 8}$ depicts the analytical form of this pumping history, where $\gamma$ specifies small signal guin growth and decay and $\beta$ specifies length (in time) of muximum inversion. If $\beta=0$ one has then specificd a triangular gain prolile.

For a ty pical example of experimental results showing amplifier output stimulated by an oscillator

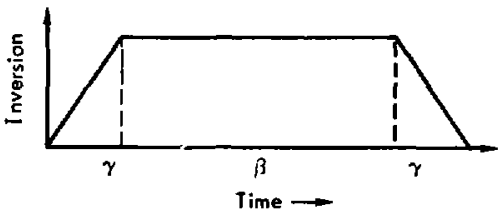

Fig. 48. Gain profile for caleulating performance in a chemical leser.

input whose profile is that of a slowly decreasing linear ramp, see Fig. 36.

Figure 49 is a computer calculation corresponding to the 95 Torr case, Fig. 36, without chemical gain effects encluded.

It is immediately seen that the signature of both figures is a short, highly peaked initial pulse followed by a second pulse of longer duration but smaller amplitude. For both cases substantially all the area (energy) is contained in the second pulse.

The striking difference between Figs. $3 u$ and 49 is the time scale over which the second pulse develops.

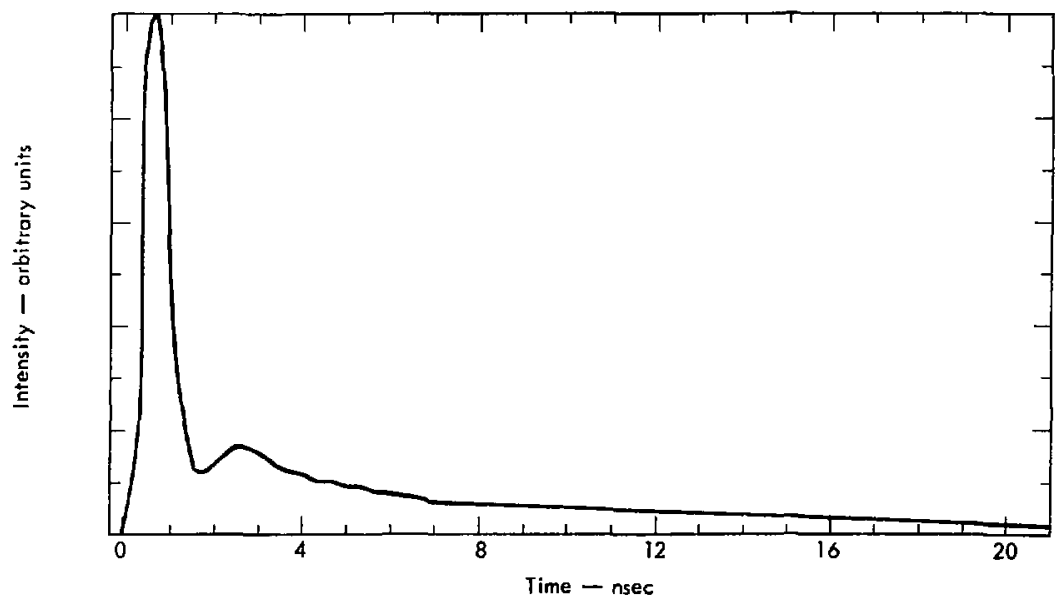

Fig. 49. Computer output; amplifier response without chemical efferts. Constant oscillator pulse egol $=10^{4}, T_{2}=0.8$ nsec, $T_{2}^{*}=0.8$ nsec, $T_{1}^{\prime}=1$ nsec, $T_{1}^{\prime \prime}=2$ nsec, $T_{1}^{\prime \prime \prime}=\infty, T_{1}=\infty$. (Entirc pulsc history shown.) 
For Fig. 36 the time scale follows almost txactly the retistion:

$$
\text { pr }=8.3 \pm I \text { nsel-Torr }
$$

where $\boldsymbol{\tau}=$ time to maximum gain. This equation was derived under sinal; signal gain conditions, i.e., $\mathbf{p} \leq$ 15 Torn @ $4 / 1 \overrightarrow{\mathrm{NF}_{3}} / \mathrm{H}_{2}$, where one expects a reasonable description of the unperturbed gain history of the system.

For Fig. 49 one expects the second pulse to develop with a time scale characteristic of the rotational feedin time ( $T_{1^{\prime}}=2.0 \mathrm{nsec}$ was the input parameter) and indeed this occurs. The experimental detection bandwidth corresponds to about 6-10 nsec because of the inductance associated with the particular Dewar/cable geometry available for the $\mathrm{Cu}$ :Ge detector. Amplitude of the initial spike is surely underestimated because of system band width effects.

Figure 50 shows the calculated amplifier output that results when a chemistry risetime $a=70$ nsec is specified. Three features of this result are particularly noteworthy. First the leading edge spike, indicative of coherent behavior, still appears but no longer dominates, in amplitude, th: long second pulse. Second, after the initial transient has subsided, the amplifier output follows the themically produced inversion exactly. Third, there is a trailing edge perturbation generated by the rapid dectease in gain. The trailing edge phenomenon is believed to be "real" but rechll that detector resolution prevented seeing a perturbation this fast experimentally.

Figures $\$ 1-55$ represent computer generated amplifier outputs for all parameters fixed as in Fig. 50 except for $a$ (the chemical rise time). The sequence is arranged in order of decreasing $a$.

Figures 50 and 51 taken together clearly demonstrate the extent to which tracking of the inversion history occurs after the nonlinear perturbation subsides.

The horizontal scales of Figs. \$2-55 are expanded to better show the spike development; the trailing edge performance is not shown.

As $a$ is decreased from 70 nsec we see the spike amplitude increasing to the point where, at 7 nsec = $a$, its amplitude clearly exhibits a qualitative behavior similar to the experimental results (Fig-36). The requirement for fast rising gain (small $a$ ) was at first a source of some concern. It was difficult to imagine the gain growing faster than $1 / \tau=(70.0 \mathrm{nsec})^{-1}$.

This troublesome requirement for an explanation of initially large d(gain)/dt is satisfied as follows:

Recall the assumption that only (F- $+\mathrm{H}_{2} \rightarrow \mathrm{HF}^{*}$ $+\mathrm{H}$ ) contributed to gain production and that the electron beam had deposited substantially all of its initiation energy within one chemical reaction time.

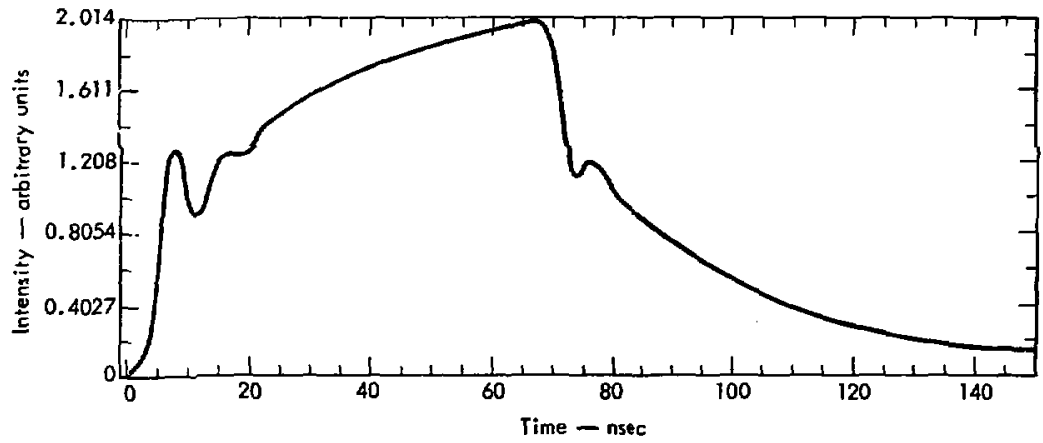

Fig. 50. Computer puiput, amplifier response with chemical effects. Chemlcal buildup time $=\mathbf{7 0}$ nsec (triangular thape-fall time $=70$ nsec). Constant oscillator pulse $\mathrm{e}^{\mathrm{gol}}=10^{43} . T_{7}=5$ nsoc, $T_{2}{ }^{\prime \prime}=20 \mathrm{nsec}, \mathrm{T}_{1^{\prime}}=10 \mathrm{nsec}, \mathrm{T}_{1^{\prime \prime}}=50$ nsec, $T_{1^{\prime \prime \prime}}=20$ 115ec. (Entire chemical history shown.) 


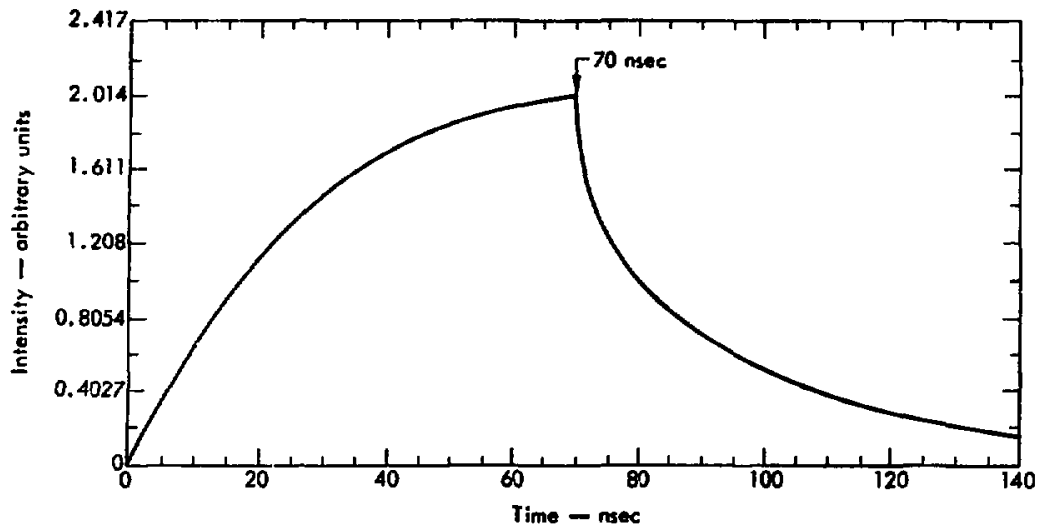

Fig. 51. Snall signal gain profle used $\mathbf{x}$ a mockup of chemistry input to code.

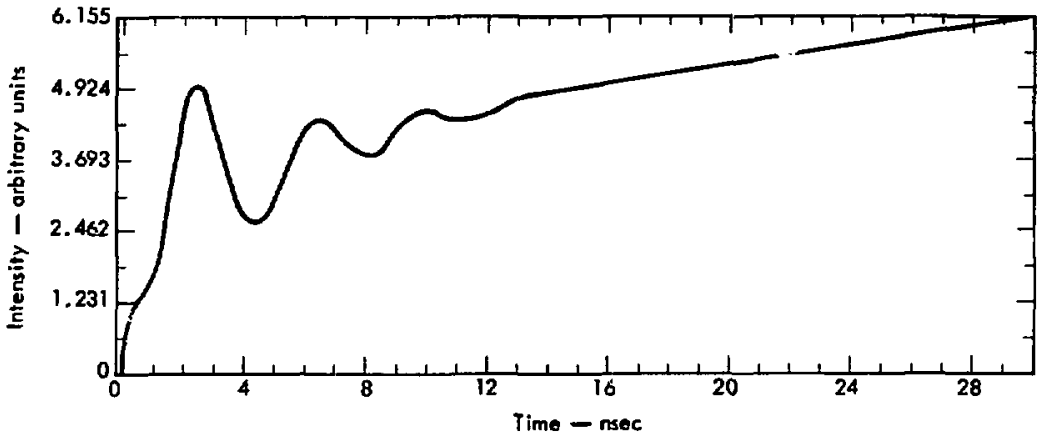

Fig. 52. Cakculated emplifer oulput with chemical bulldup time $=70$ nsec. Constant oscllator pulse $\mathrm{f}^{80 \mathrm{~d}}=10^{108}$ (pulte fully developed at $\left.10^{40}\right), T_{2}=5$ nsec, $T_{2}^{*}=20$ nsec, $T_{1}^{\prime}=10$ nsec, $T_{1}^{\prime \prime}=50$ neec, $T_{1}$ "'t $=20$ nuec. (Expanded time scale: Only firs part of the chemical history ts shown.) 


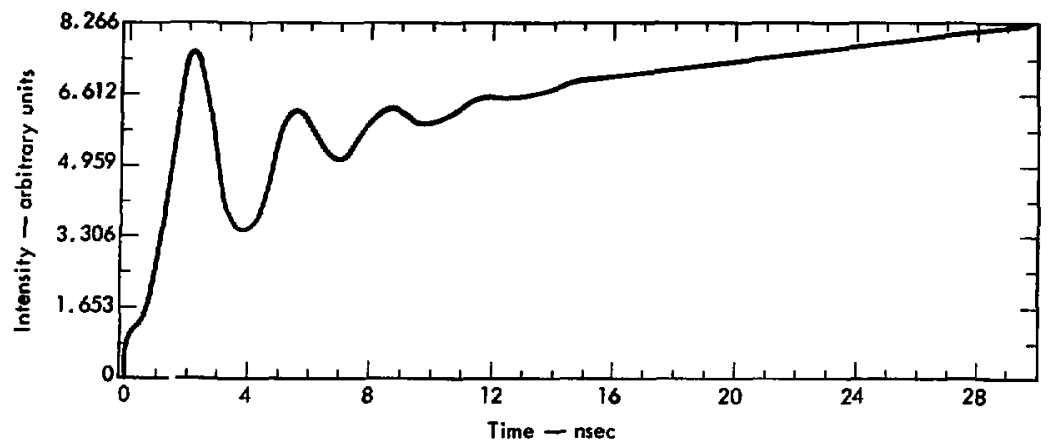

Fig. 53. Calculated amplifier output with chemical buildup time $=30$ nsec. Constant oscillator pulse $e^{g 0 l}=10^{108}$ (pulse fully developed at $10^{40}$. $T_{2}=5$ nsec, $T_{2}=20$ nsec, $T_{1^{\prime}}=10$ nsec, $T_{1}^{\prime \prime}=50$ nsec, $T_{1^{\prime \prime \prime}}=20$ nsec. (Expanded time scale: Whole chemical history not shown.)

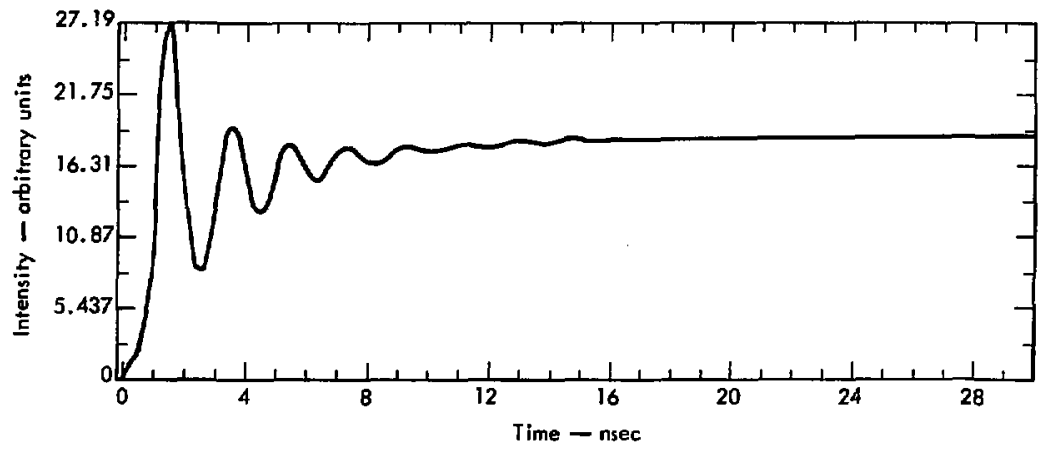

Fig. 54. Calculated amplifier output with chemical bulldup time $=7.0$ nsec. Constamt oscillator pulse e $e^{\text {gol }}=10^{\text {LOB }}$ (pulse fully developed at $10^{40}$ ). $T_{2}=5$ nsec, $T_{2}=20$ nsec, $T_{1^{\prime}}=10$ nsec, $T_{1^{\prime \prime}}=50$ nsec, $T_{1}{ }^{\prime \prime}=20$ nsec. (Expanded time scale: Entire chemical history not thown.) 


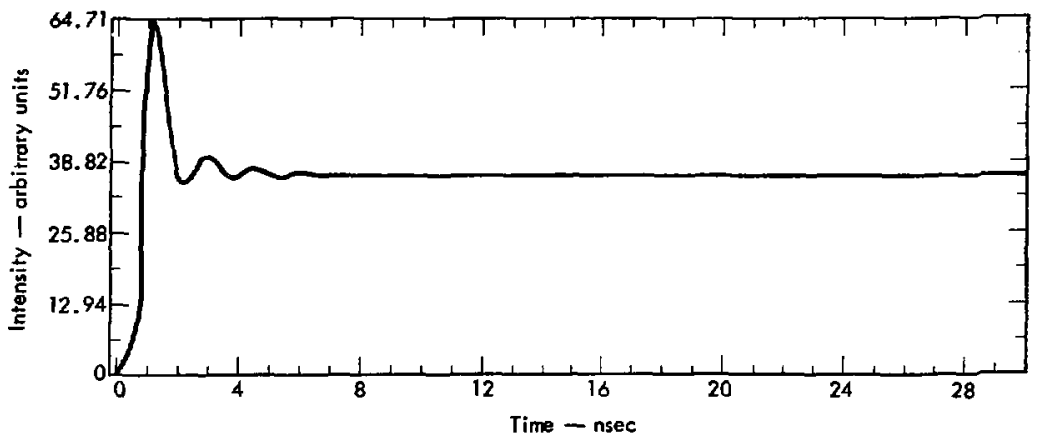

Fig 55. Calculated amplifier output with chemica) buildup time $=1.0$ nsec. Constant oscillator pulse $\mathrm{e}^{\text {gol }}=10^{108}$ (pulse fully developed it $10^{\text {th }}$. $T_{2}=5$ nsec, $T_{2}=20$ nser. $T_{1^{\prime}}=10$ nsec. $T_{1^{\prime \prime}}=50$ nsec. $T_{1}^{\prime \prime \prime}=20$ nsec. (Expanded time scale: Whole chemical history not shown.)

This implies

$$
\left.\left.\frac{d N_{H F}}{d t}\right|_{t \simeq t_{p}} \simeq \frac{N_{F}\left(t_{p}\right)}{T}\right|_{t \simeq T}>\left.\frac{d N_{H F}}{d t}\right|_{D t_{p}}
$$

where $\mathrm{N}_{\mathbf{H F}}=\mathrm{HF}$ concentration (excited) $N_{F}=$ flourine concentration

$\tau=$ mean time between chemical reactions

$t_{p}=$ election beam pulse duration $=80 \mathrm{nsec}$.

This argument can be made graphically as well. Assume that Fig. 56 characterizes the long second pulse.

Taking $\tau=t_{m}$ is equivalent to taking the average growth rate represestes by the line lakelled A. Physically the coherent effect "runs away" in times of the order of the dephasing time (taken as 5 nsec for this series). In the first 5 nsec, the slope of the gain curve is more correctly represented by the line labelled B. It is clear that slope B > slope A.

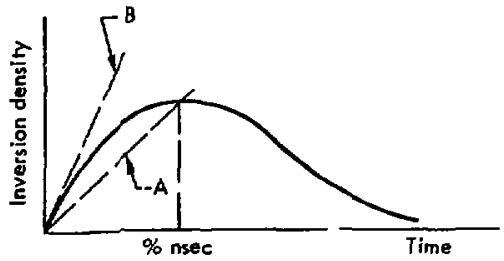

Fig. 56. Chentical gain hirtory input for computer simulation.
The excellent ayreement between experiment and calculation (Figs. 36 and 55) confirmed that nonlinear, field-molecule coupling was observed. Earlier in this stetion the comment was made that the time from initiation to the peak of the second pulse was identical to the value obtained from studies of small signal gain behavior, Eq. (52). One concludes that once saturation of the nonlinear effect occurs, subsequent behavior of the amplilier output becomes adiabatically coupled to the gain chemistry. Reference 32 makes it cleas that nonlinear coupling is favored when $\mathrm{d}($ gain $) / \mathrm{dt}$ is high. This condition occurs only immediately after initiation; consistent wi'l the assumption that chain branching chemistry is not involved, Eqs. (71 - 73).

The compuler generated output, Figs. 49-55, verify the statement that amplilier output rigorously tracks the chemical gain history at late times. One can visualize the adiabatic coupling result in an alternative way. Immediately after initiation, the rate of change of gain and the gain itself are high: nonlinear coupling occurs. Once the rapidly formed inversion reservoir is emptied via the nonlinear effect, the optical field intensity/gain rate are such as to generate a raithful record of the inversion-producing chemistry.

Prior to this study, the theoretical model ${ }^{24}$ was capable of predicting the existence of, and conditions for, nonlinear pulse formation/propagation. The results presented in this-section are the first evidence of "steady state" pulse propagation in a high gain medium. The adiabatic coupling hypothesis/verification is entirely new. 


\section{Rare Gas Studies}

\section{A. INTRODUCTION}

The ultraviolet continua of the excited rare gas systems have been known since the 1930's. ${ }^{36}$ These continuum emissions have also been examined more recently ${ }^{37}$ and have found application as convenient light sources covering essentially the entire vacuum ultraviolet for wavelengths longer than approximately $1000 \AA$. These continuous radiations originate from bound-free transitions of the molecular dimers (e.g., $\mathrm{Ar}_{2}, \mathrm{Kr}_{2}$, or $\mathrm{Xe}_{2}$ ). In typical cases of interest the excited state is characterized by a potential function that has a substantial potential minimum at the equilibrium internuclear separation and that supports several vibrational levels. In contrast, the ground state interatomic potential is generally strongly reput sive although it does exhibit a relatively shallow van der Waals minimum at internuclear distances substantially greater than the equilibrium separation of the excited state. It is characteristic that the triplet state lies somewhat below the singlet level due to exchange. In the literature the data on $\mathrm{He}_{2}$ and $\mathrm{Xe}_{2}$ are the most complete although large uncertainties nevertheless do exist in the precise location of many of the potential curves even in these cases. ${ }^{38,} 39$ The complex nature of these molecular systems is immediately recognized by the fact that oyer 60 clectronic states are currently known for even the simplest syst'm, $\mathrm{He}_{2}^{*}$.

To a very good approximation, these excited molecular dimers can be reganded as Rydberg states. In this view the molecular configurations are then composed of two parts; the molecular ion core (e.g. Het) and a single excited electron orbiting largely outside of the region occupied by the core. One then has a relatively simple Rydberg serits ${ }^{40}$ characteristic of that core state. This model predicts that the equilibrium internuclcar separation, the molecular tibrational frequency, and the molecular moment of inertia are deternined largely by the corresponding properties of the molecular ionic core. The potential curves given by Ginter and Battino ${ }^{39}$ for $\mathrm{He}_{2}^{*}$ quite strikingly indicate the valjdity of this approximate model. It would appear that this feature introduces a very desirable simplification into an otherwise rather complicated situation, since it should be possible to formulate meaningful estimates of matrix cluments on the basis of an essentialiy one slectron picture.
An interesting property of these systems is that continuous bands are observed with very similar characteristics in all three phases, gas, liquid, and solid. For example, the argon continuum centered near 1300 A resulting from excitation by Americium aparticles exhibits essentially identical lineshapes (within $\sim 10 \%$ ) for all three phases. 41 On the basis of this observation, one is strongly motivated to conclude that the excited species in all cases very closely resemble the gaseous dimer which is only negligibly influenced by the weak van der Waals forces of the surrounding neighbors in the liquid and solid. This immediately suggusts the possibility that these systems may be successfully operated at liquid or solid density. In this connection it is useful to note that at an active density of $2 \times 10^{19} \mathrm{~cm}^{-3}$ ( 1 atmosphere) and assuming roughly one Rydberg per systen the stored energy density corresponds to nearly $\mathbf{5 0}$ $\mathrm{J} / \mathrm{l}$.

Recent Soviet experiments with xenon excited by high energy electrons reported by N.G. Basov, et. al. ${ }^{42}$ have demonstrated the feasibility of coherent generdtion with these systems at liquid density. The Russian workers have also indicated in private communication that they have obtained similar results in high pressure xenon gas. It is anticipated that oscillation may be obtained from the other rare gases in a similar manner.

The basic purpose of this work is to provide a more detailed experimental analysis of the rare gas systems excited by pulsed, high current, relativistic electron beams. In order to achieve this goal we have begun experiments that enable us to measure the time resolved spontaneous emission spectrum of the material excited by the electron bcam. In this way we have obtained data concerning the kinetic steps and time scales associated with these systems. Herein we present some preliminary data and analysis relating to our experiments examining $A r, K r$, and $X e$ at pressures from $0-5 \mathrm{~atm}$.

\section{B. EXPERIMENTAL MODIFICATION FOR RARE GAS WORK}

Previous sections detail the physical and electrical arrangement used to study the gain properties of the $\mathrm{NF}_{3} / \mathrm{H}_{2}$ system, Figs. 5-27. In this section, the changes to the chemical apparatus necessary to study noble gas processes will be examined. 
The electrical interconnection scheme as outlined by Fig. 25 was left unchanged. Mechanically, the following modifications proved necessary:

\section{The Reaction Vessel}

The Teflon amplifier vessel was replaced with industrial glass pipe carefully cleaned with ethyl alcohol beforc pump-out. As discussed earlier the teflon, while chemically inert, proved to be porous and therefore made hard vacuums $<10^{-7}$ Torr unattainable. Glass pipe permitted base pressures of $\leqslant 5 \times 10^{-8}$ Torr and allowed safe operating conditions up to pressures of $10 \mathrm{~atm}$. (Pressure capability of the glass pipe was verified by hydrostatic test of a sample unit.)

Prior to installation of the glass section, all components exposed to chemical detonation products were thoroughly cleaned and vacuum baked at temperatures in excess of $200^{\circ} \mathrm{C}$ for about $48 \mathrm{hr}$.

\section{Output Optics and Line of Sight Path}

The transitions of interest in the rare gas systems all lie in the vacuum ultraviolet region of the spectrum. It was therefore necessary to replace the sapphire output windows (useful at $3 \mu$ for $H-F$ ) with $L i F$ to provide useful transmission down to wavelengths $\geqslant 1075 \mathrm{~A}$. Further, the light path connecting the output window to the vacuum spectrometer (SPEX model 1500 DP with a grating blazed at $1500 \AA$ ) required evacuation. Both the line-or-sight pipe and the spectrometer were evacuated with a single turbomolecular pump (450 I/sec) to a base pressure $\lesssim 10^{-6}$ Tort.

One $90^{\circ}$ tum was required to direct the output beam from along the electron beam path to the screen room, see Fig. 57. It was necessary to install a magnesiun fjowride overcoated, aluminum mirror housed

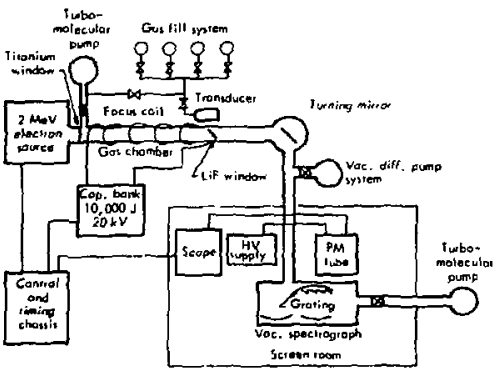

Fig. 51. Diagram of syutem interconnections. in a vacuum chambet in an attempt to minimize $a b$ sorption and scattering losses. At the time this experiment was performed no facilities existed at LLL to verify reflectivity at wavelengths shorter than $2000 \AA$, hence no absolute intensity calculations were possible. Fortunately, thete was always sufficient signal/noise available for adequate data coltection and interpretation.

\section{Gas Handling Systems}

The various gases studied ( $\mathrm{Xe}, \mathrm{Kr}, \mathrm{Ar}$ ) were Matheison research grade, (99,995\% pure). Introduction of the gases was accomplished via the all metal, prebaked fill line used in the chemical phase of this work. Pressures never exceeded 150 psia because of the pressure limitation of certain small toggle valves appearing in the system. After the injtial bakeout of the system, the gas under study was flowed into the system and let stand for about $24 \mathrm{hr}$ at 1 atm (absolute). This procedure forced absorption of the gas into system components that may not have been reached by the cleaning procedures discussed above. This technique helped assure the general contamination-free state of the system. As further insurance, several dozen firings of the electron beam into the "clean" system were performed to scour the surfaces with scattered electrons. Data taking began only after the cleanup procedure was complete.

\section{Instrumentation}

The primary detection system was composed of the SPEX (1500 DP) monochromator/spectrometer operated in the monochromator mode. The detection device was an Amperex, 56 TUVP photomultiplier (gain $\simeq 10^{8}$ ) viewing a sodium salicylate uv converter. The converter formed the spectrometer output window and vacuum/atmosphere interface. Data were displayed via oscilloscope pictures (Tektronix 7904, 2 nsec risetime) and subsequently digitized. A computer routine develored by E.P. Sims ${ }^{43}$ produced the time resolved spectro appearing in Sec. V-B, below.

Becalse of the extreme sensitivity of the photomultiplier to ionizing radiation, extensive lead shielding of both tube and the spectrometer were requited. The tube was housed in a lead "pig" providing 2.5 in. of lead shielding from all directions save for a $3 / 8$ in. dia opening through which the sodium salicylate flourescence could be monitored. The entire spectrometer was enclosed in I/4 in. lead sheet.

Substantial $x$-radiation was to be expected in the case of the heavier rare gases where the fraction of 
primary loss appearing as radiation approaches $10 \%$ (Xe) ${ }^{20}$

Additional lead shielding was provided in any path directly connecting the radiation source with the phototube or ascilloscope. The lead bricks were placed both besidc the entrance region and reaction vessel of the amplifier and directly along the screen room walls. The average thickness of this shielding was about $25 \mathrm{~cm}$. Total source-to-phototube shielding thick ness including "pig" thickness $\simeq 31 \mathrm{~cm}$.

Recall that the peak $x$-ray energy available via the bremsstrahlung process was $2.5 \mathrm{MeV}$. The total attenuation coefficient for lead at this energy is $\simeq 0.4 \mathrm{~cm}^{-1} .4$

The at tenuation expected is therefore:

$$
\frac{1}{I_{0}}=\mathrm{e}^{-(0.4)(31)}=4 \times 10^{-6}
$$

On the other hand, the ty pical electron gain of this tube for the bias voltage used was $10^{8}$. Therefore about $\mathbf{4 0 0}$ secondary electrons for each primary are to be expected. The noise signals were never reduced to unobservable levels but in all cases the signal/ photon noise $\gtrsim 50 / 1$.

\section{Alignment Procedurc}

To assure proper alignment, the entrance region sapphire window and beryllium turning mirror used in the chemical study were left in place. A He-Ne alignment laser was placed in the position that the spiral pin laser formerly occupied. The beam was made to shine through the entire system including spectrometer. The spot appearing at the output of the spectrometer was easily bright enough to allow precise positioning of the photomultiplier.

\section{Pressure Diaphragm}

For the lightweight noble gases (Ar, $\mathrm{Kr}, \mathrm{He}, \mathrm{Ne}$ ) operation at 10 atm could be achieved with a 5 mil thick titanium diaphragm separating the pressure vessel from the electron source. With $\mathrm{Xe}$, however, the diaphragm was violently deformed after one firing. The deformation was due to the high absorption coefficient of Xe coupled with its high mass (inhibited heat conduction). The high local deposition adjacent to the diaphragm produced sufficient heating and peak pressure to destroy the $5 \mathrm{mil}$ diaphragm on the second exposure. Ten mils was the minimum thick ness that permitted long life $\simeq 100$ shots at $10 \mathrm{~atm}$ absolute. This diaphragm "disled" out after the first firing but no further deformation occurred. When failure did finally result, an examination revealed that work hardening in the region of the most intense electron deposition accounted for the thin cracks that appeared.

\section{Results of Rare Gas Experiments}

\section{A. Ar/Xe ENERGY TRANSFER}

Substantial investigation 2,45 has recently been undertaken into rapid noble gas molecule-atom energy exchange as represented by the following reaction:

$$
\operatorname{Ar}_{2}^{*}\left({ }^{1} \Sigma_{u}^{+}\right)+X_{\iota}\left({ }^{1} S_{o}\right) \rightarrow \operatorname{Ar}\left({ }^{1} S_{o}\right)+\operatorname{Ar}\left({ }^{1} S_{o}\right)+X e\left({ }^{1} P_{1}\right)
$$

The referenced work was undertaken under conditions of relatively weak excitation (with high repetition rate) in order to study the time integrated emission spectra of the mixed systems. The signature of reaction (76) is the disappearance of the normal molecular continuum associated with $\mathrm{Ar}_{2}^{*} \rightarrow \mathrm{Ar}+\mathrm{Ar}+\mathrm{hw}$ when relatively small concentrations of impurity $(\mathrm{Xe})$ are added. The noteworthy feature of the work to be described below is the extremely high excitation rate availablc with the electron beam source at our disposal. (Again, the constant energy deposition/gram available with high energy electrons permitted homogeneous excitation of substantial gas volumes up to the pressure Jimits of the apparatus.)

The excitation power available is approximated by

$$
E / t_{p} \simeq 375 /\left(80 \times 10^{-9}\right) \simeq 5 \mathrm{GW}
$$

where energy loss due to bremsstrahlung is considered unimportant in the $\mathrm{Ar}_{2}^{*}$ formation process.

Figurc 58 shows the pure argon emission vs time at $1300 \AA$ (850 Torr). 


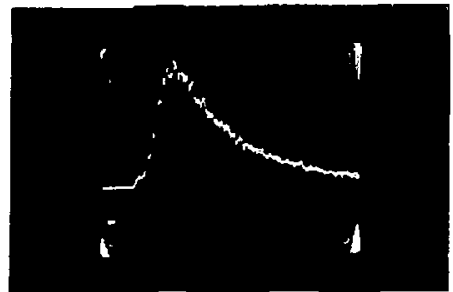

Fjg. 58. Argon emission @ I300A, 850 Tort (12 kG magnetic fjeld). Horizontal scale: $100 \mathrm{nsec} / \mathrm{cm}$. Vertical scale: $400 \mathrm{mV} / \mathrm{crn}$. $\mathrm{S} / \mathrm{N} \geq \mathrm{BO} / \mathrm{l}$, where the noise $(\mathrm{N})$ is de. fined as the residual signal with the detector blinded.

This emission, centered at about $1300 \AA$ for $\mathrm{Ar}_{2}^{*}$, $1500 \AA$ for $\mathrm{Kr}_{2}^{*}$, and $1700 \AA$ for $\mathrm{Xe}_{2}^{*}$, has been explained by Mulliken. ${ }^{40}$ Further discussion appears in the next section.

The uddition of $X_{e}$ ( 30 Torr) to the system while keeping the total number density fixed (850 Torr total $\mathrm{A} t+\mathrm{Xe}$ ) produces the result shown in Fig. 59. Vertical, horizontal sensitivities and monochromator settings are identical in Figs. 58 and 59.

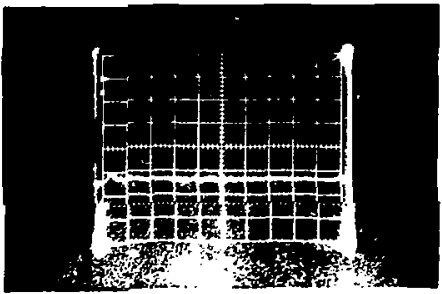

Fig. 59. Ar/ Xe mixture (a: $1300 \AA$, with 820 Torr argon +30 Torr xenon ( $12 \mathrm{kG}$ magnetic field). Compare with Fig, 58. Horizontal scale: $100 \mathrm{nsec} / \mathrm{cm}$. Vertical scale: $200 \mathrm{mV} / \mathrm{cm} . \mathrm{S} / \mathrm{N} \geq 40 / 1$.

The threshold for near total extinguishment of the $\mathrm{Ar}_{2}^{*}$ continulum occurs at xenon concentration of 2000 pprii, a substantially greater impurity level than previously reported. ${ }^{2}$

In the next series of experiments, the appearance of Xe* emission via the reaction (77) was examined

$$
\mathrm{Xe}^{*}+\mathrm{Xe}^{*}\left({ }^{1} \mathrm{~S}_{\mathrm{o}}\right)+\operatorname{Ar}\left({ }^{1} \mathrm{~S}_{\mathrm{o}}\right) \rightarrow \mathrm{Xe}_{2}^{*}+\operatorname{Ar}\left({ }^{1} \mathrm{~S}_{\mathrm{o}}\right)
$$

With the monochromator tuned to $1700 \mathrm{~A} \pm 5 \mathrm{~A}$ (still preserving the $\mathrm{Xc} / \mathrm{Ar}$ concentrations at $30 / 820$ ) one obseryes the gradual appearance of the characteristic $\mathrm{Xe}_{2}^{*}$ continuum emission, see Fig. 60.

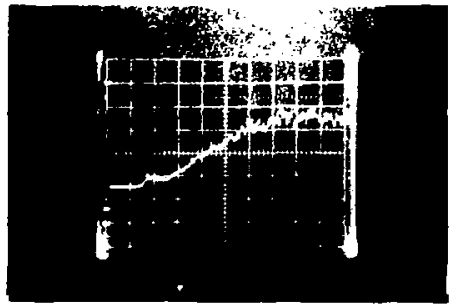

Fig. 60. $X_{2}^{*}$ emission (1700A) in Ar/Xe mixture, 820 Tort argon + 30 Torr xenon ( 12 kG magnetic field). Horizontal scale: $100 \mathrm{nsec} / \mathrm{cm}$. Vertical scale: $200 \mathrm{mV} / \mathrm{cm}$.

Figure 61 is a repeat of the exposure teading to Fig. 60 but at a sweep speed of $500 \mathrm{nsec} / \mathrm{cm}$ to show the ompletc time development of the $1700 \mathrm{~A}$ emission.

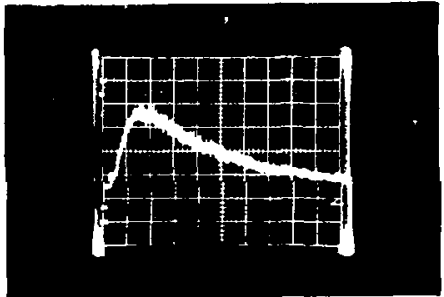

Fig. 61. $\mathrm{Xe}_{2}^{*}$ emission (1700A) in $\mathrm{Ar} / \mathrm{Xe}$ mixture but with compressed horizontal scale, $500 \mathrm{rsec} / \mathrm{cm}$. Cf. Fig. 60.

Trese results are completely consistent with conclusions of Gedanken, et. al. ${ }^{2}$ except in the matter of the xenon impurity concentration necessary to accomplish complete elimination of $\mathrm{Ar}_{2}^{*}$ emission.

A comparison of Figs. 58 and 60 suggests strongly that the $\mathrm{Xe}_{2}^{*}$ emission may be the time integral of the $\mathrm{Ar}_{2}^{*}$ emission shown in Fig. 58. This is consistent with the proposition of very efficient transfer from 
$\operatorname{Ar}_{2}^{*} \rightarrow \operatorname{Xe}^{*}\left({ }^{1} P_{1}\right)$. The $\left({ }^{1} P_{1}\right)$ is then expected ${ }^{46,47}$ to relax to ${ }^{3} \mathbf{P}_{7}$ via collisional cascade. It is from ${ }^{3} \mathbf{P}_{\mathbf{2}}$ that $\mathrm{Xe}_{2}^{*}$ is most readily formed. It was not possible at this writing to conclude how precisely the "integral" assumption was followed. Additional work ${ }^{\mathbf{4 B}}$ involving absolute intensity measurements should shed more light on this point. It is interesting to postulate the possibility of complete inversion of the $\mathrm{Xe}\left({ }^{{ }} \mathrm{P}_{1}\right) \rightarrow \mathrm{Xe}\left({ }^{1} \mathrm{~S}_{\mathrm{O}}\right)$ transition by this process. $\mathrm{A}$ conservative approximation would be to find that $\mathrm{Ar}_{2}^{*}$ concentration for which the rate of formation of $\mathrm{Xe}\left({ }^{{ }} \mathrm{P}_{1}\right)$ by the reaction

$$
\mathrm{Ar}_{2}^{*}+\mathrm{Xe} \rightarrow \mathrm{Ar}+\mathrm{Ar}+\mathrm{Xe}_{\mathrm{e}}\left({ }^{1} \mathrm{P}_{1}\right)
$$

exceeds the $\mathrm{Xe}\left({ }^{3} \mathrm{P}_{1}\right) \rightarrow \mathrm{Xe}\left({ }^{1} \mathrm{~S}_{\mathrm{o}}\right)+\gamma$ emission rate (untrapped).

The untrapped transition rate for this process ${ }^{2}$ $\left(10^{-4}\right.$ Torr Xe $)$ is $5 \times 10^{8} / \mathrm{sec}$.

The cross section for energy transfer from $\mathrm{Ar}_{2}^{*}$ to $\mathrm{Xe}^{*}\left({ }^{1} \mathrm{P}_{1}\right)$ is given ${ }^{2}$ as $2.9 \times 10^{-13} \mathrm{~cm}^{2}$

$$
\left.\frac{1}{\bar{t}}\right|_{\mathrm{Ar}_{2}^{*}-\mathrm{Xe}^{*}}=\mathrm{N}_{\mathrm{Ar}_{2}^{*}} \sigma \overline{\mathrm{V}}=\mathrm{N}\left(2.9 \times 10^{-13}\right) \frac{1}{8} \times 10^{5}
$$

Thus, for the collisional rate [Eq. (78)] to exceed the $\mathrm{Xe}\left({ }^{3} \mathrm{P}_{1}\right)$ radiative rate,

$$
3.625 \times 10^{-9} \mathrm{~N}>5.0 \times 10^{8} \text {. }
$$

This implies

$$
\mathrm{N}>1.5 \times 10^{17} / \mathrm{cm}^{3},
$$

where $\mathrm{N}_{\mathrm{Ar}_{2}^{*}}=\mathrm{Ar}_{2}^{*}$ concentration $\left(\mathrm{cm}^{-3}\right)$, $\sigma=$ energy transfer cross section for $\mathrm{Ar}_{2}^{*} \rightarrow \mathrm{Xe}^{*}$ $10^{-16} \mathrm{~cm}^{2}$.

$\overline{\mathrm{V}}=$ relative approach speeds $\mathrm{Ar}_{2}^{*}, \mathrm{Xe} \mathrm{cm} / \mathrm{sec}$, or about 4 Torr $\mathrm{Ar}_{2}^{*}$. This concentration should be easily achievable with the apparatus operated at about 10 atm of Ar.

The required $\mathrm{Ar}_{2}^{*}$ concentration as derived above is clearly conservative because $\mathrm{Xe}\left({ }^{1} \mathrm{P}_{1} \rightarrow{ }^{1} \mathrm{~S}_{\mathrm{O}}\right)$ is strongly allowed and radiation trapping accounts for an increase of effective lifetime of four orders of magnilude to $10 \mu \mathrm{sec}$ at Xe pressures of $0.1 \mathrm{Torr}^{2}$

The existence of complete inversion should be readily apparent experimentally. One should observe increasingly immediate and more intense emission as the concentration of absort "rs approaches zero. This kind of study is presently umelerway. 48

\section{B. Xe, $\mathrm{Kr}, \mathrm{Ar}$ STUdIES}

In this series of experiments, samples of pure Ar. $\mathrm{Xe}$, and $\mathrm{Kr}$ were studied over a wide range of pressures. The data for this phase consisted of a series of intensity us time traces taken with $5.0 \AA$ resolution in $50 \AA$ steps fron $1100 \AA$ to $2500 \mathrm{~A}$. A set of traces for each pressure of interest was taken. The photographs were then converted to digital data and, with the aid of a computing machine, time resolved spectra were obtained. It was anticipated that with this data time dependent atomic and molecular properties could be appraised. Structural strength considerations limited test zas pressure to $\leq \mathbf{8 5 0}$ Torr. More recent work has permitted examination of molecular behavior up to $10 \mathrm{~atm}^{.49}$

\section{Argon}

The time resolved spectra of argon at 850 Torr are illustrated in Figs. 62 and 63 . Figure 62 gives the spectra for times of $50,75,100,125$, and 150 nsec after $t=0(t=0$ is defined as the time at which the voltage across the field emitting diode reached $50 \%$ of its peak value). Figure 63 similarly represents argon at 850 Torr but at later times $(150,200,250$ 300 , and $400 \mathrm{nsec})$.

The main spectral feature of Fig. 62 centered about $1300 \AA$ is attributable to the principle continuum generated by the vibrationally relaxed transition ${ }^{1} \Sigma_{\mathrm{u}}^{+} \rightarrow{ }^{1} \Sigma_{\mathrm{g}}^{+}$. Additional prominent features of this spectrum are the wide "continuum" observed in the range $1800 \AA<\lambda<2400 \AA$, and the marked time dependence of the emission (compare Figs. 62 and 63). Long wavelength emissions have been observed under other experimental conditions. 50,51 It has been suggested by Hurst, et. al. 52 that such emissions are explained by recombination radiation "involving the formation of argon excimers with binding energies of about $4.0 \mathrm{eV}$ ". The information available on $\mathrm{He}^{38}$ and $\mathrm{Xe}^{39}$ and the expected decreased binding energy one expects in the progression $\mathrm{He}_{2}^{*} \rightarrow \mathrm{Ne}_{2}^{*} \rightarrow \cdots \rightarrow \mathrm{Xe}_{2}^{*}$ suggests that a value of $4 \mathrm{eV}$ is excessive. These long wavelength enissions will be considered more fully in Sec. VI below. 


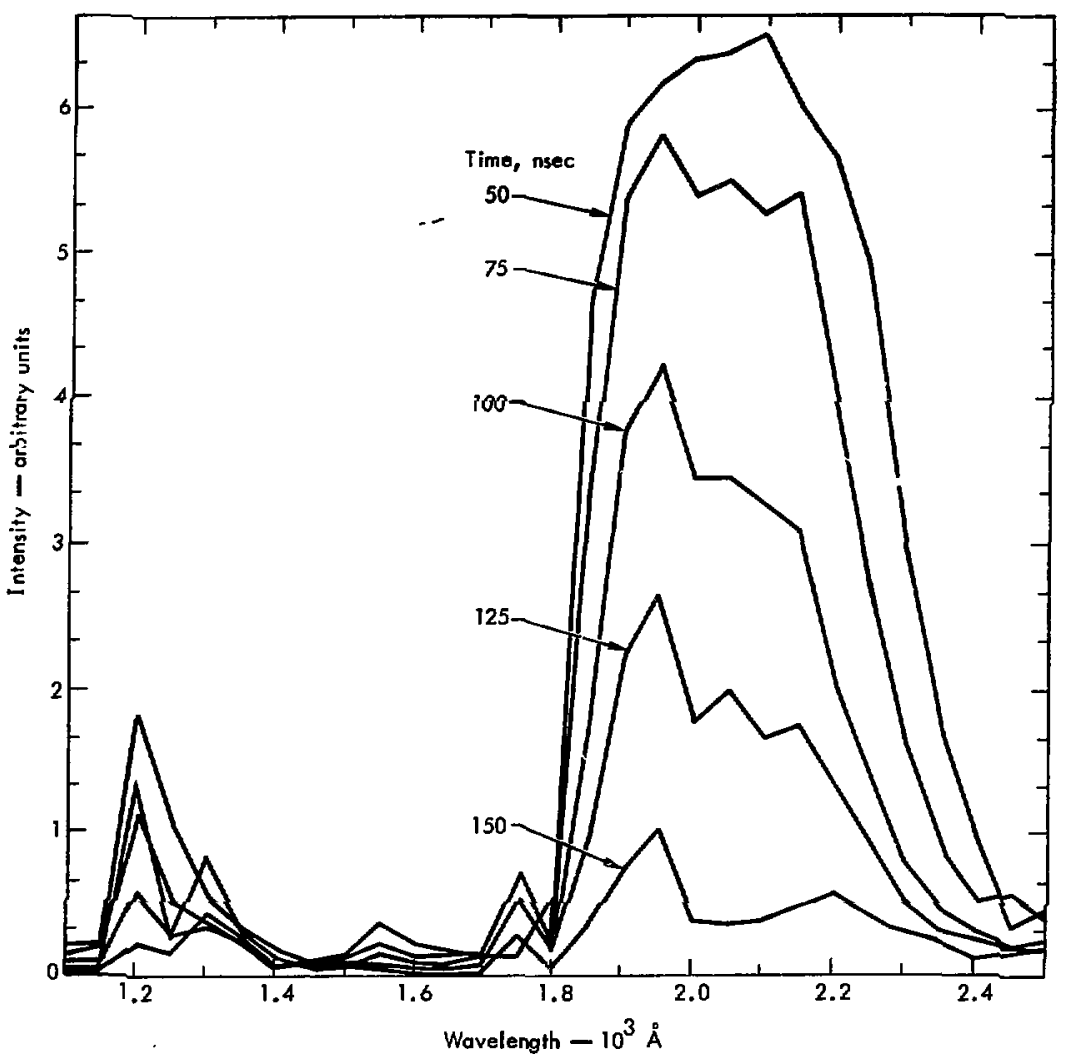

Fig. 62. Time resolved spectra for pure argon; 850 Torr, $t \leq 150$ nsec, $(t=0$ taken as the $50 \%$ point on the rise of the voltage across the field emitting diode). Magnetic field $12 \mathrm{kG}$.

\section{Krypton}

As in the case of argon, emission spectra at 850 Torr for two time sequences are presented (see Figs. 64 and 65 ).

The spectral prominence at $1500 \mathrm{~A}$ is attributed to ${ }^{3} \Sigma_{y}^{+},{ }^{1} \Sigma_{\nu}^{+} \rightarrow{ }^{1} \Sigma_{g}$ transitions. The resolution of this data is inadequate to clearly distinguish between tirem. As in the case of argon, krypton exhibits another spectral prominence in the $2200 \AA$ region. Figure 64 reveals that the $2200 \AA$ feuture is broad at early times and subsequently narrows. At the same time, the $\mathrm{Kr}_{2}^{*}\left({ }^{1} \Sigma_{\mathrm{u}}^{+},{ }^{3} \Sigma_{\mathrm{u}}^{+}\right)$emission centered at 1500A appears to exhibit a reciprocal behavior. This strongly suggests an energy feed-in from the states responsible for the $2200 \AA$ behavior. This radjative cascade has not been attributed unambiguously to the ground state core of $\mathrm{Kr}_{2}^{*}$. This matter is discussed further in Sec. VI. 


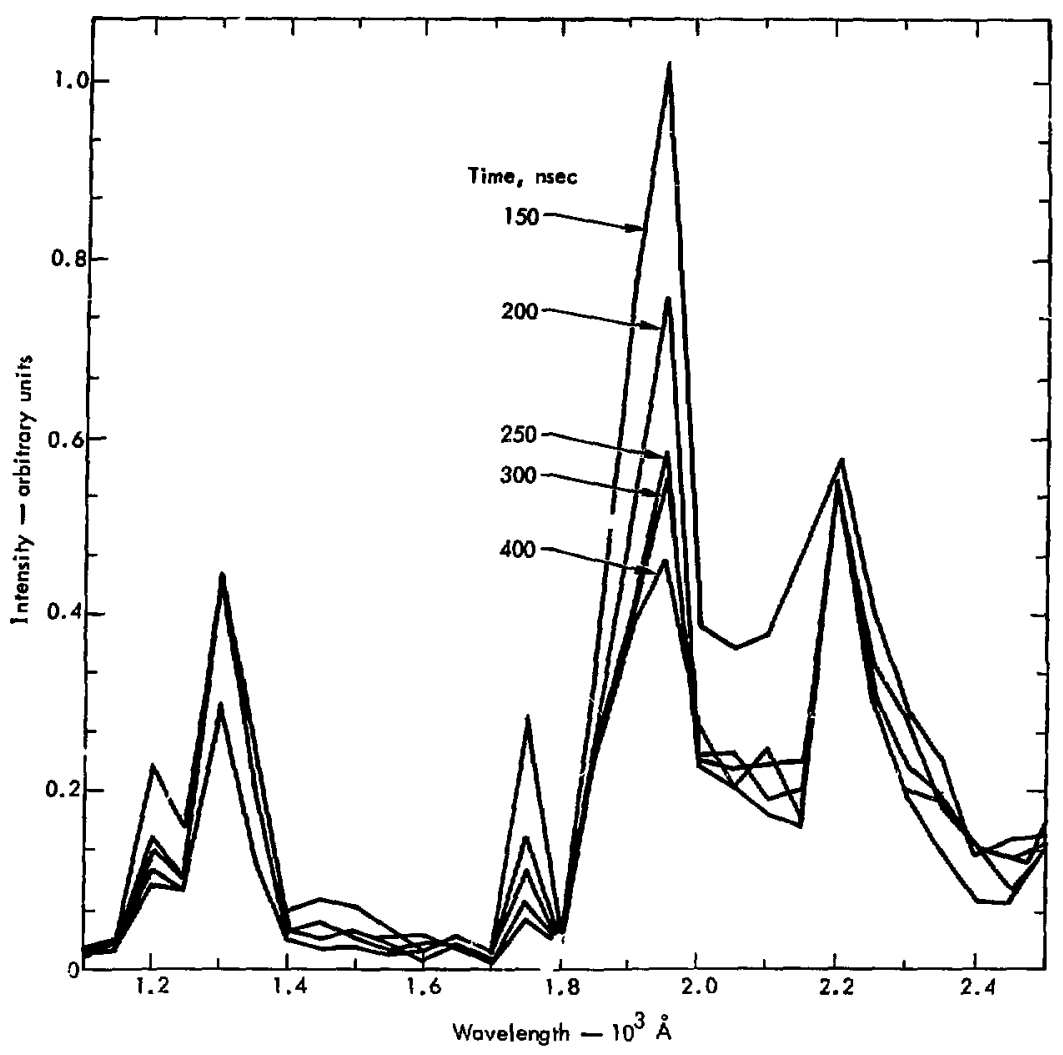

Fig. 63. Tine resolved spectra for pure argon; 850 Torr, $150 \leq t \leq 400$ nsec-

$\underline{\text { Xenon }}$

Experiments were conducted on pure xenon under conditions identical to the argon and krypton studies. Figure 66 illustrates a typical result for the spectrum observec in xenon at 850 Torr for times of 50, 75, 100,125 , and 150 nsec after the initiation of the electron beam. Under these circumstances the peak emission is located somewhat longward of $1800 \mathrm{~A}$. In the spectral region from $1100 \AA$ to $2500 \AA$ essentially all of the observed radiation is confined to the interval between $1600 \AA$ and $2000 \AA$. On the basis of Mulliken's approximate curves, ${ }^{39}$ and to within the $50 \AA$ resolution of these measurements, it is possible to associate the peak $\sim 1850 \AA$ from the lowest vibrational levels of the ${ }^{3} \Sigma_{u}^{+}$state undergoing a transition to the repulsive ${ }^{\mathbf{I}} \Sigma_{u}^{+}$state. Of course, since the $1 \Sigma_{u}^{+}$state is believed to be relatively close to the ${ }^{3} \Sigma_{u}^{+}$level, a col..ponent due to this state may also be present. However, the shape of the abserved spectrum in xenon has somewhat different properties 


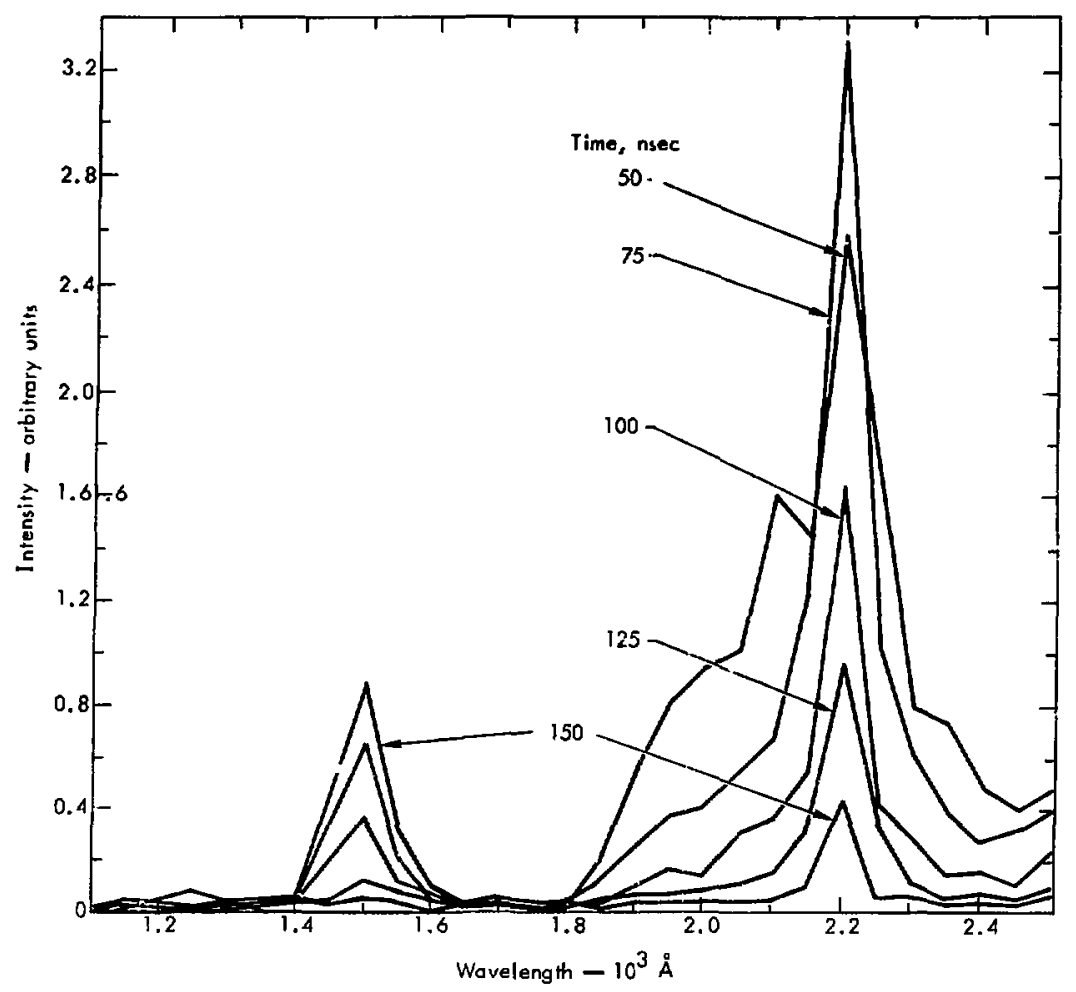

Fig. 64. Time resolved spectra for pure krypton; 850 Torr, $t \leq 150$ nsec.

at lower density (e.g., 400 Torr). Under these conditions a second peak is seen at $\sim 1700 \mathrm{~A}$. In this connection it is interesting to note that the laser oscillation recently observed ${ }^{53}$ in high pressure xenon gas occurred at the wavelength of $1716 \AA$ with an approxinnate width of $\sim 17 R$. This indicates that the transitions involved in the stimulated emission process $\sim 1716 \mathrm{~A}$ differ from those generating the peak of the spontaneous emission spectrum in our experiments at the pressure of 850 Torr. The wavelength difference suggests a differential of $\sim 4000 \mathrm{~cm}^{-1}$ in the degree of excitation of these two siets of states. Again. on the basis of Mulliken's potential curves, 39 the $1700 \AA$ component may be due to the high vibrational levels of the ${ }^{1} \Sigma_{u}^{+}$and ${ }^{3} \Sigma_{u}^{+}$states. ${ }^{54}$ This is consistent with the more marked anpearance of the $1700 \mathrm{~A}$ peak in spontanuous emission at lower pressure, since rapid vibrational relaxation at the higher pressures will have a tendency to broaden the band and cause the $1700 \AA$ peak to merge with the adjacent continum at ? 1850A. The shoulder visible at $1700 \mathrm{~A}$ in Fig. 66 is indicative of this type of betavior. 


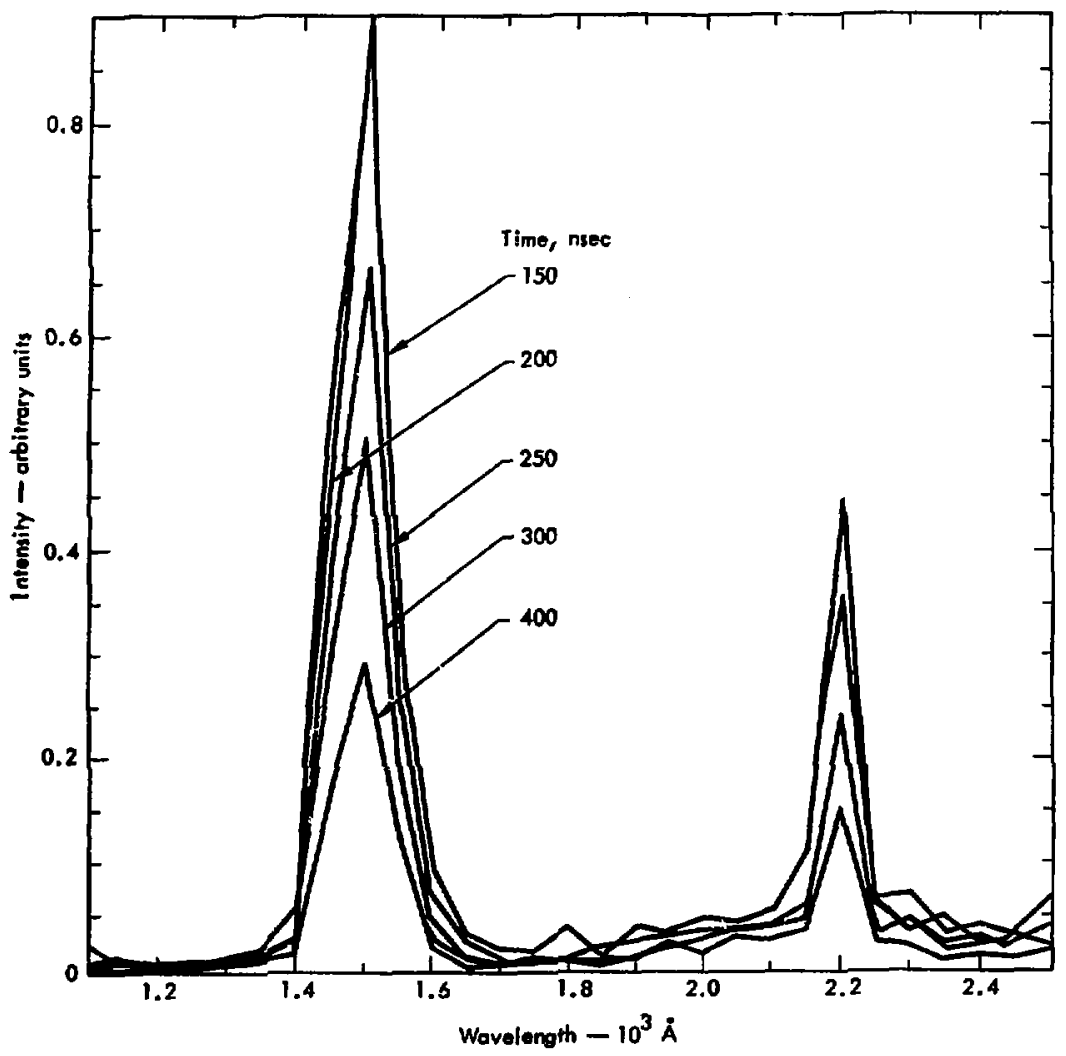

Fiz. 65. Time resolved specira for pure krypton; 850 Torr, $150 \leq t \leq 400$ nsec. 


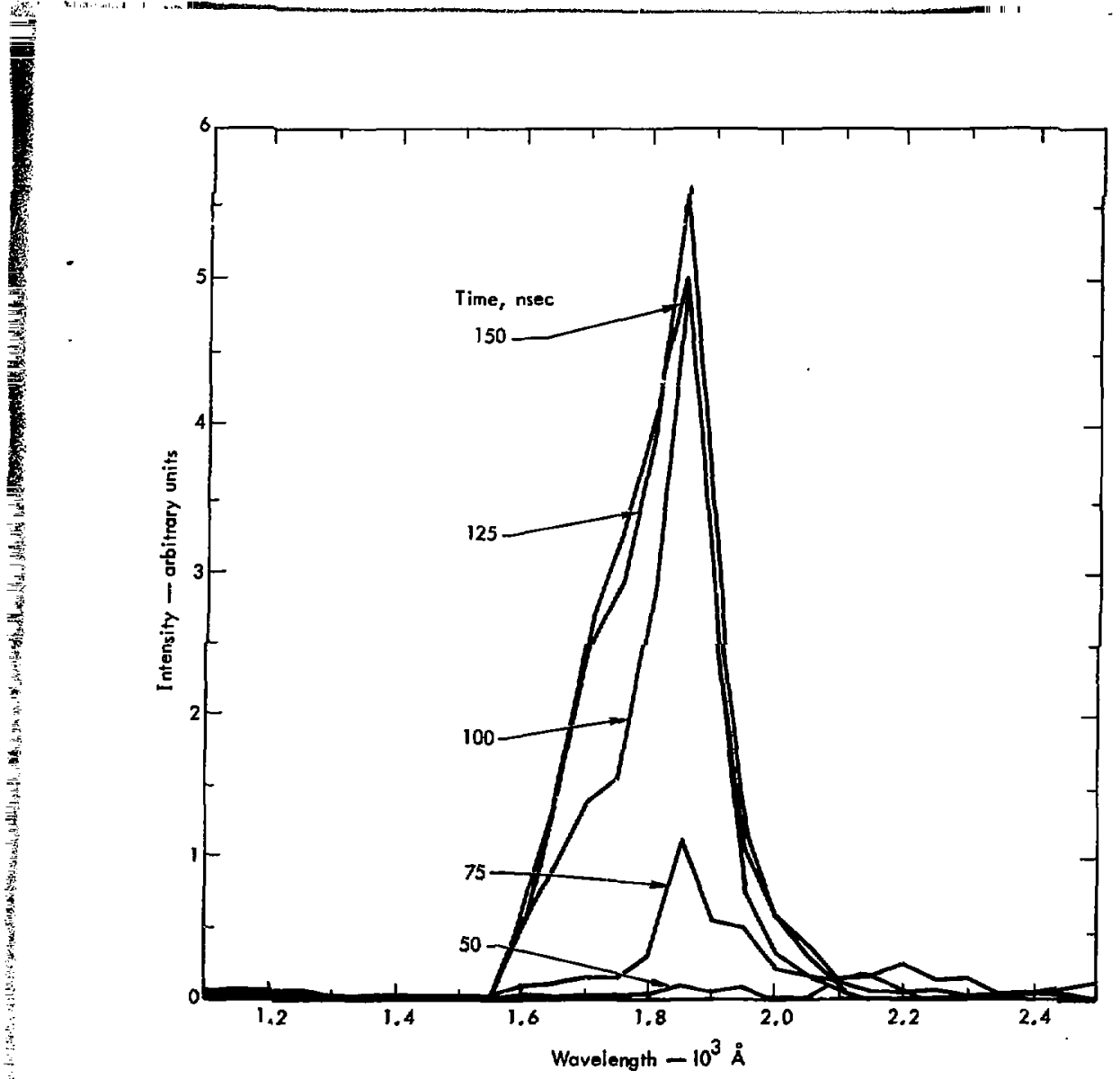

Fig. 66. Time resolved spectra for xenon gas; $B 50$ Tor, $t \leq 150$ necc. 


\section{Discussion of Rare Gas Studies}

\section{A. BASIC PROCESSES}

The following are the basic formation processes for noble gas molecular specics (taking Xe as an example).

$$
\begin{gathered}
\mathrm{e}^{-}+\mathrm{Xe} \rightarrow \mathrm{Xe}^{*}+\mathrm{e}^{-} \\
\mathrm{e}^{-}+\mathrm{Xe} \rightarrow \mathrm{Xe}^{+}+\mathrm{e}^{-}+\mathrm{e}^{-} \\
\mathrm{Xe}+\mathrm{Xe}+\mathrm{Xe} \rightarrow \mathrm{Xe} \mathrm{e}_{2}^{*}+\mathrm{Xe} \\
\mathrm{Xe}^{+}+\mathrm{Xe}+\mathrm{Xe} \rightarrow \mathrm{Xe}_{2}^{+}+\mathrm{Xe} \\
X e_{2}^{+}+\mathrm{e}^{-} \rightarrow \mathrm{Xe}^{*}+\mathrm{Xe}
\end{gathered}
$$

Reaction (80) represents the direct excitation by primary electrons and sufficiently energetic secondaries. Primary electrons can also lose energy via bremsstrahlung. For xenon, the worst case, these losses amount to $8 \%$ and will be ignored. 55 The tremsstrahlung spectrum associated with $2.2 \mathrm{meV}$ electrons is expected to contain only a trivial fraction of its energy in precisely the range to directly excite the gas of interest to a stute which readily combines to give the noble gas molecule. The result of these radiations is certainly to ionize and therefore to contribute to the production of $\mathrm{Xe}^{+}$as in ionizing Coulomb collisions, reaction (81). Reaction (84) is fast enough for the case of Helium. 56 For Helium, the lack of an appropriate crossing of a dissociative neutral state and the bound ionic molecular state is believed to explain this effect. 57

The vibrational wave function in the ground state is a gaussian, and the number of vibrational quanta increases as one approaches the correspondence limit of the "wave function" of a classical oscillator. Thus when a radiation from $1,3 \Sigma_{u}^{+} \rightarrow 1 \Sigma_{g}^{+}$occurs we know we have a transition from an harmonic oscillator upper state to an unbound (oscillatory wave function) lower state. Reactions (82) and ( 83 ) represent the three body collisional combinations to form $\mathrm{Xe}_{2}^{*}$ and $\mathrm{Xe}_{2}^{+}$ respectively. The result of reaction (83) is to prepare the way for the dissociative recombination of $\mathrm{Xe}_{2}^{+}+\mathrm{e} \rightarrow \mathrm{Xe}^{*}+\mathrm{Xe}$ (reaction (84)). Reaction (83) and $(84)$ will not be discussed further since their effect is to produce a slightly delayed $\mathrm{Xe}^{*}$ concentration, although presumably of much larger amount than from reaction (80).

Consider now the states of $\mathrm{Xe}^{*}$ which participate in the formation of $\mathrm{Xe}_{2}^{*}$ via reaction $(82)$ and the characteristics of these molecular states. The molecular continua emitted show that rare gas emissions are of two types.2. 40 The so-called first structured continuum of the heavier rare gases Ar, Kr, Xe starts at the lowest atomic resonance line and extends toward the red. The first continuum was explained by Mulliken ${ }^{40}$ as resulting from transitions of highly vibrationally excited species of the lowest two molecular bound states $\left(1 \Sigma_{u}^{+}\right.$and ${ }^{3} \Sigma_{u j}^{+}$with the triplet state lying lower than the singlet because of exchange). Once vibrational relaxation occurs, one observes what is commonly known as the second continuum, appreciably red shifted from the first. The magnitude of the red shift is comparable to the binding energy of the bound state. These features are summarized by Fig. 67.

Figure 68 illustrates the behavior of the emission from the bound upper state to the dissociative ground state as a function of the extent of vibrational excitation. Thus the 2200A continua mentioned in connection with Fig. 64 Sec. IV, which early exhibit broad spectral emission and subsequently nartow, can be thought of as representative of the approach to vibrational equilibrium. The extent to which the emission appears double-humped at early times represents the fendency for the system $\left(\mathrm{Xe}_{2}^{*}\right)$ to be "born" at highly excited vibrational levels.

The states contributing to the lowest molecular state formation are of the spectroscopic form $\mathrm{nP}^{5}(\mathrm{n}+1) 5$. The spin-orbit combination rules dictate that they should be in order of increasing energy ${ }^{3} \mathbf{P}_{2},{ }^{3} \mathbf{P}_{1},{ }^{3} \mathbf{P}_{0},{ }^{1} \mathbf{P}_{1}$. Note that the highest $\mathrm{J}$ value lies lowest in a given spin multiplet because of the greater than half-filled ( $\mathrm{nP}^{5}$ ) shell. ${ }^{18}$

All of these states are long lived at high pressure:

- ${ }^{1} P_{1},{ }^{3} P_{1} \rightarrow{ }^{1} S_{0}$ are dipole allowed resonance transitions, and as such are strongly trapped. ${ }^{46}$

- ${ }^{3} \mathbf{P}_{0} \rightarrow{ }^{1} S_{0}$ is strictly forbidden in any multiple approximation,

- ${ }^{3} \mathbf{P}_{2} \rightarrow{ }^{1} S_{0}$ is allowed yia magnetic quadrupole,

- ${ }^{3} \mathbf{P}_{0} \rightarrow{ }^{3} \mathbf{P}_{1},{ }^{3} \mathbf{P}_{2}$ is allowed via magretic dipole and electric quadrupole respectively.

Mulliken ${ }^{40}$ has shown that ${ }^{3} \mathbf{P}_{1},{ }^{3} \mathbf{P}_{2}$ form the molecular states of interest. $\left({ }^{1} \Sigma_{u}^{+},{ }^{3} \Sigma_{u}^{+}\right)$and that ${ }^{3} P_{0},{ }^{1} P_{1}$ lead to antibonding states. 


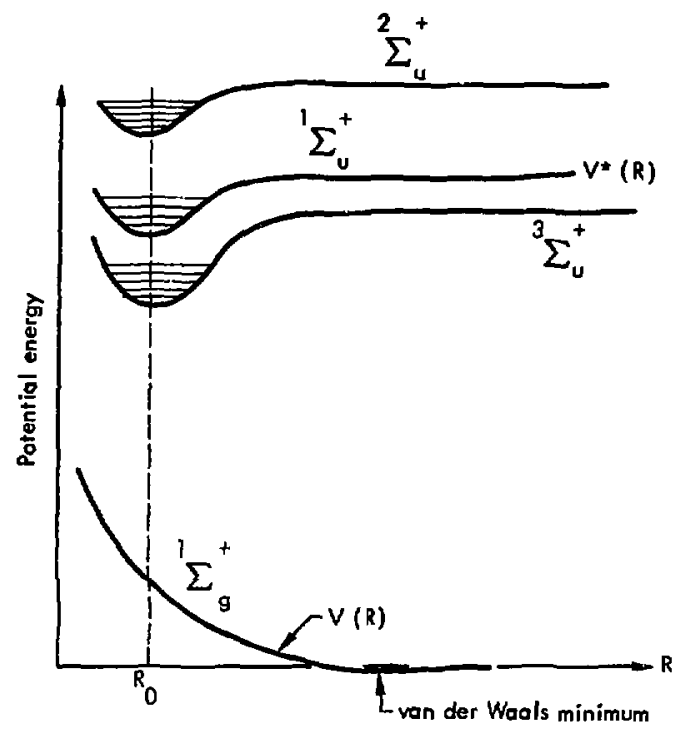

Fig. 67. Plot of potential energy vs internuciear separation.

Another feature of the molecular trunsition matrix elements is that one would expect to ses ${ }^{1} \Sigma_{u}^{+}$emission dominate over ${ }^{3} \Sigma_{u}^{+}$at large internuclear scpiration. The dipole transition amplitude vanishes at large separations betuusc

$$
\underbrace{{ }^{3} \mathrm{P}_{2}+{ }^{1} \mathrm{~S}_{0}}_{\begin{array}{c}
\text { weakly bound } \\
{ }^{3} \Sigma_{u}
\end{array}} \rightarrow \underbrace{{ }^{1} \mathrm{~S}_{0}+{ }^{1} \mathrm{~S}_{0}}_{\begin{array}{c}
\text { ground statc } \\
{ }^{\Sigma_{\Sigma_{g}}}
\end{array}}
$$

must proceed via ${ }^{3} \mathrm{P}_{2} \rightarrow{ }^{1} S_{0}$, which is forbidden. The same transition at large separation for ${ }^{1} \Sigma_{\mathrm{u}}^{+} \rightarrow \Sigma_{\mathrm{g}}^{+}$is more more strongly allowed because ${ }^{3} \mathbf{P}_{1}$ can proceed via dipole radiation emission.

Consider the following reactions

$$
\mathrm{Xe}_{2}^{*} \rightarrow \mathrm{Xe}+\mathrm{Xe}+\gamma
$$

$$
X \mathrm{u}+\mathrm{Xe}_{2}^{*}(\mathrm{v}) \rightarrow \mathrm{Xe}_{2}^{*}\left(\mathrm{v}^{\prime}\right)+\mathrm{Xe}_{\mathrm{e}}
$$

Equation (85) represents the spontaneous emission of $\mathrm{Xe}_{2}^{*}$ to the repulsive ground state. In the heavier molecules $\left(\mathrm{Kr}_{2}, \mathrm{Xe}_{2}\right)$ this reaction proceeds quite rapidly due to bucakdown of the spin selection rule. In the case of $\mathrm{Ar}_{2}$ one would expect a lower rate for ${ }^{3} \Sigma$ decay (spin rulc) than for ${ }^{1} \Sigma$ decay.

Equation (86) represents vibrational relaxation of the molecules. This reaction is expected to proceed rapidly vìa resonant atom exchange. Again hetium is anomalous, Calleur and Hedges ${ }^{58}$ report the $\mathrm{He}_{2}^{*}\left(a^{3} \Sigma_{u^{+}}^{+}, v=1\right)$ relaxation as "abnormally slow" because a long range repulsive potential keeps the wllision partners apart, thus inhibiting the atom exchange.

The Following equations:

$$
\begin{aligned}
& X_{c^{*}}^{* *}+X_{L} \rightarrow X_{L^{*}}+X_{\mathrm{c}} \\
& \mathrm{Xe}^{* *}+\mathrm{c}^{-} \rightarrow \mathrm{Xc}^{*}+\mathrm{c}^{-}
\end{aligned}
$$




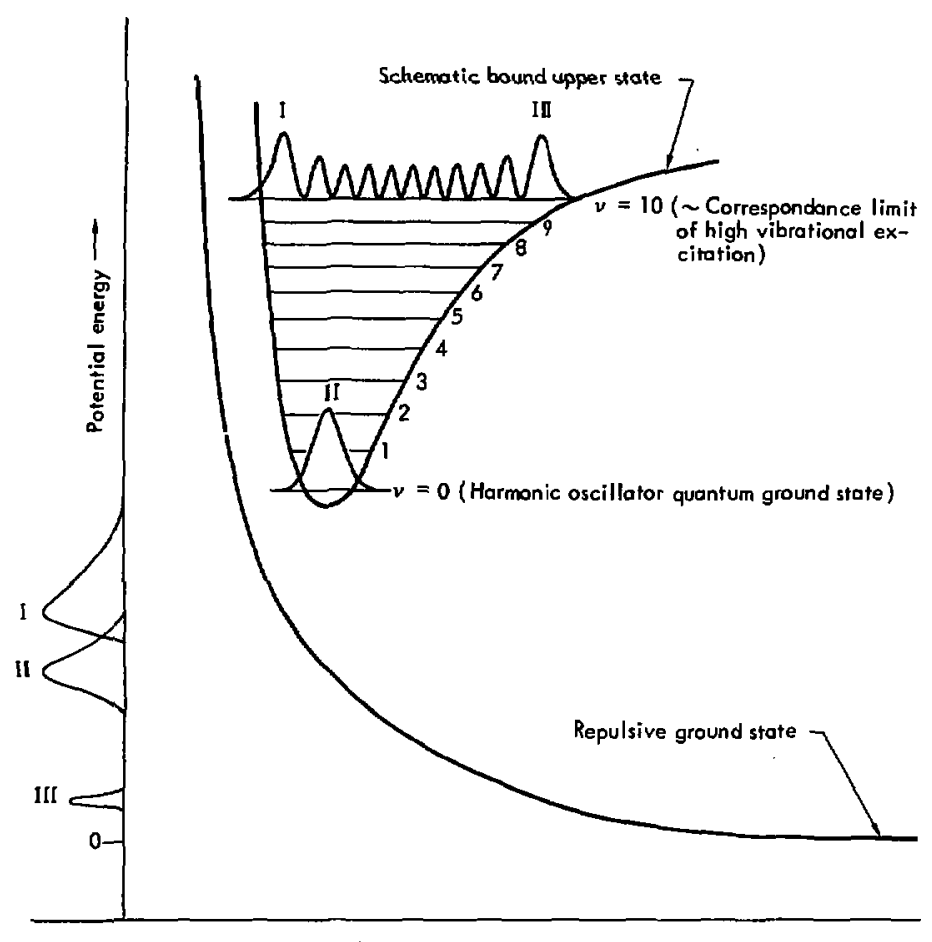

Internuclear separation -

Fig. 68. Infuence on emission spect rum of vibrational excitation of upper state.

represent excited atom relaxation via atomic and electronic processes respectively. For atomic collision partners the cross sections are of the order of $10^{-19}$ $\mathrm{cm}^{2}$ whereas Phelps ${ }^{59}$ has suggested that the relaxation or ${ }^{3} P_{1} \rightarrow{ }^{3} P_{2}$ via electron (spin exchange) collision proceeds with cross sections of $\sim 10^{-13} \mathrm{~cm}^{2}$.

The following equations:

$$
\begin{gathered}
\mathrm{Xe}_{2}^{*}+\mathrm{y} \rightarrow \mathrm{X} \mathrm{e}_{2}^{+}+\mathrm{e}^{-} \\
\mathrm{Xe}_{2}^{*}+\mathrm{Xe}_{2}^{*} \rightarrow \mathrm{Xe}_{2}^{+}+\mathrm{e}^{-}+\mathrm{Xe}+\mathrm{Xe}
\end{gathered}
$$

represent photoionization and Penning ionization. respectively. These two processes will operate to place an upper bound on the $\mathrm{Xe}_{2}^{*}$ concentration and therefore on the gain of the laser system.

Since the lowest excited molecular state is more than halfway up from the molecular ground state to the convergence of the Rydberg series at the ground molecular ionic state, ${ }^{60}$ the frequency of ${ }^{3} \Sigma_{u} \rightarrow{ }^{1} \Sigma_{g}$ is clearly high enough to ionize the ${ }^{3} \Sigma_{u}$ state. This then is counted as a stimulated loss process serving to dimirish the gain on the ${ }^{3} \Sigma_{\mathrm{u}} \rightarrow{ }^{1} \Sigma_{\mathrm{g}}$ transition. 
The Perning process Eq. (90) is undesirable because it removes two excited xenon molecules from action and therefore limits the achievable $\mathrm{Xe}_{2}^{*}$ concentration.

Givin the pumping time scale 80 nsec, we ask at what $\mathrm{Xe}_{2}^{*}$ concentration does the Penning rate become comparable to the pump rate? Unfortunately the cross section for $\mathrm{Xe}_{2}$ is not known but the following reaction cross section has been measured: 61

$$
\begin{gathered}
H e\left(2^{3} S_{1}\right)+H e\left(2^{3} S_{1}\right) \rightarrow H e^{+}\left(1^{2} S_{1 / 2}\right) \\
+H e\left(1^{1} S_{0}\right)+e^{-} \\
J=10^{-14}
\end{gathered}
$$

Assuming the 0 for reaction (90) is of the same order, we find that

$$
N \bar{V}_{\sigma} \approx l / T
$$

where $r=80$ nsec,

$\sigma=10^{-14} \mathrm{~cm}^{2}$

$\bar{V}=$ relative velocity $\simeq \frac{1}{8} \times 10^{5} \mathrm{~cm} / \mathrm{sec}$,

$\mathrm{N}=$ number of density of $\mathrm{Xe}_{2}^{*}$,

gives

$$
\mathrm{N} \simeq 6.25 \times 10^{16} / \mathrm{cm}^{3} .
$$

Assuming about $8.0 \mathrm{eV} / \mathrm{Xe}_{2}^{*}$ available; the upper bound on the energy storage becomes $110 \mathrm{~J} / \mathrm{l}$. This fundamental limitation clearly emphasizes the need for rapid excitation.

\section{B. SOURCE OF $2200 \AA$ CONTINUA}

At this writing the source of the long wavelength emission for the rare gases is not precisely known. It is tempting to attribute this emission to a state between the first excitcd molecular state and the series limit corresponding to the ionization of $\mathrm{Xe}_{2}^{*}$ to form $\mathrm{Xe}_{2}^{+}$ (ground state).

It is immediatcly seen that in the case of Krypton, the available energy between the $\mathrm{Kr}_{2}\left({ }^{3} \Sigma_{u}^{+}\right)$state and the lowest corresponding ionic state $\mathrm{Kr}_{2}^{+}+\mathrm{e}$ admits a minimum wijvelength in excess of $2200 \AA$. The same systematics occur in the cise of $\mathrm{Ar}_{2}^{*}$ and $\mathrm{Xe}_{2}^{*}$ (in the use of the $3000 \AA$ contisuum) as pointed out by Mulliken. 40 If one wishes to assign the origin of these spectral fuatures to the rare gas dimer states, an al: $\mathrm{r}$ nativc description is required. One possibility, although by no means a certainty, is a resort to the states of an excited core configuration ${ }^{62}$ as suggested by Mulljken in the example of xenon. ${ }^{39}$ It has not been possible to definitely establish the excited core proposition, but the systematic nature of the experimental observations provides a strong suggestion that the origins of these emissions are related in a regular fashion in the three materials under study.

\section{EXCITED ATOM DECAY PROCESSES}

This section will deal primarily with the atomici molecular process associated with the transfer of electronic energy between $\mathrm{Ar}_{2}^{*}$ and $\mathrm{Xe}\left({ }^{1} \mathrm{~S}_{0}\right)$ and the subsequent decay of $\mathrm{Xe}^{*}$ as represented by the following reactions:

$$
\begin{aligned}
& \mathrm{Ar}_{2}^{*}+\mathrm{Xe} \rightarrow \mathrm{Xe}^{*}+\mathrm{Ar}+\mathrm{Ar} \\
& \mathrm{Xe}^{*}+\mathrm{Xe}+\mathrm{Ar} \rightarrow \mathrm{Xe}_{2}^{*}+\mathrm{Ar}
\end{aligned}
$$

For laser applications it is desirable to achieve the highest inversion dcnsities possible. As noted earlier the lifetime of the heavy rare gas dimers is unacceptably low. This, coupled with the limitations of Penning collision, puts a fundamental upper bound on the inversions achievable.

This limitation can be circumvented if reaction (93) can be employed to store energy in the metastable $X e\left({ }^{3} P_{2}\right)$ state. Radiation can then be extracted via two-photon processes (e.g., stimulated anti-Stokes processes on $\mathrm{Xe}\left({ }^{3} \mathrm{P}_{2}\right)$ with $\mathrm{CO}_{2}$ light). This procedure permits high density energy storage at zero gain.

Two-photon processes gencrally obey the following class of differential equation:

$$
\frac{d I}{d \xi}=a I^{2}
$$

where I = intensity at amplifier output, $\alpha=$ effective gain for a two-photon process whose solution is of the form:

$$
I=\frac{I_{0}}{I-a I_{0} x}
$$

where $x=$ amplifier gain length.

Thus at low stimilating intensity $I=I_{0}$. As $\mathrm{aI}_{\mathrm{o}} \mathrm{x} \simeq 1$, I becomes large. This leads to subsequent complete removal of stored energy. 
Figure 61 suggests that the lifetime of the ${ }^{3} \mathrm{P}_{2}$ state of xenon is of the order of $2 \mu \mathrm{sec}$ and is considerably longer than that of the molecular system $\mathrm{Xe}_{2}^{*}$ [estimated to be of the order of $10 \mathrm{nsec}$ (dipole allowed)].

Reaction (93) has been observed ${ }^{2}$ to produce $X \mathrm{e}^{*}$ by two different nethods depending on the Xe pressure. At low pressure the $\mathbf{A r}_{2}^{*}$ continuum is known to cover the range $1150 \mathrm{~A}-1400 \mathrm{~A}$ which overlaps the $\mathrm{Xe}\left({ }^{1} \mathrm{P}_{1}\right)$ at $1296 \AA$; rapid transfer is therefore expected to occur and is evidenced by strong $1296 \AA$ emission.

At higher $X_{e}$ concentrations, one observes not ${ }^{1} P_{1}$ emission but rather ${ }^{3} P_{1}$ emission located at $1497 \AA$. Cedanken, et. al. ${ }^{2}$ have postulated a rapid ${ }^{1} \mathbf{P}_{1} \rightarrow{ }^{3} \mathbf{P}_{1}$ collapse via the process:

$\operatorname{Xe}\left({ }^{1} P_{1}\right)+\operatorname{Ar}\left({ }^{1} S_{0}\right)+84 \operatorname{cm}^{-1} \rightarrow \operatorname{Xe}\left({ }^{6} P^{3} Q_{1}\right)+\operatorname{Ar}\left({ }^{1} S_{0}\right)$

with subsequent radiative decay to

$$
X e\left({ }^{6} P^{3} D_{1}\right) \rightarrow X e\left({ }^{3} P_{1}\right) \text { or } X e\left({ }^{3} P_{2}\right)+\gamma
$$

(As discussed in Sec. VI-A, ${ }^{3} \mathrm{P}_{1} \rightarrow{ }^{3} \mathrm{P}_{2}$ proceeds very rapidly.)

Thus, one can control the $\mathrm{Xe}^{*}$ population by choosing a ratio of $\mathrm{Ar} / \mathrm{Xe} \gg 1$ thereby inhibiting $\mathrm{Xe}_{2}^{*}$ formation via reaction (94). Further, ${ }^{1} \mathbf{P}_{1}$ formation should be of no consequence because radiation trapping ${ }^{63}$ provides a very long effective lifetime $(10 \mu \mathrm{sec} @ 0.1$ Torr $\mathrm{Xe})$. Both experimentally, Fig. 61, and theoretically, the prospects for storage of energy in the metastable $\mathrm{Xe}\left({ }^{3} \mathrm{P}_{2}\right)$ appear to be excellent.

\section{LASER GAIN EXTIMATE FOR Xe}

The spontaneous lifetime of $\mathrm{Xe}_{2}^{*}$ is expected to be $\tau \simeq 20$ nsec (fajlure of L-S spin selection rule).

The gain of the transition is given by

$$
g=\frac{8 \pi^{2}}{h c}|\mu|^{2} \frac{v}{\Delta v} \Delta N
$$

or

$$
\sigma_{\operatorname{gain}}=\frac{8 \pi^{2}}{h c}|\mu|^{2} \frac{p}{\Delta v}
$$

$$
|\mu|^{2}=\frac{h \lambda^{3}}{\left(\tau_{\text {spont }}\right) 32 \pi^{3}}
$$

Combining Eqs. (98) and (99) gives us

$$
a_{\text {gain }}=g / N=\frac{\lambda^{2}}{T_{\text {spont }} 4 \pi \Delta v}
$$

$$
\begin{aligned}
& \text { where } \lambda=1.7 \times 10^{-5} \mathrm{~cm} \\
& T_{\text {spant }}=2 \times 10^{-8} \\
& \Delta \nu=\frac{1}{2} 10^{15} \text { (derived from experimental band- } \\
& \text { width measurements) }
\end{aligned}
$$

giving

$$
0_{\operatorname{gain}}=7.2 \times 10^{-18} \mathrm{~cm}^{2} \text {. }
$$

A competing process serving to deplete ${ }^{3} \Sigma_{u}^{+}$in the presence of a stimulating field is photoionization of $\mathrm{Xe}_{2}^{*}$ to yield $\mathrm{Xe}_{2}^{+}$.

Bandsley and Biondi ${ }^{57}$ give the cesium photoionization cross section as $0.22 \times 10^{-18} \mathrm{~cm}^{2}$ at the ionization band head. Cesium is used in approximating the $\mathrm{Xe}_{2}^{*}$ Rydberg state because of its single outer 6 s electron. Thus the net gain cross section can be written as

$$
c_{\text {net }}=\left(\sigma_{g \text { gin }}-\sigma_{\text {photoelectric }}\right)=7 \times 10^{-18} \mathrm{~cm}^{2}
$$

The density of $\mathrm{Xe}_{2}^{*}$ that produces $5 \% / \mathrm{cm}$ net gain (probably 5\% is required because of high cavity losses in the vacuum ultraviolet region) is

$$
\mathrm{N}=\frac{5 \times 10^{-2}}{7 \times 10^{-18}} \simeq 7 \times 10^{15} / \mathrm{cm}^{3} \simeq \frac{1}{3} \text { Torr. }(103)
$$

The current needed to produce $7 \times 10^{15} \mathrm{Xe}^{*} / \mathrm{cm}^{3}$ can be estimated as follows: One requires about 10 $\mathrm{eV}$ of axcitation to produce a $\mathrm{Xe}^{\star}$ atom. Thus the energy dumped by the electron beam must exceed $7 \times 10^{16} \mathrm{eV} / \mathrm{cm}^{3}$.

Recalling Eq. (42), the energy deposited per $\mathrm{cm}^{3}$ per $\mathrm{A} / \mathrm{cm}^{2}$ for a medium of density $\rho$ by $1.2 \mathrm{MeV}$ electrons is:

$$
\text { Energy/Ampere-cm }=3.7 \times 10^{17} \mathrm{\rho} .
$$


The density of Xe gas at $1 \mathrm{~atm}$ is approximitely $5.85 \times 10^{-3} \mathrm{gm} / \mathrm{cm}^{3}$. Thus the energy/A-cm-atm delivered to the medium at $1 \mathrm{~atm}$ is:

$$
2.1 \times 10^{-5} \mathrm{eV} / \mathrm{A}-\mathrm{cm} .
$$

The number of $\mathrm{A} / \mathrm{cm}^{2}$ required at $1 \mathrm{~atm}$ is therefore:

$$
\frac{7 \times 10^{16} \mathrm{eV} / \mathrm{cm}^{3}}{2.1 \times 10^{15} \mathrm{eV} / \mathrm{A}-\mathrm{cm}}=33 \mathrm{~A} / \mathrm{cm}^{2} \text {. }
$$

Assuming $90 \%$ of the energy deposited is lost (i.e., does not wind up in $\mathrm{Xe}^{*}$ ) one obtains for $5 \% / \mathrm{cm}$ gain:

$$
330 \mathrm{~A} / \mathrm{cm}^{2} @ 1 \text { atm }
$$

$\boldsymbol{\alpha}$

$$
33 \mathrm{~A} / \mathrm{cm}^{2} @ 10 \mathrm{~atm} .
$$

Current densities of this order are readily attainable with the existing apparatus. 


\section{References}

I. C. K. Rhodes and A.Szöke, Phys. Rev. 184, 25 (1969).

2. A. Gedanken, B. Raz, A. Szöke and J. Jortner, J. Chem. Phys, 57, 3456 (1972).

3. K. L. Kompa and G. C. Pimentel, J. Chem. Phys. (Commun.), 47, 857-858 (1967).

4. R. L. Jaffe and J. B. Anderson, J. Chem Phys. 54 (5), 2224 (197)).

5. J. C. Polanyi and D. C. Tardy, J. Chem. Phys. 51,5717 (1969).

6. D. W. Gregg, B. Krawetz, R. K. Pearson, B. R. Schleicher, S. J. Thomas, E. B. Huss, K. J. Pettipiece,

J. R. Creighton, R. E. Niver, and Y. -L. Pan, Chem. Phys, Lett. 8, 609 (1971).

7. S. Marcus and R. J. Carbone, IEEE J. Quant. Elec., QE-7, 493 (1971).

8. J. Goldhar, R. M. Osgood, Jr., and A. Javan, Appl. Phys. Lett. 18, 167 (1971).

9. J. Townsend, Electrons in Gases, (Huthinsons Scientific and Technical Publication, 1947). pp. 50-85.

10. S. Marcus and R. J. Carbone, Performance of a Transversely Excited Pulsed HF Laser, Lincoln Laboratory, Massachusetts Institute of Technology, Cambridge, Proj. Rep. LTP-1) (1971).

11. G. Hermann, Lawrence Livermore Laboratory, private communication (1971).

12. A. E. Siegman, An Introduction to Lasers and Masers (McGraw Hill Book Company, New York, 1971 ).

13. A. Yariv, Quantum Electronics, (John Wiley \& Sons, New York, 1967).

14. A. G. Fox and T. Li, Bell System Tech. J., 40, 453 (1961).

15. L. Andrussow, Landolt-Bornstein, Zahlemwerte und Funktionen, Vol. Z, Pr Sa Table 25, (Springer-Verlag, Berlin, 1968). p. 1112.

16. J. C. Slater, Quantum Theory of Atomic Stricture, (McGraw-Hill Book Company, 1960), Vol I.

17. R. Herman and R. F. Wallis, J. Chem. Phys. 23, 637 (1955).

18. G. Herzberg, Molecular Spectra and Molecular Structure: I. Spectra of Diatomic Molecules, (Van Nostrand, New York, 1950) pp. 106, 107, 124, 125, 213.

19. Handbook of Tables for Applied Engineering Science, R. E. Baltz and G. L. Tuve, Eds., (The Chemical Rubber Company, Cleveland, 1970) p. 95.

20. E. Fermi, Nuclear Physics (The University of Chicago Press, 1950) pp. 123-140.

21. S. Putnam, "Intense Relativistic Electron Beam - Plasma Interactions in Finite Cavities". in Record of 11 th Symposium on Electron, Ion and Laser Beam Technology, R. F. M. Thomley, Ed.; San Frantisco Press. Inc., 1970) p. 561.

22. W. H. Green and M. C. Liu, J. Chem. Phys. Lett., 54, 3222 (1971).

23. C. K. N. Patel, Phys. Rev. Lett., 12, $588(1964)$.

24. F. A. Hopf and C. K. Rhodes, Phys. Rev. A, 8, 912 (1973).

25. C. K. Menkes and N. Goldstein, Color films for Megarad Dosimetry, U.S. Naval Radiological Defense Laboratory, Rept. TR-1097, (1966).

26. E. V. George, Physics Department, Massachusetts Institute of Technology, expressed concern over the existence of such instabilities in a private communication, (June, 1972).

27. Handbook of Chemistry and Physius (The Chemical Rubber Company, Cleveland, 1971) Edition 51, p. B. 79.

28. R. E. Kidder and W. Curry, A Multilevel Pulsed Chemical Laser Model, Liw rence Livermore Laboratory, Rept. UCRL-74024 (1973).

29. R. K. Pearson, J. O. Cowles, G. L. Hermann, K. J. Pettipiecc, and D. W. Gregg, IEEE J. Quantum Electronics QE-9, 723 (1973)

30. R. W. F. Gross, The Aerospace Corp., private communication (1971).

31. R. Jensen, Los Alamos Scientific Laboratory, performed an experiment on $\mathbf{H} \cdot+\mathrm{NF}_{3}$ and reported that it did not proceed witl a significant rate at $300^{\circ} \mathrm{K}$, private communication (1971).

32. N. N. Semenov, Some Problems of Chemical Kinetics and Reactivity, (Pergamon Press, New York, 1958 and 1959), vols. I and II.

33. P. W. Hoff, H. A. Haus and T. J. Bridges, Phys. Rev. Lett. 25, 82 (1970).

34. F. A. Hopf, Phys. Rey, B, 1, 2833 (1970).

35. S. L. MoCall and E. L. Hahn, Phys, Rev. 183,457 (1969).

s6. The tarlier work on continuous spectra is reviewed in W. Finkelnhurg, Kontisuicrliche Spektren (Springer Verlin. P.rlin, 1938). 
37. Y. Tanaka and M. Zclikoff, J. Opt. Soc. Am. 44, 254 (1954); P. G. Wilkinson and Y. Tanaka, J. Opt. Soc. Am. 45. 344 (1955): Y. Tanuka, J. Opt. Soc. Am. 45, 710 (1955).

38. For He"; sci M. L. Ginter and R. Battino, J. Chem. Phys. 52, 4469 (1970).

39. Iior Xo, sit R. S. Multiken, J. Cliem. Phys. 52,5170 (1970).

40. R. S. Mulliken, J. Am. Chum. Soc. 86, 3183 (1964); R. S. Mulliken, J. Am. Clium. Soc. 88, 1849 (1966); R. S. Mulliken, J. Am. Chem. Sou. 91,4615 (1969).

41. O. Cheshnovsky. B. Raz, und J. Jortne:- private communication relating to work performed in the Department of Cliemistry at Tel-Aviv University (1972). Also see J. Jortner, L. Mayer, S. A. Rice, and E. G. Wilson, J. Chem. Pliys. 42. 4250 (1965) and M. Martin, J. Chem. Pliys. 54. 3289 (1971) for other data on the condinsed phases.

42. N. G. Basorv, V. A. Danilchey, and U. M. Popov, Kvuntovaya Elektronika 1. 29 (1971).

43. E. P. Sims, Luwrence Livirmore Laboratory. private communication (1971).

44. W. Heitler. The Quantum Theory of Radiation, (Oxford Press, 1954) Edition 3, p. 189

45. Since the xernon ${ }^{1} P_{1} \rightarrow{ }^{I} S_{0}$ resonance line falls $\sim 1296 \AA$ this process is esentially exactly resonant Furthermore, Gedanken, et. al. (Ref. 2) attribule the process to a resonant dipoledipole interaction in a very tussonable and intuitive wuy.

46. The radiuting ${ }^{1} \mathbf{P}_{1}$ and ${ }^{3} \mathrm{P}_{1}$ levels are completely trapped while the ${ }^{3} \mathbf{P}_{0}$ and ${ }^{3} \mathbf{P}_{2}$ are radiatively metastahle. For single photon processes the ${ }^{3} \mathrm{P}_{0}$ can decay by $M 1$ and $\mathrm{E} 2$ radiation to the ${ }^{3} \mathrm{P}_{1}$ and ${ }^{3} \mathrm{P}_{2}$ kevels respectively with the ${ }^{3} \mathrm{P}_{0} \rightarrow{ }^{1} \mathrm{~S}_{0}$ channul strictly forb dden; the lowest order process for ${ }^{3} \mathrm{P}_{2} \rightarrow{ }^{1} \mathrm{~S}_{0}$ decay is M2. Fot data on neon, argon, and krypton see R. S. Van Dyck. Jr., C. E. Johnson, and H. A. Shugart. Pliys. Rev. A5, 991 (1972).

47. The formation of heteronuclear diners such as ArXe* cannot be ruled out in these mixtures. The current paucity of information on these systems precludes a cefinite statentent at this time.

48. P. Hoff and C. K. Rhodes. ongoing experimentation on rar: gas systens, Lawrence Livermone Laboratory, Y-Division.

49. L. V. Georze and C. K. Rhodes, Appl. Phys. Lett. 23, 139 i1973).

50. Y. Tanaka and K. Yoshino, J. Chem. Phys. 53, 2012 (1970). It is interesting to note that this assignment does not agree with the earlier work reported in Ref. 52.

51. T. D. Strickler and E. T. Arakawa, J. Chem. Phys. 41, 178 j (1964).

52. G. S. Hurst. T. E. Bortner. and T. D. Strickler. Pl!ys. Rev. 178 (1). 4 (1969).

53. H. A. Koeller, L. J. Ferderher, D. L. Redhead, and P. J. Ebert. App. Phys, Lett. 21. 198 (1972).

54. It is expected that the radiated intensity from the higher vibrational states of the ${ }^{3} \Sigma_{u}^{+}$level will be somewlyat reduced as compared to the ${ }^{i} \Sigma_{u}^{+}$Ievels due to the decrease in the transition moment at the larger internuclegr separations. Clearly at very large internuclear distances the dipole amplitude vanishes, since the atomic transition ${ }^{3} \mathrm{P}_{2} \rightarrow{ }^{1} \mathrm{~S}_{0}$ is forbidden.

55. M. J. Berger and S. M. Selizer. Tubles of Energy Losses and Ranges of Electrons and Positrons. N65-1 2506 (NASA. Washington, D.C., 1964).

56. For thuse rates sec H. J. Oskam and V. R. Mittelstadt, Phys. Rev. 132, 1445 (1963). They are reported in this work to be $<4 \times 10^{-9},(2.2 \pm 0.2) \times 10^{-7},(6.7 \pm 0.5) \times 10^{-7},(1.2 \pm 0.1) \times 10^{-6}$, and $(1.4 \pm 0.1) \times 10^{-6} \mathrm{~cm}^{3} / \mathrm{sec}$ for $\mathrm{He}_{2}^{+}, \mathrm{Ne}_{2}^{+}, \mathrm{Ar}_{2}^{+}, \mathrm{Kr}_{2}^{+}$, and $\mathrm{Xe}_{2}^{+}$respectively. Since the measurements detect the total recombination rate, these numbers are upper bounds on the dissociative process. More recent data on $\mathrm{He}_{2}^{+}$are reported in A. W. Johnson and J. B. Gerando, Plys. Rev. Lett. 28, 1096 (1972).

57. J. N. Bardsley and M. B. Biondi, in Advances in Atomic and Molecular Physics, D. R. Bates, Ed. (Academic Press, New York, 1970), Vol. 6, pp. 256-262.

58. A. B. Callear and R. E. Hedges, Trans. Faraday Soc. 66, 2921 (1970).

59. A. V. Phclps, Phys. Rev. 114, 1011 (1959). Also sue H. S. W. Massey, "Slow Collisions of Heavy Particles" in Elcitronic and Ionic Impact Phenomena, (Oxford University Press, London, 1971) Vol. 3.

60. The molecular configurations have an excited state structura not greatly different from the rare gas atoms tlicmsilves; that is, a large energy gup from the ground state to the first excited stste followed by a relatively narrow band of excited states from there to the first ion level. 
61. A. V. Phelps and J. P. Molnar, Phys, Rev. 89,1202 (1953). Also ste H. S. W. Massey. ${ }^{59}$

62. W. W. Robertson, Chem. Phys. Lett. 3, 30 (1969), contains a nery similar suggestion involving excited ionic core states of $\mathrm{He}_{2}^{+}$to explain the presence of the $1.08 \mu \mathrm{He}$ atomic line in helium afterglows.

63. T. Holstein, Plyys. Rev. 72 (12) 1212 (1947). 